\title{
SUBTASK 7.1 - STRATEGIC STUDIES
}

\author{
Final Report \\ (for the period of April 1, 2005 through March 31, 2009) \\ Prepared for:
}

AAD Document Control

U.S. Department of Energy

National Energy Technology Laboratory

PO Box 10940, MS 921-107

Pittsburgh, PA 15236-0940

Cooperative Agreement No. DE-FC26-98FT40320

Project Manager: Richard Read

Prepared by:

Thomas A. Erickson

Energy \& Environmental Research Center University of North Dakota 15 North 23rd Street, Stop 9018

Grand Forks, ND 58202-9018 


\section{DOE DISCLAIMER}

This report was prepared as an account of work sponsored by an agency of the United States Government. Neither the United States Government, nor any agency thereof, nor any of their employees, makes any warranty, express or implied, or assumes any legal liability or responsibility for the accuracy, completeness, or usefulness of any information, apparatus, product, or process disclosed, or represents that its use would not infringe privately owned rights. Reference herein to any specific commercial product, process, or service by trade name, trademark, manufacturer, or otherwise does not necessarily constitute or imply its endorsement, recommendation, or favoring by the United States Government or any agency thereof. The views and opinions of authors expressed herein do not necessarily state or reflect those of the United States Government or any agency thereof.

This report is available to the public from the National Technical Information Service, U.S. Department of Commerce, 5285 Port Royal Road, Springfield, VA 22161; phone orders accepted at (703) 487-4650.

\section{ACKNOWLEDGMENT}

This report was prepared with the support of the U.S. Department of Energy (DOE) National Energy Technology Laboratory Cooperative Agreement No. DE-FC26-98FT40320. However, any opinions, findings, conclusions, or recommendations expressed herein are those of the authors(s) and do not necessarily reflect the views of DOE.

\section{EERC DISCLAIMER}

LEGAL NOTICE This research report was prepared by the Energy \& Environmental Research Center (EERC), an agency of the University of North Dakota, as an account of work sponsored by U.S. Department of Energy. Because of the research nature of the work performed, neither the EERC nor any of its employees makes any warranty, express or implied, or assumes any legal liability or responsibility for the accuracy, completeness, or usefulness of any information, apparatus, product, or process disclosed or represents that its use would not infringe privately owned rights. Reference herein to any specific commercial product, process, or service by trade name, trademark, manufacturer, or otherwise does not necessarily constitute or imply its endorsement or recommendation by the EERC. 


\title{
SUBTASK 7.1 - STRATEGIC STUDIES
}

\begin{abstract}
The Energy \& Environmental Research Center (EERC) has recently completed 11 years of research through the Cooperative Agreement with the U.S. Department of Energy (DOE) National Energy Technology Laboratory (NETL) focused on fossil energy technology development and demonstration. To support a significant number of the different activities being considered within all of our research contracts with NETL, a subtask (7.1 Strategic Studies) was created to focus on small research efforts that came up throughout the year which would support an existing EERC-NETL project or would help to develop a new concept for inclusion in future efforts. Typical efforts conducted under this task were usually between $\$ 15,000$ and $\$ 60,000$ in scope and had time lines of less than 6 months. A limited number of larger studies were also conducted, generally at the direct request of NETL.
\end{abstract}

Over the life of this task, 46 projects were conducted. These efforts ranged from quick experiments to gain fundamental knowledge to support a current effort, to literature reviews, to a few larger engineering efforts. 


\section{TABLE OF CONTENTS}

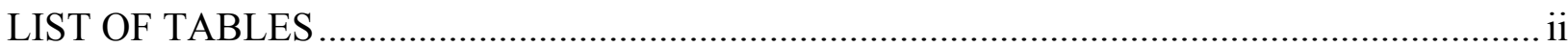

EXECUTIVE SUMMARY .........................................................................................ii

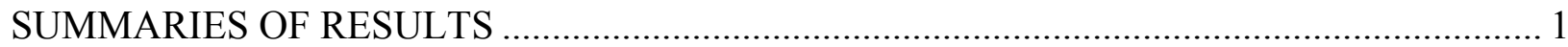

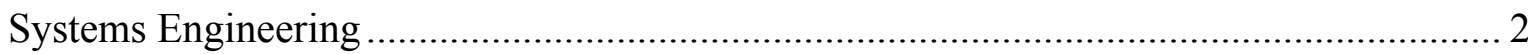

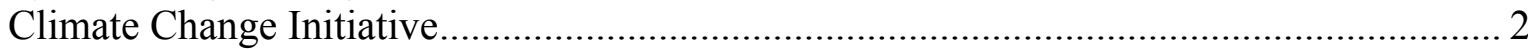

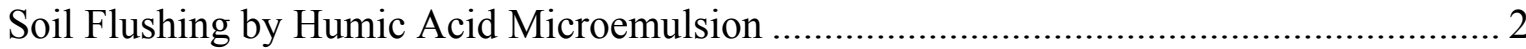

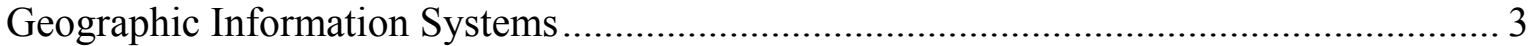

Alternative Sorbents for the Removal of Contaminants from Fluids.................................. 3

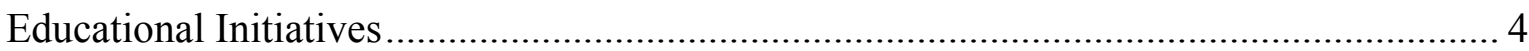

Science in North Dakota ................................................................................ 4

Educational Initiatives in Fossil Energy, Air Toxics, and Other Air Quality Issues... 4

A Novel $\mathrm{CO}_{2}$ Photoreduction System via Sol-Gel Processing ...................................... 5

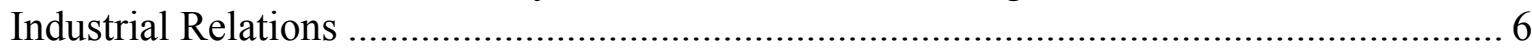

Technology Adoption - Ceramic Materials Market ..................................................... 6

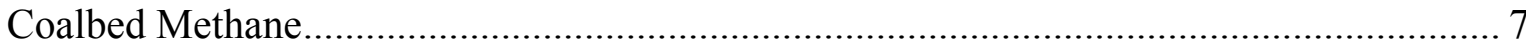

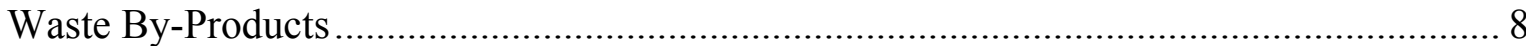

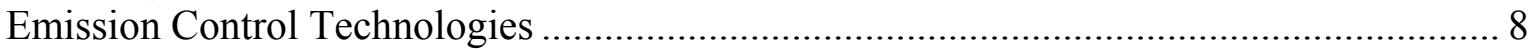

Economic Evaluation of the Use of Manure-Based Reburn Fuels for the Reduction

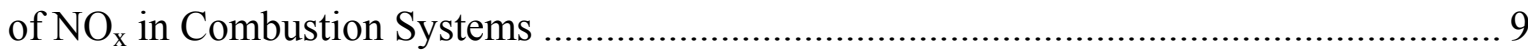

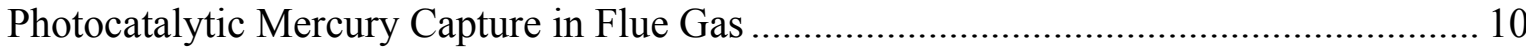

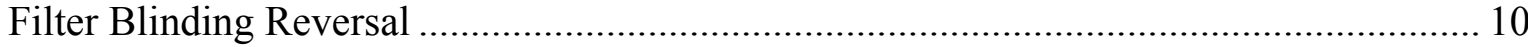

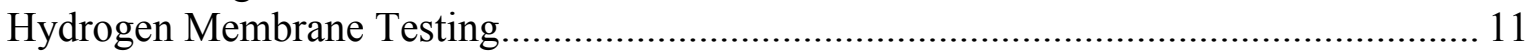

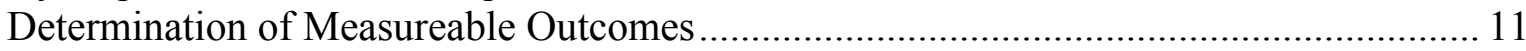

Waste Tire Recycling with Subcritical Water ........................................................... 12

Feasibility of Using Freeze-Thaw Evaporation ${ }^{\circledR}\left(\right.$ FTE $\left.^{\circledR}\right)$ Technology for Power

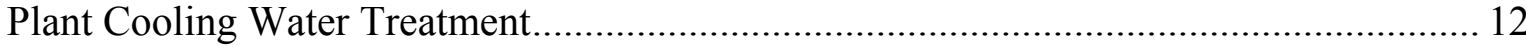

Effects of Fossil Fuel Power Plant Emissions on Precipitation .................................... 12

Remediation Seminar ......................................................................................... 13

Short Course - Ash Behavior and Mercury Control in Coal Combustion......................... 13

Review of Utility-Scale Energy Storage Technologies........................................... 14

Evaluation of ChemCAD Software ......................................................................... 15

Subcritical Water Fractionation of Particulate Matter ................................................ 15

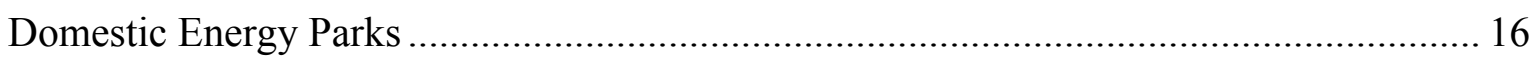

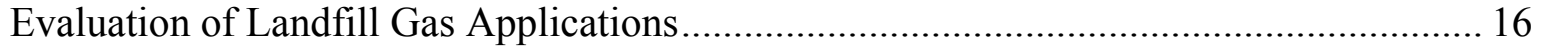

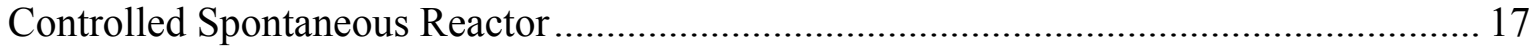

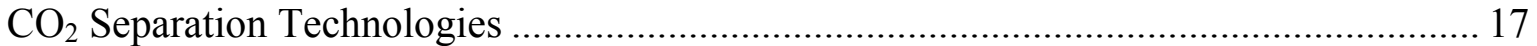

Mercury Measurement in Combustion Flue Gases Short Course ................................... 18

Installation of an Additional Wet Scrubber on the Energy \& Environmental

Research Center's 7-kW Combustion System ............................................................ 19

Continued... 


\section{TABLE OF CONTENTS (continued)}

Microbial Cycling of $\mathrm{CH}_{4}, \mathrm{CO}_{2}$, and $\mathrm{N}_{2} \mathrm{O}$ in Wetland Environments - A Scoping Study. 19

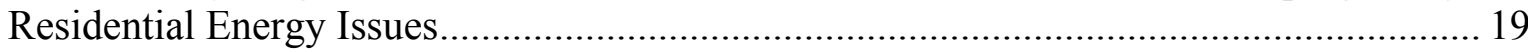

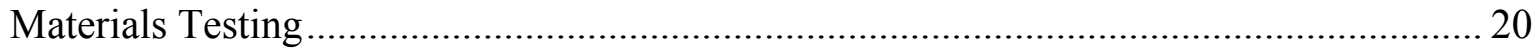

Oil Field Applications for Low-Btu Associated Gas .................................................... 21

Development of a Novel Petroleum Biotechnology .................................................... 21

Potential for Conversion of Beet Sugar.................................................................... 21

Biomass Product Separation and Characterization for the Generation of Fuel Additives .. 22

Analysis of Oil and Gas Environmental Issues Affecting Domestic Production............... 23

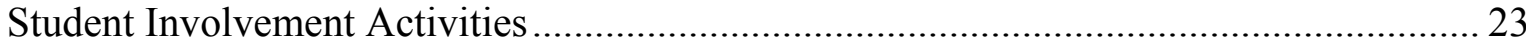

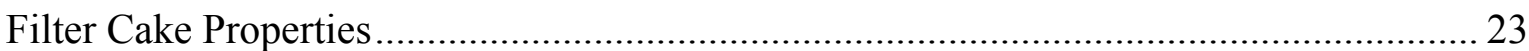

High-Temperature Corrosion of Alloys in Simulated Boiler Tube Conditions ................. 24

On-Demand High-Pressure Hydrogen Extraction and Dispensing for Vehicle Fueling .... 24

Indirectly Fired Combined Cycle with Condensing Heat Exchanger .............................. 25

Engineering Opportunities and Challenges of $\mathrm{CO}_{2}$ Mitigation Using Microalgae in Fossil Fuel-Fired Power Plants .............................................................................. 26

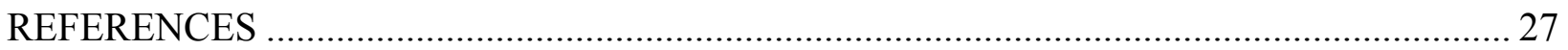

FINAL REPORT FOR RESEARCH PROJECT ENTITLED TECHNOLOGY

ADOPTION - CERAMIC MATERIALS MARKET …………………………............ Appendix A

MERCURY MEASUREMENT IN COMBUSTION FLUE GASES

SHORT COURSE ................................................................................................ Appendix B

FINAL REPORT FOR RESEARCH PROJECT ENTITLED DEVELOPMENT

OF A NOVEL PETROLEUM BIOTECHNOLOGY .................................................. Appendix C

FINAL REPORT FOR RESEARCH PROJECT ENTITLED ENGINEERING

OPPORTUNITIES AND CHALLENGES OF $\mathrm{CO}_{2}$ MITIGATION USING

MICROALGAE IN FOSSIL FUEL-FIRED POWER PLANTS

Appendix D

\section{LIST OF TABLES}

1 Sources of $\mathrm{CO}_{2}$ Emissions from U.S. Fossil Fuel Combustion in 2002 ........................... 18 


\section{SUBTASK 7.1 - STRATEGIC STUDIES}

\section{EXECUTIVE SUMMARY}

The Energy \& Environmental Research Center (EERC) has recently completed 11 years of research through the Cooperative Agreement with the U.S. Department of Energy (DOE) National Energy Technology Laboratory (NETL) focused on fossil energy technology development and demonstration. To support a significant number of the different activities being considered within all of our research contracts with NETL, a subtask (7.1 Strategic Studies) was created to focus on small research efforts that came up throughout the year which would support an existing EERC-NETL project or would help to develop a new concept for inclusion in future efforts. Typical efforts conducted under this task were usually between $\$ 15,000$ and $\$ 60,000$ in scope and had time lines of less than 6 months. A limited number of larger studies were also conducted, generally at the direct request of NETL.

Over the life of this task, 46 projects were conducted. These efforts ranged from quick experiments to gain fundamental knowledge to support a current effort, to literature reviews, to a few larger engineering efforts. The following is a list of the research projects conducted:

- Systems Engineering

- Climate Change Initiative

- Soil Flushing by Humic Acid Microemulsion

- Geographic Information Systems

- Alternative Sorbents for the Removal of Contaminants from Fluids

- Education Initiatives (Science in North Dakota and Educational Initiatives in Fossil Energy, Air Toxics, and Other Air Quality Issues)

- A Novel $\mathrm{CO}_{2}$ Photoreduction System via Sol-Gel Processing

- Industrial Relations

- Technology Adoption - Ceramic Materials Market

- Coalbed Methane

- Waste By-Products

- Emission Control Technologies

- Economic Evaluation of the Use of Manure-Based Reburn Fuels for the Reduction of $\mathrm{NO}_{\mathrm{x}}$ in Combustion Systems

- Photocatalytic Mercury Capture in Flue Gas

- Filter Blinding Reversal

- Hydrogen Membrane Testing

- Determination of Measureable Outcomes

- Waste Tire Recycling with Subcritical Water

- Feasibility of Using Freeze-Thaw Evaporation ${ }^{\circledR}\left(\mathrm{FTE}^{\circledR}\right)$ Technology for Power Plant Cooling Water Treatment

- Effects of Fossil Fuel Power Plant Emissions on Precipitation

- Remediation Seminar

- Short Course - Ash Behavior and Mercury Control in Coal Combustion 
- Review of Utility-Scale Energy Storage Technologies

- Evaluation of ChemCAD Software

- Subcritical Water Fractionation of Particulate Matter

- Domestic Energy Parks

- Evaluation of Landfill Gas Applications

- Controlled Spontaneous Reactor

- $\mathrm{CO}_{2}$ Separation Technologies

- Mercury Measurement in Combustion Flue Gases Short Course

- Installation of an Additional Wet Scrubber on the Energy \& Environmental Research Center's 7-kW Combustion System

- Microbial Cycling of $\mathrm{CH}_{4}, \mathrm{CO}_{2}$, and $\mathrm{N}_{2} \mathrm{O}$ in Wetland Environments - A Scoping Study

- Residential Energy Issues

- Hydrogen Storage Material

- Materials Testing

- Oil Field Applications for Low-Btu Associated Gas

- Development of a Novel Petroleum Biotechnology

- Potential for Conversion of Beet Sugar

- Biomass Product Separation and Characterization for the Generation of Fuel Additives

- Analysis of Oil and Gas Environmental Issues Affecting Domestic Production

- Student Involvement Activities

- Filter Cake Properties

- High-Temperature Corrosion of Alloys in Simulated Boiler Tube Conditions

- On-Demand High-Pressure Hydrogen Extraction and Dispensing for Vehicle Fueling

- Indirectly Fired Combined Cycle with Condensing Heat Exchanger

- Engineering Opportunities and Challenges of $\mathrm{CO}_{2}$ Mitigation Using Microalgae in Fossil Fuel-Fired Power Plants 


\section{SUBTASK 7.1 - STRATEGIC STUDIES}

\section{SUMMARIES OF RESULTS}

Over the life of this task, a variety of different formats were used to identify and track the activities conducted. These varying formats sometimes overlapped and sometimes conflicted with each other. For reporting purposes, the various activity numbers used throughout the years will not be used, but rather, each task will be identified by its title.

For each of the following activities, the period of performance and an identifier to the final report is listed in addition to a brief summary of the activities conducted. Depending upon the size and scope of the project, the final reports range from a short write-up within a quarterly report to a separate final report. Since these projects and reports occurred over a period of eleven years, it is noted that the assumptions and conclusions may be dated significantly, and no effort was made to redo any past studies with the most recent information.

\section{Systems Engineering}

Period of Performance: April 15, 1998 - March 31, 2009

Final Report: Appended to April 1 - June 30, 2008, quarterly status report.

Brief Summary: A series of spreadsheet programs have been developed at the Energy \& Environmental Research Center (EERC) to recursively calculate energy, mass, and elemental balances for gasification and combustion systems. These programs operate on either Lotus or Excel using an architecture that is adaptable to virtually any fuel or energy process. The user can define input and output streams and characterize their contents based on a property correlations for 52 elements or compounds, along with fuels (coal, oil, or gas) and coal ash. Enthalpies are calculated for elements or compounds as a function of temperature based on regression equations derived from the JANAF tables. The correlation developed to calculate the enthalpy of a fuel on a moisture- and ash-free basis provides estimates of heating values that match experimental data better than the Dulong Formula. Enthalpies for typical coal ash analyses for bituminous, subbituminous, and lignite coals are calculated based on enthalpies for the major constituents $\mathrm{SiO}_{2}, \mathrm{Al}_{2} \mathrm{O}_{3}, \mathrm{Fe}_{2} \mathrm{O}_{3}, \mathrm{CaO}$, and $\mathrm{MgO}$. The relationships between inputs and outputs can be variously determined by fuel and product analyses, chemical equilibrium, or (less often) kinetics. The recursive calculations that are performed to balance elements, mass, and energy use either "Solver" in Excel or a Newton Raphson macro in Lotus. Elemental balances can be performed by changing the amount of any species in any stream containing that element. The energy balance can be performed by changing either amounts or temperatures. The design of a useful spreadsheet for a particular process application depends on making an appropriate choice of the species/streams or temperatures to be changed and the order in which they are changed - which is governed by knowledge and assumptions concerning how the process operates. 


\section{Climate Change Initiative}

Period of Performance: April 1, 2000 - June 30, 2001

Final Report: In Interim Year 3 Technical Report Including Quarterly Status Report for April 1 - June 30, 2001

Brief Summary: The intensity of the debate over the relative importance of anthropogenic effects on natural ${ }^{1}$ climate variability is just beginning. Commonly reported trends in $\mathrm{CO}_{2}$ related temperature increases in this century appear to point to human influence, although such trends cannot be fully appreciated or resolved until human industrial, agricultural, and domestic impacts are understood in the context of natural changes in climate. The current tone of the debate over cause and effect will undoubtedly become very heated as attempts to implement climate policies that directly influence people's day-to-day lives come to pass.

A key element in any study of climate change (and especially in predictive climate modeling) is an understanding of the pattern of short-term cycles. EERC research in climate change studies has focused on interpreting natural climatic variations in the recent past (i.e., the last 5000 years) and providing a better context in which to examine interpretations of current climate change. The goal of this project was to provide a basis for understanding late Holocene, natural, short-term climate variability through a review of various recently reported studies. Seventy papers covering a wide range of climate interests were examined. Each of the papers was summarized in 11 categories that were present in most of the papers, including 1) basic thesis of the paper, 2) project locality (geographic location), 3) project methods, 4) data source (what kind of materials are being investigated), 5) time frame (years of geological and cultural past covered by analysis), 6) impact (scale of interpretation or consequences; i.e., global, regional, or local), 7) background context (basic information necessary to understand the investigation), 8) summary of research results, 9) interpretation of results, 10) conclusions reached by the investigator; and 11) temporal illustrations (figures that provide climate histories through time). The information in selected categories was carefully coded and input into a database to facilitate the sorting of the data according to area, time coverage, methodology, or other field of interest. By placing these data sets and methods in a position to be evaluated on the same bases, the conclusions can be more appropriately synthesized and compared.

\section{Soil Flushing by Humic Acid Microemulsion}

Period of Performance: April 1, 2000 - June 30, 2001

Final Report: In Interim Year 3 Technical Report Including Quarterly Status Report for April 1 - June 30, 2001

1 In the Climate Change Initiative summary, "natural" refers to ongoing Earth processes that are outside of human influence which result in climate change. 
Brief Summary: The EERC performed bench-scale laboratory testing to investigate the potential for humic acid/alcohol solutions to form microemulsions with dense nonaqueous-phase liquids and, thereby, increase their solubility and mobility. The EERC effort focused on evaluating the effects of varying concentrations of surfactants and pentanol alcohol on the solubility of the contaminant trichloroethylene (TCE). The testing was performed using batch water-based experiments to determine partitioning coefficients for each solution concentration. Experimental results in this study have shown significant increases in the solubility of TCE using both commercial surfactant solutions and humic acid solutions.

\section{Geographic Information Systems}

Period of Performance: April 1, 2000 - June 30, 2001

Final Report: In Interim Year 3 Technical Report Including Quarterly Status Report for April 1 - June 30, 2001

Brief Summary: The goal of this effort was to better establish geographic information systems (GIS) and decision support tools and expertise to support existing and proposed U.S. Department of Energy (DOE) joint venture projects. This was accomplished through the acquisition of software upgrades, a scanner for the incorporation of hard copy data (e.g., images and maps), and training in the use of the GIS programming language. The programming language allows for customization of the GIS software to suit particular purposes. Additional programming or applications development can simplify and streamline the use of GIS for specific tasks. A field crew was trained in the use of the University of North Dakota's (UND's) global positioning system equipment (coowned by the EERC and the UND Department of Geology and Geological Engineering), which is capable of subcentimeter accuracy.

\section{Alternative Sorbents for the Removal of Contaminants from Fluids}

Period of Performance: April 1, 2000 - June 30, 2001

Final Report: In Interim Year 3 Technical Report Including Quarterly Status Report for April 1 - June 30, 2001

Brief Summary: The removal of metal contaminants such as mercury from flue gas streams continues to be a challenge because they are not completely removed in particulate control devices or scrubbers. High-surface-area sorbents may provide a means of removal when contact between the sorbent and the flue gas is maximized. Just as the geometry of chemical reactors can be adjusted to promote or suppress mixing, it should be possible to adjust the configuration of a sorbent to maximize contact with the contaminant through the turbulence of the fluid containing the contaminant. The goal of this project was to compare the effectiveness of a corrugated sorbent configuration with that of a flow-through, packed sorbent bed.

Carbon aerogels were used as the test sorbents because they could be obtained in sheet, powdered, and monolithic forms. The carbon content and surface area of the sheet form of carbon aerogel were compared to those of -400 -mesh carbon aerogel that had been tested in the 
EERC's bench-scale mercury sorption test system during the performance of an earlier project (U.S. Environmental Protection Agency Grant No. R827649-01). Both forms had quite similar properties, indicating that any differences noted in sorption capability were likely to have been caused by configuration differences rather than physical differences between the sorbent forms.

One mercury sorption test was performed in the EERC's bench-scale mercury system for each corrugation angle. The tests were performed at $250^{\circ} \mathrm{F}$ using a synthetic flue gas comprising $6 \mathrm{wt} \% \mathrm{O}_{2}, 12 \mathrm{wt} \% \mathrm{CO}_{2}, 1600 \mathrm{ppm} \mathrm{SO}_{2}, 50 \mathrm{ppm} \mathrm{HCl}, 14.5 \mu \mathrm{g} / \mathrm{m}^{3} \mathrm{Hg}^{0}, 8 \mathrm{wt} \% \mathrm{H}_{2} \mathrm{O}$, and the balance $\mathrm{N}_{2}$. The synthetic flue gas flow rate was $0.0435 \mathrm{~m}^{3} / \mathrm{hr}$ (about $700 \mathrm{~cm}^{3} / \mathrm{min}$ ). The low flow rate was selected to highlight any differences in sorption between the two orientation angles, although it was assumed that such a low gas flow rate would probably not result in complete breakthrough within the amount of time allotted to the tests. At any given time, approximately $70 \%$ of the $\mathrm{Hg}^{0}$ fed to the system was removed by the corrugated sorbent.

\section{Educational Initiatives}

Period of Performance: April 1, 2000 - June 30, 2001

Final Report: In Interim Year 3 Technical Report Including Quarterly Status Report for April 1 - June 30, 2001

\section{Science in North Dakota}

Brief Summary: This activity was originally funded to solicit, review, and distribute a series of articles on science research conducted by North Dakota scientists. These articles were to have been publicized through public media (e.g., newspapers, talk shows, etc.) in North Dakota and adjacent states.

This effort was discontinued because the project manager, Joseph Hartman, changed positions within UND, and although still appointed to the EERC, could not allocate adequate time to carry this project to completion.

Contact was made with and initial support for this project was obtained from numerous groups including the North Dakota Academy of Science, Prairie Public Broadcasting, North Dakota high schools, and numerous North Dakota researchers.

\section{Educational Initiatives in Fossil Energy, Air Toxics, and Other Air Quality Issues}

Brief Summary: New K-12 science education standards call for activities that engage students in a continuous and integrated process of observing, questioning, investigating, and reflecting, with an emphasis on an interdisciplinary understanding of the relationships between science, technology, societal needs, and community issues. Scattered efforts to produce educational units consistent with the science education standards, including energy and environmentally focused units, have been undertaken in North Dakota, Minnesota, and elsewhere in the region. Teachers burdened with paperwork and regulations desire assistance in implementing the new standards 
and in developing curricula to integrate technology and hands-on activities into their classrooms. The EERC is uniquely qualified to provide a central role in the development and implementation of activities consistent with the science education standards with its multidisciplinary staff; comprehensive testing, fabrication, and analytical capabilities; breadth of energy and environmental project experience; proven ability in third-party assessments of critical issues; and practical project focus. Recent EERC proposals for projects providing water-related educational projects for schools and communities received enthusiastic support from a variety of stakeholders, including school districts, educators, and education facilitators; state and federal agencies; and grassroots organizations in both the North Dakota and Minnesota portions of the region. Applying these qualities to the development of hands-on, critical-thinking, and problemsolving teaching units will provide the region's students with a rich education experience. Working with teachers, administrators, and other stakeholders in the education community will ensure that the curricula are accepted and implemented.

The purpose of this 1-year task was to lay the groundwork for establishing a sustainable energy and environmental education program area at the EERC. This project 1) identified areas where the EERC can develop, complement, take part in, or build on existing individual activities, local partnerships, and statewide initiatives; 2) developed the relationships and information base necessary to ensure a relevant, sustainable education initiative; and 3) developed stakeholderapproved project concepts and preproposals.

\section{A Novel $\mathrm{CO}_{2}$ Photoreduction System via Sol-Gel Processing}

Period of Performance: April 1, 2000 - June 30, 2001

Final Report: In Interim Year 3 Technical Report Including Quarterly Status Report for April 1 - June 30, 2001

Brief Summary: Group VIII transition metal oxotitanates containing $\mathrm{Co}, \mathrm{Ni}$, and $\mathrm{Ru}$, being explored for $\mathrm{CO}_{2}$ photoreduction, were synthesized from precursors by sol-gel methods and characterized by infrared spectroscopy. Color and spectra changes are consistent with those expected for the respective metal complexes.

A low reactivity of the Group VIII transition metal oxotitanates for photoreduction of $\mathrm{CO}_{2}$ was observed for irradiation with visible light. This was also true for most other titania photocatalysts. A method for modifying the light absorbance properties of the oxotitanate catalysts is feasible and should be further explored. This would involve adding complexing reagents to the metal oxotitanate either before or after hydrolysis to the gel state. The resulting complexed metal oxotitanates would be used without calcination for tests to determine absorbance and photoreactivity properties.

Further experimentation with the Group VIII transition metal oxotitanates at shorter wavelengths (ultraviolet [UV]) is warranted. Although titanias have been extensively investigated as photooxidation catalysts for destruction of many pollutants in water treatment under UV irradiation, this kind of treatment has not reached commercialization. Thus the emphasis on design and testing would shift from $\mathrm{CO}_{2}$ reduction to photocatalytic oxidation of 
hydrocarbons, chlorinated hydrocarbons, and many other organic pollutants that produce $\mathrm{CO}_{2}$ as the final product. The metal oxotitanates may also be useful for related treatment processing such as photofenton and fenton reactions.

\section{Industrial Relations}

Period of Performance: April 1, 2000 - June 30, 2001

Final Report: In Interim Year 3 Technical Report Including Quarterly Status Report for April 1 - June 30, 2001

Brief Summary: The EERC implemented a project review approach to attempt to assess the industrial focus of EERC activities. To ensure that all projects within the Cooperative Agreement had significant industrial direction, each project underwent an initial kickoff meeting, a midpoint meeting, and a closeout meeting. Each of these meetings involved review of the activities of the project by senior EERC management and identification of industry needs and direction.

\section{Technology Adoption - Ceramic Materials Market}

Period of Performance: April 1, 2001 - June 30, 2002

Final Report: In Appendix A.

Brief Summary: Technology innovation research focuses on the adoption of technological innovations and why some innovations are adopted at a faster or slower rate than others. The rate of adoption is the relative speed at which an innovation is implemented by members of an industry group. Rogers (1) identified five perceptual characteristics of innovations that help explain differences in adoption rates: relative advantage, compatibility, complexity, trialability, and observability.

Relative advantage is the degree to which an innovation is perceived as better than the idea it supersedes. Compatibility is the degree to which an innovation is perceived as being consistent with the existing values, past experiences, and needs of potential adopters. Complexity is the degree to which an innovation is perceived as difficult to understand and use. Trialability is the degree to which an innovation may be experimented with on a limited basis. Finally, observability is the degree to which the results of an innovation are visible to an observer. In general, the rate of adoption is positively related to perceived relative advantage, compatibility, trialability, and observability and is negatively related to perceived complexity of the innovation. Rogers (1) found relative advantage to be one of the best predictors of an innovation's rate of adoption. Relative advantage, along with compatibility and complexity, is the most significant factor in explaining relationships across a broad range of innovation types.

The technological orientation of the United States provides a means for the transfer of technology out of universities. In the corporate sector, years of downsizing have led to the willingness of more companies to consider outsourcing in general and technology licensing in 
particular. Licensing in is seen increasingly as complementary to corporate business development strategies (2). Licensing is one strategy that promotes the diffusion of innovation.

Successful commercialization from universities and laboratories occurs when senior administration and management actively support cooperation with industry, with strong positive attitudes and incentives. Other key factors are the degree to which inventors of the technologies exhibit entrepreneurial attributes and have positive attitudes toward commercialization (3). Also, successful universities and laboratories are those in which the cooperating company supports commercialization and where the company's technical people perceive their counterparts in the federal laboratories as willing to take risks and able to deal with ambiguity.

This project was conducted to explore the market factors that influence the adoption of technology innovation. The goal was to better understand methods to help drive technology development to promote commercialization and acceptance of innovation for a specific technology, silicon carbide composites; determine market potential; and assist with the commercialization of the silicon carbide technology.

The market research involved the following objectives:

- Preparation of a material technology overview that is understandable to business and marketing personnel

- Preparation of a market/industry overview that quantifies market size

- Preparation of a competitive analysis

- Identification of market opportunities

- Identification of barriers to entry

- Identification of industry leads

- Recommendations for marketing strategies

\section{Coalbed Methane}

Period of Performance: April 1, 2001 - June 30, 2002

Final Report: Appended to April 1 - June 30, 2002, quarterly status report

Brief Summary: The latest and most controversial exploitations of coalbed methane (CBM) are occurring in the Powder River Basin (PRB) of southeastern Montana and northeastern Wyoming. The PRB encompasses approximately 12,145 square miles. There are currently approximately 3100 wells in the PRB, with expectations of up to 39,000 more wells to be drilled over the next 10 to 15 years. A majority of the future exploration and production activities are expected to occur in the Montana portion of the PRB where only approximately 200 wells are currently producing. There have been 270 wells permitted by Montana regulatory agencies; however, a moratorium has been placed on additional permitting until an environmental impact statement (EIS) addressing the accelerated growth is completed.

The methane extraction process involves removing large volumes of water from the aquifer. Lowering the water pressure, which confines the methane within the coal seams, results 
in methane release and migration into extraction wells. Because of the potential for thousands of wells, and because CBM extraction consists of continuous pumping and discharge of groundwater, several environmental concerns have been raised.

This activity focused on a review of the current environmental issues related to CBM development in Montana and the identification of research needs.

\section{Waste By-Products}

Period of Performance: April 1, 2001 - June 30, 2002

Final Report: Appended to April 1 - June 30, 2002, quarterly status report

Brief Summary: The EERC conducted a limited broad-scope research study to identify industrial by-products/recycling opportunities in the region. The focus was to enhance and expand the coal combustion by-product $(\mathrm{CCB})$ research program by identifying potential waste management opportunities that would combine $\mathrm{CCBs}$ with other wastes/by-products to create useful products. In some instances, non-CCB wastes provide opportunities for coal, energy, and CCB management activities. An example of this type of use is in the production of biodiesel from waste cooking oil. The biodiesel has high potential for use in hauling coal and CCBs by truck and reducing emissions related to energy production from coal.

The study indicated that sugar beet tare dirt reuse, biodiesel, food waste, composting, and glass were areas to be considered. Several project ideas were explored, and it was determined that there was a great need for an agriculture consortium in the region.

\section{Emission Control Technologies}

Period of Performance: October 1, 2001 - June 30, 2002

Final Report: Appended to April 1 - June 30, 2002, quarterly status report

Brief Summary: Complaints about diesel smoke from trucks and buses, particularly in urban areas, have been a concern for years. Experts have expressed growing concerns about the health risks associated with the emissions from diesel-powered engines. Researchers have reported diesel particulate matter contributes to or aggravates chronic lung diseases such as asthma, bronchitis, and emphysema, and there is growing evidence about the potential cancer risk from exposure to diesel particulates (4). Diesel particulates also impair visibility and contribute to structural damage through corrosion.

Despite these concerns, diesel engines are still an attractive solution in a global marketplace increasingly concerned with its energy supply. Diesel engines are known for their reliability, fuel efficiency, ease of repair, and low operational expense. They typically have a life of 1,000,000 miles in heavy-duty trucks and can power buses for up to 15-20 years (4). Aside from the problems with particulate and $\mathrm{NO}_{\mathrm{x}}$ emissions, the diesel engine has very low emissions 
of hydrocarbons and carbon monoxide, which also pose risks to public health and the environment.

The environmental issues with diesel engines may be addressed from three angles, namely engine design modifications, diesel fuel and additive technology, and emission control through exhaust gas aftertreatment. Engine and control manufacturers are working to develop, optimize, demonstrate, and commercialize advances in these categories. Emission control issues, especially diesel particulate traps, are the area of interest in this ministudy.

This project was conducted to explore the market environment for diesel emission control devices. The primary goal was to better understand the needs of the marketplace in order to aid in the direction of technology development. In addition, a goal of the project was to identify industry partners with the intent of providing opportunities for demonstration and commercialization of technologies.

The market research involved the following objectives:

- Preparation of a market/industry overview that quantifies market size

- Preparation of a competitive analysis

- Identification of market opportunities

- Identification of barriers to entry

- Identification of industry leads

- Recommendations for marketing strategies

\section{Economic Evaluation of the Use of Manure-Based Reburn Fuels for the Reduction of $\mathrm{NO}_{\mathrm{x}}$ in Combustion Systems}

Period of Performance: October 1, 2002 - December 31, 2003

Final Report: Appended to October 1 - December 31, 2003, quarterly status report

Brief Summary: Reburning is a mature process used to reduce $\mathrm{NO}_{\mathrm{x}}$ levels in flue gas. The typical reburning process provides nominally $50 \%$ to $70 \% \mathrm{NO}_{\mathrm{x}}$ reduction at reburn heat inputs above $20 \%$ (5). Advanced reburning is basic reburning with the injection of nitrogen agents and promoter compounds. It has been found to achieve $\mathrm{NO}_{\mathrm{x}}$ reductions as high as $85 \%$ to $95 \%$. Fuel properties found to have the greatest effect on $\mathrm{NO}_{\mathrm{x}}$ control include fuel nitrogen content, volatiles, and ash constituents. The most effective promoters used during advanced reburning have been sodium compounds (5). It is reasonable to assume, therefore, that a fuel produced from a high-nitrogen source such as animal waste by a process that utilizes an alkali-based catalyst or reaction promoter would be effective in a reburn scenario. Such a reburn fuel might more cost-effectively reduce $\mathrm{NO}_{\mathrm{x}}$ levels than the current "advanced reburn" combination of fuel, ammonia or urea, and alkali promoter. It is prudent to determine if the costs associated with processing animal waste to produce a reburn fuel are outweighed by the benefits of reduced $\mathrm{NO}_{\mathrm{x}}$ levels. This project was a preliminary study of the economics of producing a premium reburn fuel from animal waste for the purpose of reducing $\mathrm{NO}_{\mathrm{x}}$ levels in flue gas. Favorable economics would indicate that the process merits additional development. 
To estimate the cost-effectiveness of manure-based reburn fuels, a preliminary literature search was performed in which information comparing both various reburn fuels and reburning to other $\mathrm{NO}_{\mathrm{x}}$ removal techniques was gathered. The majority of the literature surveyed was available on the Internet; some articles in technical journals were also reviewed. Specific topic areas that were addressed included disposal costs typically associated with animal waste; various processing methods that could be used to produce premium fuels from animal wastes; geographic costs or savings due to processing plant siting; handling, environmental, or safety issues associated with animal waste-related fuels; comparison of animal waste-based reburn fuel to other methods of $\mathrm{NO}_{\mathrm{x}}$ control; and comparison of animal waste-based reburn fuel to other reburn fuels.

\section{Photocatalytic Mercury Capture in Flue Gas}

Period of Performance: October 1, 2002 - September 30, 2003

Final Report: In July 1 - September 30, 2003, quarterly status report

Brief Summary: This project focused on the development of a photocatalytic $\mathrm{NO}_{\mathrm{x}}$ control system. The effort was focused on mercury transformations across the system so as to identify opportunities for multipollutant control. The results showed that $\mathrm{NO}_{2}$ could be removed from a flowing gas stream by adsorption and reaction on $\mathrm{TiO}_{2}$. In fact, the $\mathrm{NO}_{2}$ adsorbed so strongly on the $\mathrm{TiO}_{2}$ that it could not be removed by a flowing gas stream at ambient conditions. The $\mathrm{HNO}_{3}$ formed when exposed to UV radiation was removed by rinsing with water.

\section{Filter Blinding Reversal}

\section{Period of Performance: April 1, 2003 - September 30, 2003}

Final Report: The final results from this activity were previously provided to DOE on a confidential basis and are not included in this report.

Brief Summary: EERC engineers developed a novel process for removing residual filter cakes that remain adhered to a fabric filter even after typical particulate removal methodologies have been employed, such as pulse-jet bag cleaning. The process applies to air or gas filtration media that are normally cleaned in place as part of the existing process. It applies to all cleanable filters used for air pollution control, dust control, or powder product capture.

As this process lowers filter drag, it promises greater system efficiencies by decreasing the power required to operate blowers. It also promises to greatly increase the lifespan of a set of filter bags, reducing labor and materials costs. Finally, it offers a method by which more aggressive baghouse designs may be utilized where pressure drop and filter blinding were once limiting factors. 


\section{Hydrogen Membrane Testing}

Period of Performance: April 1, 2003 - June 30, 2003

Final Report: Located in April 1 - June 30, 3003, quarterly status report

Brief Summary: Concerns over global climate change, dependence on foreign fuels, and presidential directives, among others, are driving this nation to further explore and greatly enhance the use of hydrogen as a fuel for the transportation sector and electric power generation. Programs such as DOE's VISION 21 initiative also include this as an important goal. One step on this path is to create methods of separating hydrogen from product gas streams such as those generated from coal gasification.

The goal of this work was to start the development of a membrane which can separate hydrogen to purity sufficient for use in devices such as solid oxide fuel cells. Further, it was intended that this membrane be of such integrity as to withstand the environment provided by a coal gasification system.

\section{Determination of Measureable Outcomes}

Period of Performance: October 1, 2003 - March 31, 2004

Final Report: Appended to January 1 - March 31, 2004, quarterly status report

Brief Summary: When determining whether research on a particular topic should continue, it is useful to have an idea of the value presented by the work. A cost-benefit analysis is one method of gathering and presenting this type of information, but only when a monetary value can be assigned to the process. Many research projects are not structured in a way that permits a direct calculation of the projects' monetary value. During this project, a methodology was developed by which outcomes of a project (monetary or otherwise) can be measured. The methodology consists of a decision tree containing questions that can be answered by researchers to help them determine the value of their projects. It is hoped that this decision tree can also be used as a guide when research is planned to ensure that the value of a project can be more readily determined.

Cost-benefit analysis techniques were obtained through Internet searches. Documents relating to monetary value were reviewed as well as others dealing with value indicators for projects for which monetary value cannot be assigned.

The projects performed under a multimillion-dollar EERC program over the course of 7 years were reviewed. Similar projects were combined and the groups analyzed for common characteristics. Questions were formulated to help elucidate project value, and interviews with project managers were conducted to streamline the questions. A question flow sheet/decision chart was prepared using information gathered from both the cost-benefit analysis techniques and the project analyses/interviews. 


\title{
Waste Tire Recycling with Subcritical Water
}

\author{
Period of Performance: April 1, 2003 - March 31, 2004
}

Final Report: In January 1 - March 31, 2004, quarterly status report

Brief Summary: The purpose of this limited investigation was to determine the ability of subcritical water (water heated up to its critical temperature of $374^{\circ} \mathrm{C}$ and under enough pressure to maintain the liquid state) and supercritical water (water heated above $374^{\circ} \mathrm{C}$ at pressures above $218 \mathrm{~atm}$ ) to degrade and remove the styrene-butadiene copolymer components of waste tires and produce carbon black that can be recycled into new tires. Although some polymer degradation reactions occurred with subcritical water, degradation efficiencies were low. However, supercritical water (at $450^{\circ} \mathrm{C}$ ) was much more effective in degrading the polymer material and yielding a carbon black product that may be useful for recycling (based on a high molar $\mathrm{C} / \mathrm{H}$ ratio of the product material). The polymer degradation products from the supercritical water treatment were primarily alkyl benzenes, which should be suitable to use as a petroleum refinery feedstock or fuel for waste tire processing.

\section{Feasibility of Using Freeze-Thaw Evaporation ${ }^{\circledR}\left(\right.$ FTE $\left.^{\circledR}\right)$ Technology for Power Plant Cooling Water Treatment}

Period of Performance: April 1, 2004 - March 31, 2005

Final Report: Appended to January 1 - March 31, 2005, quarterly status report (Report was mislabeled as Activity 3.7 - Review of Utility-Scale Energy Storage Technologies)

Brief Summary: FTE is an attractive and economical water treatment method for dissolved solids reduction in cooling water ponds at coal-fired power plants. FTE provides the opportunity for cost-effective treatment of brackish or contaminated water. FTE couples conventional evaporation and freeze-thaw for treatment and disposal of wastewater. Natural seasonal cycles are combined with inexpensive control equipment to automatically separate the process streams, offering industrial users reduced process water costs and reduced wastewater disposal costs. This study evaluated FTE system integration into a typical power plant cooling water operation that will ideally provide for brine concentration and disposal as well as high-quality treated water that will reduce the need for freshwater makeup. Additional power generation may be realized as a result of enhanced cooling that would be available because of cold-temperature waters during periods of ice melt.

\section{Effects of Fossil Fuel Power Plant Emissions on Precipitation}

Period of Performance: April 1, 2004 - March 31, 2005

Final Report: Appended to January 1 - March 31, 2005, quarterly status report

Brief Summary: Air pollution has been shown to inhibit as well as augment precipitation. For example, smoke from biomass burning is known to suppress warm rain processes (6). On the 
other hand, a study has shown that large salt-containing dust particles from the Aral Sea promote precipitation (7). This strategic study investigates the effects of primary particulate emissions from coal-fired power plants on precipitation processes.

Particulate matter (PM) may be solid or liquid, with diameters between 0.002 and $100 \mu \mathrm{m}$. Particles may be directly emitted into the atmosphere or formed there by chemical reactions. Particles formed in the atmosphere by chemical reactions are referred to as secondary PM, while those directly emitted from a source are called primary. Both primary and secondary PM may act as nuclei for atmospheric cloud droplets. Based on the hygroscopic properties of these particles, the particles may inhibit or augment precipitation formation.

Little information has been gathered on the interactions of primary PM from coal-fired power plants with clouds and precipitation. However, numerous studies have investigated the effects of secondary PM on precipitation. Secondary PM such as sulfuric and nitric acids leads to acid rain which has been a major air pollution topic since the 1970s. Although science can explain the formation of acid rain, no information has been found on the impact of secondary PM on precipitation amounts.

A comprehensive review of past research on the effects of PM from coal-fired power plants on precipitation is provided by this study. Suggestions for future research activities are made based on the literature review. In addition to PM, heat and moisture emissions from these plants are briefly discussed as also potentially influencing precipitation.

\section{Remediation Seminar}

Period of Performance: April 1, 2004 - March 31, 2006

Final Report: Appended to January 1 - March 31, 2006, quarterly status report

Brief Summary: A daylong seminar entitled "Site Remediation Technologies - An Update" was presented by Mr. Jaroslav Solc in Bismarck, North Dakota, on February 16, 2006. The seminar was organized by the North Dakota Department of Health.

The presentation consisted of a compilation of scientific, engineering, and economic principles relevant to environmental remediation technologies, including case studies from EERC sites. The primary goal was to target a broad audience, including federal- and state-level regulatory agencies, insurance companies, and industries responsible for the manufacturing, distribution, and handling of potential petroleum-based contaminants. A total of 42 participants attended the presentation.

\section{Short Course - Ash Behavior and Mercury Control in Coal Combustion}

Period of Performance: April 1, 2004 - September 30, 2004

Final Report: In July 1 - September 30, 2004, quarterly status report 
Brief Summary: A short course entitled "Ash Behavior and Mercury Control in Coal Combustion" was developed. Presentation materials were gathered and compiled into a PowerPoint presentation for a 2-day short course.

The 2-day short course includes a 1-day presentation on ash transformation and deposition and a 1-day presentation on mercury transformation and emission control. The ash behavior presentation includes an overview of the physical and chemical processes related to ash transformation and deposition in coal-fired boilers; an introduction of the EERC-developed computer models, which predict the characteristics of ash deposits specific to the boiler configuration/operation and the coal fired; and guidelines for identifying and managing slagging and fouling problems.

The $\mathrm{Hg}$ emission control presentation covers mercury regulations, the occurrence of $\mathrm{Hg}$ in coals, the $\mathrm{Hg}$ transformation mechanisms in combustion and postcombustion systems, and the latest measurement and emission control technologies. Emphasis is given to an overview of the technologies promoting oxidation and capture of $\mathrm{Hg}$ to achieve the minimum level of $\mathrm{Hg}$ emission.

As part of separate DOE projects, the ash behavior short course was presented at the Western Fuels Symposium and at Ameren. We received excellent feedback on the course content.

\section{Review of Utility-Scale Energy Storage Technologies}

Period of Performance: April 1, 2004 - December 31, 2004

Final Report: Appended to October 1 - December 31, 2004, quarterly status report

Brief Summary: Bulk energy storage technologies have the potential to offer utilities opportunities to reduce electrical costs and improve energy service to customers. Installation of energy storage technologies can provide improvements in efficiency, reliability, and stability of energy supply by reducing requirements for spinning reserves to meet peak demands, making better use of baseload generation and allowing for better integration of intermittent renewable energy sources. Barriers to utility implementation of energy storage technologies include, but are not limited to, high capital costs, lack of familiarity with more advanced energy storage options and limited field demonstration, and lack of analysis tools for evaluating technical and financial merits of energy storage.

Numerous bulk energy storage technologies are commercially available or nearing commercial applicability today. Such technologies include advanced electrochemical battery storage, pumped hydropower, superconducting magnetic energy storage (SMES), flywheels, compressed air energy storage (CAES), and hydrogen energy storage and regenerative (reversible) fuel cells. Leading technologies (based on proven demonstration and costcompetitiveness) include CAES, SMES, and advanced electrochemical battery storage. Through a review of current literature, this project aimed to identify potential opportunities for energy 
storage development and implementation with emphasis on identifying means for improved integration of wind energy into current energy infrastructure in the region.

\section{Evaluation of ChemCAD Software}

Period of Performance: July 1, 2004 - September 30, 2004

Final Report: In July 1 - September 30, 2004, quarterly status report

Brief Summary: ChemCAD is a provider of chemical process simulation software. The primary purpose of this task was to determine if this software is appropriate for use within the chemical process research and development activities that the EERC is currently pursuing with DOE.

An academic ChemCAD workstation license was acquired through the UND Chemical Engineering Department for evaluation. The software package was supplied with a tutorial that familiarizes the user with the most basic operations and uses interactive help screens to assist the user with screen options. The tutorial was completed, and much of the help screen information was read to become more fluent in the functionality. A considerable effort was applied toward modeling processes that were previously used at the EERC. The premise was to determine if any information gleaned from the use of ChemCAD could have assisted these projects or, at a minimum, supported the results found through direct measurement. The benefit of this approach was that it helped to quantify the modeling limitations, or at least the modeler's limitations of describing a process adequately through the use of the available operations. However, like most sophisticated software packages, the ability to augment the standard package with user-supplied data, code, and processes blurs the line of ChemCAD's ultimate capability.

\section{Subcritical Water Fractionation of Particulate Matter}

Period of Performance: April 1, 2005 - June 30, 2005

Final Report: Manuscript for publication in Toxicological Sciences entitled Midpolarity and Nonpolar Wood Smoke PM Fractions Deplete Glutathione in RAW 264.7 Macrophages.

Brief Summary: Wood smoke PM is a complex mixture of components falling in a spectrum of highly polar to nonpolar species. Wood smoke PM is a likely factor in pulmonary disease and induces oxidative damage. Most toxicity studies focus on nonpolar species such as polycyclic aromatic hydrocarbons (PAHs). However, the role of more polar PM constituents as toxicants is not clear. In this work, we evaluated the ability of multiple fractions of varying polarity to deplete glutathione (GSH) in RAW 264.7 macrophages and BEAS-2B bronchial epithelial cells. We utilized hot pressurized (subcritical) water to fractionate wood smoke PM into seven fractions of decreasing polarity. In contrast to polar fractions, midpolarity and nonpolar fractions exhibited greater GSH depletion (ED50 at PM concentrations $\sim 50 \mu \mathrm{g} / \mathrm{mL}$ ). GSH depletion caused by nonpolar fractions (extracted at $250^{\circ}-300^{\circ} \mathrm{C}$ ) was associated with the presence of PAHs. In midpolarity fractions (extracted at $100^{\circ}-150^{\circ} \mathrm{C}$ ), oxy-PAHs, syringylguaiacyls, disyringyls, and lower-molecular-weight PAHs were found. Direct comparison of GSH depletion by individual oxy-PAHs and PAHs suggests that oxy-PAHs are contributors to oxidative stress 
caused by wood smoke PM. However, other unidentified PM constituents contribute to GSH depletion as well. The results indicate the toxicological importance of oxygenated organics found in midpolarity PM fractions.

\section{Domestic Energy Parks}

Period of Performance: July 1, 2006 - September 30, 2007

Final Report: Appended to July 1 - September 30, 2007, quarterly status report

Brief Summary: The findings of this study show that coproduction of liquid transportation fuels, heat, and electric power in plants that integrate biomass and coal gasification into existing pulp and paper mills can contribute significantly to moving the nation closer to energy independence. Transportation fuels and electric power can be produced at prices that are competitive with current markets. Fuels produced from biomass are essentially carbon neutral in the environment, and the processes used for gasifying coal and converting syngas to liquid fuels and power offer opportunities for strict control of carbon emissions and priority pollutants. Carbon capture and coprocessing with biomass can appreciably reduce the carbon intensity of the overall process in the interest of using the nation's abundant coal resources to reduce dependency on imported oil.

The driving forces that governed this study were the need to produce alternative transportation fuels from domestic resources at or below market prices and the growing recognition that high levels of carbon management will be required in the future. The objective is to develop energy parks that process biomass and coal to produce transportation fuels, chemicals, and electricity under policies that place strict controls on carbon emissions. This study evaluates the integration of synfuels and power production from biomass and coal in four pulp and paper mills in different regions of the country (South, Northeast, Midwest, and West) to reflect differences in local markets, including coal and electricity prices, environmental regulations, water use restrictions, and demand for various products.

\section{Evaluation of Landfill Gas Applications}

Period of Performance: April 1, 2005 - March 31, 2007

Final Report: Appended to January 1 - March 31, 2007, quarterly status report

Brief Summary: Landfill gas (LFG) comprises approximately 50\% methane and $50 \%$ carbon dioxide and is produced by the decomposition of organic waste under anaerobic conditions. EPA estimates that there are about 6000 landfills in the United States, mostly made up of municipal solid waste, that are producing methane. This is assumed to be the largest source of anthropogenic methane emissions in the United States and is speculated to contribute an estimated 8.8 to 12.7 terragrams ( 450 to 650 billion cubic feet) of methane to the atmosphere a year (8).

This activity completed a preliminary feasibility study that evaluated potential applications of LFG from a 40-year-old municipal open dump turned into a landfill in the far northern 
climatic conditions of Grand Forks, North Dakota. This investigation examined the characteristics and constituents of the potential fuel source, the power generation potential of this site, and the local parameters for using microturbine technology for continuous electricity and heat generation.

\section{Controlled Spontaneous Reactor}

Period of Performance: April 1, 2005 - March 31, 2007

Final Report: Appended to January 1 - March 31, 2007, quarterly status report

Brief Summary: The overall goal of this project was to obtain data at a laboratory scale using the pressurized fluidized-bed reactor (PFBR) to establish that the controlled spontaneous reactor (CSR) can be used to remove and concentrate mercury into the CSR exit gas stream prior to the coal or fuel being fed directly into a combustion or gasification system. The CSR is an EERCpatented concept for drying coal at low temperatures or, at higher temperatures, drying and partially devolatilizing the coal with low-oxygen gas for various applications with circulating fluidized-bed boilers, pulverized coal-fired boilers, gasifiers, or other coal- or biomass-fired system. For this testing, the PFBR will be operated in an atmospheric mode over a range of selected operational bed temperatures. A secondary objective was to identify potential economic means of removing the mercury from the gas stream produced by the CSR process.

\section{$\mathrm{CO}_{2}$ Separation Technologies}

Period of Performance: April 1, 2005 - March 31, 2007

Final Report: Appended to January 1 - March 31, 2007, quarterly status report

Brief Summary: The emission of carbon dioxide $\left(\mathrm{CO}_{2}\right)$ to the atmosphere has been identified as a leading contributor to global warming. In most countries, burning fossil fuels such as coal and natural gas is far and away the greatest source of $\mathrm{CO}_{2}$ to the atmosphere, accounting for $>95 \%$ of the total anthropogenic $\mathrm{CO}_{2}$ generated in the United States (9). Although emissions from mobile sources such as automobiles and other sources of $\mathrm{CO}_{2}$ will need to be addressed, it is clear that $\mathrm{CO}_{2}$ emissions from coal-fired power generation will need to be substantially reduced to have any real effect on global $\mathrm{CO}_{2}$ levels. Table 1 shows the sources of $\mathrm{CO}_{2}$ emissions from fossil fuel combustion in the United States in 2002 (9).

Sequestration of $\mathrm{CO}_{2}$ in geological formations or in the deep ocean is considered to be the leading candidate for disposal. Based on the results from DOE's carbon sequestration program, there is enough $\mathrm{CO}_{2}$ geological storage capacity for over 3500 billion tons (10). In general, to economically sequester $\mathrm{CO}_{2}$ requires a relatively pure, high-pressure gas stream. However, in conventional fossil fuel-fired electric generation plants, flue gas $\mathrm{CO}_{2}$ is only a small portion, $10 \%-20 \%$, of gases generated during combustion, with most of the remainder being nitrogen $\left(\mathrm{N}_{2}\right)$, oxygen $\left(\mathrm{O}_{2}\right)$, and water. Therefore, it will be required that $\mathrm{CO}_{2}$ be separated from the remainder of the flue gas before it can be sequestered or that new fossil fuel-fired systems be developed. 
Table 1. Sources of $\mathrm{CO}_{2}$ Emissions from U.S. Fossil Fuel Combustion in 2002

\begin{tabular}{lcc}
\hline Sector & $\mathrm{CO}_{2}$ Emissions, million tons carbon & Percent of Total \\
\hline Electrical Generation & 2240.1 & 39.9 \\
Transportation & 1764.4 & 31.4 \\
Industrial & 955.8 & 17.0 \\
Residential & 373.1 & 6.7 \\
Commercial & 231.2 & 4.2 \\
Other & 46.5 & 0.8 \\
Total & 5611.0 & 100.0 \\
\hline
\end{tabular}

Separation of $\mathrm{CO}_{2}$ from other gas species is not new and has been conducted on the commercial scale for over 50 years (11). Most plants were designed to produce $\mathrm{CO}_{2}$ to sweeten natural gas (remove $\mathrm{H}_{2} \mathrm{~S}$ ) and purify syngas to produce hydrogen $\left(\mathrm{H}_{2}\right)$ in refinery operations and ammonia production. These technologies were designed to treat relatively low volumes of gases compared to what would be needed for large-scale sequestration of $\mathrm{CO}_{2}$ generated from power plants. In fact, the idea of separating and capturing $\mathrm{CO}_{2}$ from power plants did not start with concern about climate change but, rather, as a potential economic source of obtaining $\mathrm{CO}_{2}$ for enhanced oil recovery (EOR). Several commercial plants were built in the United States in the 1970 s and early 1980 s to produce $\mathrm{CO}_{2}$ for $\mathrm{EOR}$, but when the price of petroleum dropped in the 1980 s, most of these plants were shut down (11).

\section{Mercury Measurement in Combustion Flue Gases Short Course}

Period of Performance: April 1, 2005 - September 30, 2005

Final Report: Located in Appendix B

Brief Summary: A comprehensive evaluation of mercury measurement techniques was completed. The study included the following topics:

- Upfront planning that is needed

- Regulations regarding mercury measurement (40 Code of Federal Regulations [CFR], Part 75 and Part 60)

- Wet-chemistry methods for mercury measurements

- Sorbent trap methods (40 CFR, Part 75, Appendix K)

- Continuous mercury monitors

An overriding element of each of these topics was the quality control/quality assurance necessary to ensure that the data generated are of high quality. If the data are collected for regulatory purposes, this will ensure that they are acceptable to the regulating agency, either EPA or the state. 


\section{Installation of an Additional Wet Scrubber on the Energy \& Environmental Research Center's 7-kW Combustion System}

Period of Performance: April 1, 2005 - June 30, 2005

Final Report: In April 1, 2005 - June 30, 2005, quarterly status report

Brief Summary: The capability to conduct dual wet scrubber pollution $\left(\mathrm{SO}_{\mathrm{x}}, \mathrm{NO}_{\mathrm{x}}, \mathrm{Hg}\right.$, etc.) removal testing on a small-scale $(<10-\mathrm{kW})$ combustion system is appealing to the pollution control industry. The EERC's 7-kW combustion system, however, is only equipped with one wet scrubber. The existing wet scrubber tower and packing comprise plexiglas and polypropylene, respectively. These materials are not conducive to mercury emission control testing because they readily absorb mercury. An additional pilot-scale wet scrubber at the EERC recently became available. The tower and packing of this additional scrubber comprise glass and stainless steel, respectively. These materials are chemically inert in the presence of mercury and are, therefore, ideally suited for mercury emission control testing. The EERC removed and transported the additional wet scrubber and installed it as a secondary scrubber on the 7-kW combustion system.

\section{Microbial Cycling of $\mathrm{CH}_{4}, \mathrm{CO}_{2}$, and $\mathrm{N}_{2} \mathrm{O}$ in Wetland Environments - A Scoping Study}

Period of Performance: October 1, 2005 - September 30, 2006

Final Report: Appended to September 30, 2006, quarterly status report

Brief Summary: This activity was undertaken to survey the literature on microbially mediated biogeochemical cycling of $\mathrm{CH}_{4}, \mathrm{CO}_{2}$, and $\mathrm{N}_{2} \mathrm{O}$ in terrestrial ecosystems, with the objective of preparing a proposal on microbial cycling of these greenhouse gases in the glaciated North American prairie, which previously supported the largest wetland complex in North America. However, cultivated agriculture has shifted the function of the wetlands from net sinks to net sources of atmospheric $\mathrm{CO}_{2}$. Recently, based on changes in soil organic carbon, it has been proposed that restoration of previously farmed wetlands in the Prairie Pothole Region (PPR) may sequester atmospheric $\mathrm{CO}_{2}$, but wetland restoration also impacts $\mathrm{CH}_{4}$ and $\mathrm{N}_{2} \mathrm{O}$ cycling in the ecosystem, and the global-warming potential (100 years) of $\mathrm{CH}_{4}$ and $\mathrm{N}_{2} \mathrm{O}$ is 21 and 310 times that of $\mathrm{CO}_{2}$, respectively. Therefore, it is necessary to study microbial $\mathrm{CH}_{4}$ and $\mathrm{N}_{2} \mathrm{O}$ cycling in the wetland environment so that an overall budget of $\mathrm{CO}_{2}$ sequestration by restoring the wetlands in PPR can be obtained. The proposed study is expected to provide experimental data to support development of action plans and long-term postrestoration management strategies so that wetland restoration and management may be economical, sustainable, and environmentally sound.

\section{Residential Energy Issues}

Period of Performance: January 1, 2006 - March 31, 2007

Final Report: Appended to January 1 - March 31, 2007, quarterly status report 
Brief Summary: Attention is increasingly being placed on the energy and environmental impacts of buildings and homes in the United States. According to DOE, over one-third of the total energy consumed every year is attributed to 87 million homes and commercial buildings in this country-energy derived predominantly from fossil fuels. Further, buildings use two-thirds of all electricity generated nationally, and that usage continues to rise.

The EERC has a focused interest in supporting the development, demonstration, and evaluation of energy-efficient technologies for buildings and in supporting education and outreach opportunities to the varied stakeholders in the building industry, especially those in cold climates. To fully achieve efficient buildings, especially as we move toward a hydrogen economy, a combination of reduced energy demand and increased use of environmentally friendly and/or hydrogen-based distributed power generation will be required, with special attention paid to system interaction and a whole-building approach. The EERC has unique capabilities related to development and integration of energy-efficient technologies to achieve greater energy efficiency in buildings.

Project activities were focused on developing a strategic plan to support commercial activities related to improving building efficiency. Activities included reviewing available literature on state-of-the-art building practices and energy-efficient technologies, communicating with stakeholders to collaborate on more energy-efficient buildings, and quantifying the energy savings associated with several energy-efficient building technologies.

\section{Materials Testing}

Period of Performance: January 1, 2006 - September 30, 2006

Final Report: In July 1 - September 30, 2006, quarterly status report

Brief Summary: A new type of reaction-bonded silicon carbide ( $\mathrm{SiC}$ ) has been developed at the EERC that can be cast in complex near-net shapes, maintains its strength to at least $1450^{\circ} \mathrm{C}$ (above the melting temperature of silicon), and is $35 \%$ porous to allow low-temperature secondary materials such as polymers or metals to be infiltrated into its structure to substantially increase its toughness (resistance to fracture). As such, the EERC SiC has both high-temperature and low-temperature uses. Potential high-temperature uses are as heat exchanger tubing, burner nozzles, very high-temperature mechanical fasteners (nuts and bolts), and turbine blades or combustor liners. At lower temperatures, composites of our $\mathrm{SiC}$ can be used for tough, abrasionresistant thin coatings in power and industrial applications, such as solids handling, grinding and cutting of hard materials, and high and hypervelocity impact. It also has potential use as meteoroid protection and thermal protection during aerobraking by spacecraft.

Because of its potential use in spacecraft, we have been given an opportunity to expose coupons of the material to a low-earth environment during the Materials International Space Station Experiment 6 (MISSE-6). 


\section{Oil Field Applications for Low-Btu Associated Gas}

Period of Performance: January 1, 2007 - June 30, 2007

Final Report: In April 1 - June 30, 2007, quarterly status report

Brief Summary: The EERC explored opportunities to utilize gases associated with oil production. Secondary oil recovery operations produce associated gas that is typically unused. In many cases, the gas has a low heating value $<400 \mathrm{Btu} / \mathrm{scf}$. The EERC is exploring opportunities for utilization that will produce energy and reduce emissions. This strategic studies project provided experience for EERC personnel to implement solutions using microturbines and/or burners capable of firing very dilute associated gas.

Training was completed with Capstone Turbine Corporation for service and operation of $30-\mathrm{kW}$ and $60-\mathrm{kW}$ microturbine systems. The training enables the EERC to understand turbine operation and relevant concerns for oil field applications and low-Btu gas implementation. The training was utilized on field installations of microturbines firing gas less than $300 \mathrm{Btu} / \mathrm{scf}$. A certificate was obtained from Capstone, and the project objectives have been completed.

\section{Development of a Novel Petroleum Biotechnology}

Period of Performance: January 1, 2007 - March 31, 2009

Final Report: In Appendix C

Brief Summary: This project is an effort to develop a novel biotechnology to mitigate production of hydrogen sulfide $\left(\mathrm{H}_{2} \mathrm{~S}\right)$ in the petroleum industry, to promote methane $\left(\mathrm{CH}_{4}\right)$ production in oil and gas fields, and to enhance oil recovery, based on a recently developed EERC sulfide control additive capable of effectively controlling microbial $\mathrm{H}_{2} \mathrm{~S}$ production.

\section{Potential for Conversion of Beet Sugar}

Period of Performance: April 1, 2001 - September 30, 2001

Final Report: In July 1 - September 30, 2001, quarterly status report

Brief Summary: This study was originally focused on producing ethanol and lactic acid from sugar beets; however, because of the poor initial economics, the effort was refocused to look at higher-value products from existing ethanol facilities. The following results are from the conversion of an ethanol facility to a lactic acid facility:

- There is a 3,000,000-ton potential market for ethyl lactate as a biodegradable solvent to replace conventional toxic solvents. The comparative market price of ethyl lactate is $\$ 1.00 / 1 b$.

- Assumed a plant basis of $1 \%$ potential market (7,000,000-gallon plant) 
- 8,000,000-gallon ethanol plant equivalent; Heartland Grain Fuel in Aberdeen, South Dakota

- 3,000,000 bushels of corn per year

- Produce 3,600,000 gallons of ethanol, 4,600,000 gallons of lactic acid.

- Coproduct: 35,700 tons of distillers grain per year

- Predicted annual revenue $\$ 64,200,000$

- Raw materials estimated to be $\$ 8,100,000$ annually; predicted product cost of $\$ 43,400,000$ per year.

- Cost of equipment approximately $\$ 3,200,000 ; \$ 17,100,000$ capital investment.

- Estimates give $68 \%$ internal rate of return, first-year payback.

- Plant economics most sensitive to product conversion of lactic acid and ethanol.

\section{Biomass Product Separation and Characterization for the Generation of Fuel Additives}

Period of Performance: April 1, 2001 - December 31, 2001

Final Report: In October 1 - December 31, 2001, quarterly status report

Brief Summary: Solubilization (low-intensity liquefaction) of biomass and a mixture of coal and biomass was successful in converting $>95 \%$ of the solids using the initial two steps in a process originally designed for producing refinery stock from coal. High-pressure hydrotreating, originally designed for reducing solubilized coal, was not applied to the biomass-only or biomass-coal liquids. Although the conversion process was highly successful, analysis of the product waited until this project. Liquid products from recent solubilization tests involving lowintensity liquefaction of wood of the genus Populus and a 50:50 wt:wt mixture of Populus and lignite coal were analyzed using thermogravimetric analysis procedures, gas chromatographymass spectrometry (GC-MS) and $1 \mathrm{H}$ nuclear magnetic resonance spectrometry (NMR). The liquid from biomass-only was distilled over the range of $50^{\circ}-370^{\circ} \mathrm{C}$, and that of the biomasscoal was distilled over the range of $50^{\circ}-360^{\circ} \mathrm{C}$. NMR showed an aliphatic:aromatic proton ratio for biomass liquids to be 2.96 , and hydroxyl proton:aromatic proton was negligible, whereas ratios for the biomass-coal liquids were 3.42 and 0.13 , respectively. GC-MS results indicated primarily oxygenated compounds, e.g., guaiacol, alkylated benzofurans, carboxylic acids greater than 10 carbons in length, and small amounts of unidentified homologous series of large compounds. The concentration of guaiacol relative to other compounds in the mixture was much greater in biomass-coal than in biomass-only liquids. Although the reaction is catalyzed and 
supplied with hydrogen by $\mathrm{H}_{2} \mathrm{~S}$, sulfur compounds were not detected in the liquid product of either biomass-only or biomass-coal by either elemental analysis or GC-MS.

\section{Analysis of Oil and Gas Environmental Issues Affecting Domestic Production}

Period of Performance: July 1, 2002 - September 30, 2003

Final Report: In July 1 - September 30, 2003, quarterly status report

Brief Summary: In general, the upstream oil and gas industry appeared to be less inclined to become a financial partner in environmental research activities. There are many reasons for the lack of funding support from industry in the past year: 1) the majors are generally selling their domestic on-shore operations and putting most of their capital into the acquisition and development of offshore and/or foreign on-shore operations and, therefore, have a lessened interest in solving environmental problems that are driven by American regulations; 2) independent producers do not typically have the financial resources to support environmental research activities that address issues other than those that address immediate or very short-term needs; and 3) instability in the prices of oil and gas has made it difficult for companies to commit funding to research projects, especially long-term (greater than 1 year) research projects. The decreased participation by industry in environmental research was reflected by a noticeable decline in attendance at the historically most important petroleum environmental conferences (IPEC and SPE).

\section{Student Involvement Activities}

Period of Performance: April 1, 2002 - June 30, 2004

Final Report: NA

Brief Summary: A series of very small studies were conducted by a variety of students in support of other projects at the EERC supported by DOE. Any significant results generated by the students have been reported through other projects.

\section{Filter Cake Properties}

Period of Performance: April 1 - June 30, 2004

Final Report: In April 1 - June 30, 2004, quarterly status report

Brief Summary: Efficient removal of particulates from the gas flow prior to reaching the turbine is the key to the success of solid fuel direct-fired turbine power generation. Severe problems of fouling, erosion, and corrosion of the turbine may be caused if the ash is not removed from the gas stream. Currently, removal of the ash particles from the gas stream is accomplished by filtration with ceramic or metallic filters at high temperature to ensure a high system efficiency. However, higher temperatures usually increase the stickiness of the ash particles, causing the 
cake to adhere to the filter walls. Such adherence causes an increased pressure drop, thereby increasing the cost of filtration, and can lead to blinding or breaking of filter elements.

The EERC worked with the New Energy and Industrial Technology Development Organization (NEDO) of Japan and DOE to perform research to determine the relationship between two system operating variables that affect the development of dust cakes that are difficult to remove and can bridge between candle filter elements, causing their failure.

\section{High-Temperature Corrosion of Alloys in Simulated Boiler Tube Conditions}

Period of Performance: April 1 - June 30, 2004

Final Report: In April 1 - June 30, 2004, quarterly status report

Brief Summary: Current utility boilers operate with steam at 175 bar and $550{ }^{\circ} \mathrm{C}$ which creates a coal pile-to-busbar efficiency of $35 \%$ on a higher-heating-value basis. To improve efficiency, higher pressures and temperatures must be reached. In the next generation of steam-cycle power plants, ultrasupercritical steam will be produced in the near term at 280 bar and $580^{\circ} \mathrm{C}$ and, in the longer term, at 325 bar and $650^{\circ} \mathrm{C}$. One program funded by DOE and several large boilermakers is testing new alloys at these temperatures in bituminous and subbituminous coal-fired power plants. However, no known work has been done under biomass-coal cofire conditions or lignitefired conditions.

The alloys tested were HR3C, TP347HFG, MA754, MA956, and a modified MA956 alloy. The HR3C is a $25 \% \mathrm{Cr}, 20 \% \mathrm{Ni}$ super stainless steel, while the TP347HFG contains only $18 \%$ $\mathrm{Cr}$ and $10 \% \mathrm{Ni}$. Each contains minor amounts of alloying elements with a balance of iron. MA754 and MA956 are oxide dispersion-strengthened (ODS) alloys in which yttrium oxide is finely distributed throughout the grain boundaries in a mechanical alloying procedure that gives them excellent high-temperature creep strength. The MA754 is a Ni-based chromia-scaleforming alloy, whereas the MA956 is an iron-based alumina-scale-forming alloy. The modified MA956 is an experimental material being developed by Special Metals Incorporated under a Vision 21 program to have a greater hoop strength than the standard MA956. The temperature to be used in this study is $700^{\circ} \mathrm{C}$, and the durations of the exposures are 200,500 , and $1000 \mathrm{hr}$. At each of the specified times, samples are removed from the furnace and cleaned according to ASTM International Procedure G1-88 for mass wastage calculations. This procedure involves cleaning the samples through a series of chemical baths to remove corrosion products and then weighing the samples to determine mass loss due to metal corrosion.

\section{On-Demand High-Pressure Hydrogen Extraction and Dispensing for Vehicle Fueling}

Period of Performance: April 1, 2002 - September 2003

Final Report: Appended to July 1 - September 30, 2003, quarterly status report

Brief Summary: The reforming of natural gas is an industrially established process for the production of hydrogen of sufficient purity to be used for operating a fuel cell. The following 
reaction equation for steam reforming can be formulated for methane as the main component of natural gas:

$$
\begin{array}{ll}
{[1] \mathrm{CH}_{4}+\mathrm{H}_{2} \mathrm{O}} & \rightarrow \mathrm{CO}+3 \mathrm{H}_{2} \\
{[2] \mathrm{CH}_{4}} & \rightarrow \mathrm{C}+2 \mathrm{H}_{2}
\end{array}
$$

Like the steam reforming of higher hydrocarbons or alcohols, the above reaction for steam methane reforming (SMF) is strongly endothermic, with a standard formation enthalpy of $+206 \mathrm{~kJ} / \mathrm{mol}$ (49 kcal/mol), and is commonly carried out on a suitable catalyst (nickel or noble metals on a substrate material) on an industrial scale at temperatures above $700^{\circ} \mathrm{C}$.

A key barrier to commercialization of fuel cell-powered vehicles is the lack of a viable hydrogen fueling infrastructure. Automakers and oil companies are developing technologies for on-board vehicle extraction of hydrogen from gasoline and methanol, but all generally agree that this is a near-term approach to be utilized only until the advent of economical hydrogen fueling via dispensers that are similar in safety and ease of operation to today's gasoline pumps. Project scientists envision a relatively small dispenser-level system where high-pressure natural gas (which is easier, safer, and cheaper to compress than hydrogen) is run through a high-pressure water chamber for hydrogen extraction, and extracted hydrogen is then purified and dispensed into a vehicle.

The objectives of the proposed activity were to assess the technical feasibility and economic viability of high-pressure water extraction of hydrogen from high-pressure natural gas. The overall goal of this activity is to develop sufficient data to pursue (with an industry partner) commercial development of a modular, on-demand, high-pressure hydrogen extractionpurification-dispensing system that will be a key component of a national strategy for distributed hydrogen based on natural gas and the natural gas pipeline system.

\section{Indirectly Fired Combined Cycle with Condensing Heat Exchanger}

Period of Performance: July 1, 2004 - June 30, 2005

Final Report: Appended to April 1 - June 30, 2005, quarterly status report

Brief Summary: As the demand for power increases and environmental controls tighten, future power plants will increasingly need to be designed and operated to conserve both fuel and water. Water is becoming scarce and expensive in many parts of the western United States, especially California where there is already a strong economic incentive to reduce the net cooling water requirements of power plant subsystems, cooling steam turbine condensers, and scrubbing stack gases. Future escalation in prices for natural gas and possible restrictions on carbon emissions from fossil fuels will likewise provide a strong incentive for increasing generating efficiencies. Coal utilization would be most severely impacted by climate change policy initiatives since a coal-fired steam plant emits nearly three times more $\mathrm{CO}_{2}$ than a natural gas-fired combined-cycle plant with similar generating capacity. The three critical factors of water recovery, plant efficiency, and emissions are closely linked, so that technical options for recovering water will open up new opportunities for integration that can improve performance relating to the other two 
factors. The potential amount of water that could be recovered from flue gas is sufficient to significantly reduce and, in some cases with air or hybrid air-water cooling, eliminate the need for off-plant sources of water. In addition, condensing water from flue gas may provide opportunities for removing $\mathrm{SO}_{2}$ and $\mathrm{NO}_{\mathrm{x}}$ to lower levels to approach near-zero emissions of acid gases. Further integration with oxygen-blown combustion would both enhance water recovery by increasing the partial pressure of water in flue gas and provide a clean source of $\mathrm{CO}_{2}$ that could be used for tertiary oil recovery or sequestration.

In this investigation, calculations were performed to determine the amounts of water that could be recovered from flue gases generated from the combustion of different fuels under varying conditions of temperature, combustion mode (air versus oxygen combustion), use of a condensing heat exchanger, and use of a desiccant dehumidification system. The purpose for using a desiccant is to facilitate the recovery of useful amounts of water at flue gas temperatures that can be reasonably achieved in operating a power plant. When a Wyoming subbituminous coal is burned, the temperature required for recovering $50 \mathrm{gal} / \mathrm{MWh}(0.05 \mathrm{~L} / \mathrm{MJ})$ drops from $90^{\circ} \mathrm{F}\left(33^{\circ} \mathrm{C}\right)$ with the desiccant to $50^{\circ} \mathrm{F}\left(10^{\circ} \mathrm{C}\right)$ without. Fifty gal $/ \mathrm{MWh}(0.05 \mathrm{~L} / \mathrm{MJ})$ represents $11 \%$ of the cooling load on the steam condenser for a supercritical boiler, assuming that the cooling tower operates at ambient conditions of $\left.80^{\circ} \mathrm{F}\left[27^{\circ} \mathrm{C}\right]\right)$. At a water dew point of $110^{\circ} \mathrm{F}$ $\left(44^{\circ} \mathrm{C}\right)$, the desiccant would recover $43 \mathrm{gal} / \mathrm{MWh}(0.05 \mathrm{~L} / \mathrm{MJ})$. Without the desiccant and at very low ambient temperatures, flue gases could possibly be cooled to $50^{\circ} \mathrm{F}\left(10^{\circ} \mathrm{C}\right)$ using an air-flue gas heat exchanger, but significant engineering and economic problems would have to be resolved (e.g., pressure drop, corrosion and fouling of a condensing heat exchanger, and discharge of nonbuoyant stack gas). Combustion with oxygen instead of air also facilitates condensation of water at moderately elevated flue gas temperatures because of the proportionally higher partial pressure of water vapor in the absence of a high percentage of nitrogen in the flue gas. When a Wyoming subbituminous coal is combusted, oxygen combustion shows slightly more water recovery without a desiccant-based system than air combustion does with the desiccant-based system. Recovery of $50 \mathrm{gal} / \mathrm{MWh}(0.05 \mathrm{~L} / \mathrm{MJ})$ would be possible at $100^{\circ} \mathrm{F}$ $\left(38^{\circ} \mathrm{C}\right)$ in the oxygen-blown mode.

\section{Engineering Opportunities and Challenges of $\mathrm{CO}_{2}$ Mitigation Using Microalgae in Fossil Fuel-Fired Power Plants}

Period of Performance: January 1 - March 30, 2009

Final Report: In Appendix D

Brief Summary: Public concerns over global climate change due to anthropogenic emissions of greenhouse gases such as $\mathrm{CO}_{2}$ have resulted in significant pressure on all industries to seek effective ways to reduce $\mathrm{CO}_{2}$ emissions. Because coal-fired electric utilities are one of the largest sources of $\mathrm{CO}_{2}$ emissions, the pressure has been more intense. All fossil fuels originate from biomass produced by photosynthetic fixation of $\mathrm{CO}_{2}$, the process in which green plants produce sugar from sunlight, $\mathrm{CO}_{2}$, and water, with oxygen as a waste product. Photosynthesis is essentially nature's way of recycling $\mathrm{CO}_{2}$. However, the process of indirect $\mathrm{CO}_{2}$ capture by planting forests and other agricultural crops has been deemed to be an inadequate solution to the accumulation of greenhouse gases in our atmosphere. The potential $\mathrm{CO}_{2}$ capture by planting 
agricultural crops is expected to result in only a 3\%-6\% reduction compared to the $\mathrm{CO}_{2}$ generated burning fossil fuels (12). The one possible exception is to utilize microalgae for the direct treatment of flue gas. Microalgae have the ability to fix $\mathrm{CO}_{2}$ using solar energy, with an efficiency 10 times greater than that of terrestrial plants (13). In addition, it grows rapidly and can be incorporated into engineered systems such as photobioreactors. It has been found that the high $\mathrm{CO}_{2}$ content of power plant flue gas, $\sim 14 \%$ compared to only $350 \mathrm{ppm}$ in the atmosphere, greatly enhanced algae growth (14). It is estimated that algae produce between $73 \%$ and $87 \%$ of the net global production of oxygen (15).

\section{REFERENCES}

1. Rogers, E.M. Diffusion of Innovations, 4th edition; Free Press: New York, 1995.

2. Allen, M. F. A Review of Best Practices in University Technology Licensing Offices. The Journal of the Association of University Technology Managers 2001, 13.

3. Jaffe, A.B.; Lerner, J. Reinventing Public R\&D: Patent Policy and the Commercialization of National Laboratory Technologies. RAND Journal of Economics 2001, 32 (1), 167.

4. Manufacturers of Emissions Control Association. In Emission Control of Diesel-Fueled Vehicles; Washington, DC, 1997, pp 1-3.

5. Maly, P. et al. Alternative Fuel Reburning. Fuel 1999, 78, 327-334.

6. Rosenfeld, D. TRMM Observed First Direct Evidence of Smoke from Forest Fires Inhibiting Rainfall. Geophys. Res. Lett. 1999, 26 (20), 3105-3108.

7. Rudich, Y.; Khersonsky, O.; Rosenfeld, D. Treating Clouds with a Grain of Salt. Geophys. Res. Lett. 2002, 29 (22), 2060; doi:10.1029/2002GL016055.

8. Landfill Gas Primer - An Overview for Environmental Health Professionals; U.S. Department of Health and Human Services, Agency for Toxic Substances and Disease Registry, Division of Health Assessment and Consultation; Nov 2001.

9. Elwell, L.C.; Grant, W.S. Technical Overview of Carbon Dioxide Capture Technologies for Coal-Fired Power Plants. MPR Associates, Inc., Alexandria, VA, June 22, 2005.

10. DOE Regional Partnerships Find More Than 3500 Billion Tons of Possible $\mathrm{CO}_{2}$ Storage Capacity. U.S. Department of Energy, National Energy Technology Laboratory, News Release, March 27, 2007.

11. Thambimuthu, K.; Soltanieh, M.; Abanades, J.C. IPCC Special Report on Carbon Dioxide Capture and Storage; ISBN 92-9169-119-4, Intergovernmental Panel on Climate Change, Sept 2005. 
12. Hutchinson, J.J.; Campbell, C.A.; Desjardins, R.L. Some Perspectives on Carbon Sequestration in Agriculture. Agricultur. Forest Meteorol. 2007, 142, 288-302.

13. Usui, N.; Ikenouchi, M. The Biological $\mathrm{CO}_{2}$ Fixation and Utilization Project by RITE (1) Highly Effective Photobioreactor Systems. Energy Conserv. Mgmt. 1996, 38, S487-S492.

14. Sheehan, J.; Dunahay, T.; Benemann, J.; Roessler, P. A Look Back at the U.S. Department of Energy's Aquatic Species Program - Biodiesel from Algae; NREL/TP-580-24190, July 1998.

15. The Algae Energy Industry Opportunities \& Prospects. Oilgae Digest, updated Feb 15, 2009. 


\section{APPENDIX A}

\section{FINAL REPORT FOR RESEARCH PROJECT ENTITLED TECHNOLOGY ADOPTION - CERAMIC MATERIALS MARKET}




\section{TECHNOLOGY ADOPTION - CERAMIC MATERIALS MARKET}

\section{INTRODUCTION}

Technology innovation research focuses upon the adoption of technological innovations and why some innovations are adopted at a faster or slower rate than others. The rate of adoption is the relative speed by which an innovation is implemented by members of an industry group. Rogers (1995) identified five perceptual characteristics of innovations that help explain differences in adoption rates: relative advantage, compatibility, complexity, trialability, and observability.

Relative advantage is the degree to which an innovation is perceived as better than the idea it supersedes. Compatibility is the degree to which an innovation is perceived as being consistent with the existing values, past experiences, and needs of potential adopters. Complexity is the degree to which an innovation is perceived as difficult to understand and use. Trialability is the degree to which an innovation may be experimented with on a limited basis. Finally, observability is the degree to which the results of an innovation are visible to an observer. In general, the rate of adoption is positively related to perceived relative advantage, compatibility, trialability, and observability and is negatively related to perceived complexity of the innovation. Rogers (1995) found relative advantage to be one of the best predictors of an innovation's rate of adoption. Relative advantage, along with compatibility and complexity, is the most significant factor in explaining relationships across a broad range of innovation types.

The technological orientation of the United States provides a means for the transfer of technology out of universities. In the corporate sector, years of downsizing have led to the willingness of more companies to consider outsourcing in general and technology licensing in particular. Licensing in is seen increasingly as complementary to corporate business development strategies (Allen, 2001). Licensing is one strategy that promotes the diffusion of innovation.

Successful commercialization from universities and laboratories occurs when senior administration and management actively support cooperation with industry, with strong positive attitudes and incentives. Other key factors are the degree to which inventors of the technologies exhibit entrepreneurial attributes and have positive attitudes toward commercialization (Jaffe and Lerner, 2001). Also, successful universities and laboratories are those in which the cooperating company supports commercialization and where the company's technical people perceive their counterparts in the federal laboratories as willing to take risks and able to deal with ambiguity.

\section{OBJECTIVES}

This Energy \& Environmental Research Center (EERC) project was conducted to explore the market factors that influence the adoption of technology innovation. The goal was to better understand methods to help drive technology development to promote commercialization and 
acceptance of innovation for a specific technology, silicon carbide composites; determine market potential; and assist with the commercialization of the silicon carbide technology.

The market research involved the following objectives:

- Preparation of a material technology overview that is understandable to business and marketing personnel

- Preparation of a market/industry overview that quantifies market size

- Preparation of a competitive analysis

- Identification of market opportunities

- Identification of barriers to entry

- Identification of industry leads

- Recommendations for marketing strategies

\section{SCOPE OF WORK}

\section{Material Technology Overview}

A technology overview was prepared and presented in a full-color brochure format. The brochure lists relative and competitive advantages of the technology. Presentation of the information was designed to appeal to both technical and marketing managers.

The brochure was completed in April 2002. Copies were distributed at the American Ceramic Society Meeting in St. Louis, Missouri, in April 2002. The brochure provides an excellent marketing tool for the technology.

\section{Preparation of a Market Industry Overview}

According to the U.S. Advanced Ceramics Industry Status and Market Projections as of September 1998, the total market value for advanced structural ceramics was \$425 million. According to the latest U.S. reports, the advanced structural ceramics market is expected to grow from \$541 million in 2000 to \$736 million in 2005 and will have the largest average annual growth rate $(6.3 \%)$ over the next 5 years.

Wear-resistant parts dominate the market at 51.8\%. Other applications include heat exchangers (1.9\%), aerospace and military (3.9\%), bioceramics (24.5\%), automotive engines (0.9\%), and cutting-tool inserts (17.6\%). Applications in catalyst systems and chemical plants were not included in this total market value, nor were applications in semiconductor processing equipment.

Among structural ceramics, $43 \%$ are used as wear-resistant parts such as liners, guides, pulleys, dies, nozzles, grinding media, valves, seals, plungers, bearings, and parts for pulp and paper making. Although the cost of many applications of structural ceramics has been a barrier, structural ceramics are being increasingly commercialized. Another important application has been for components used in semiconductor manufacturing equipment. 


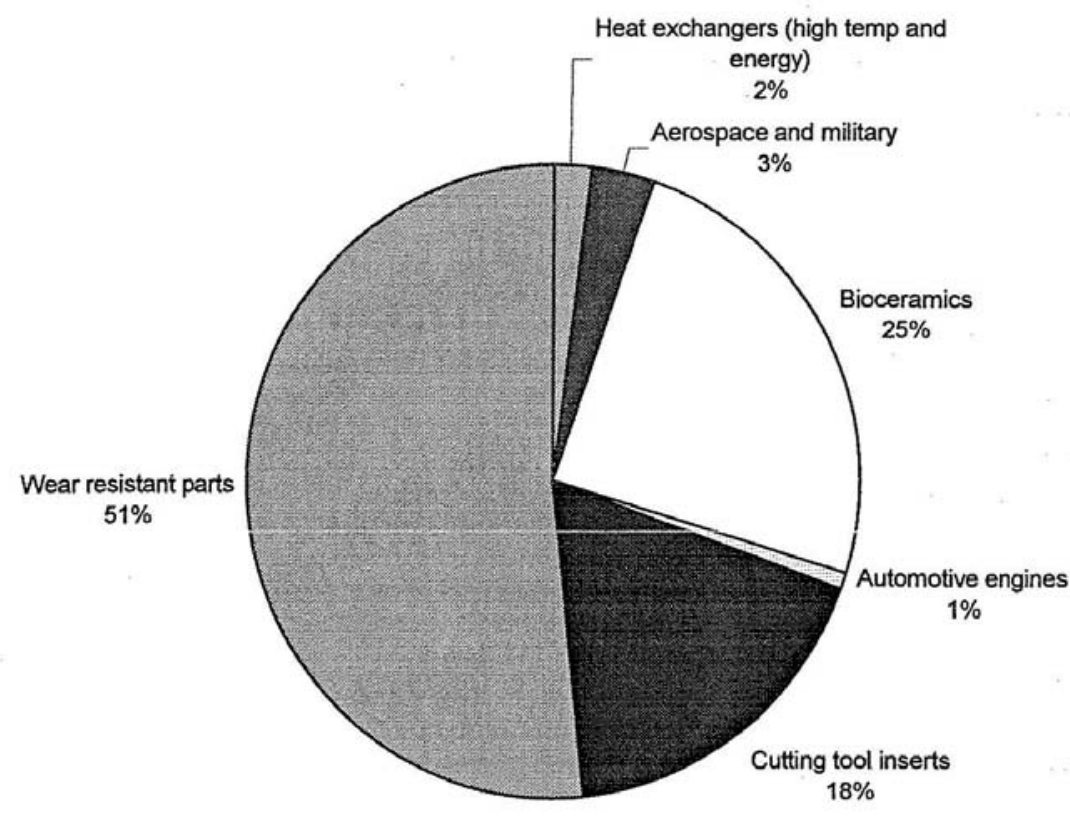

According to Richard Tressler of the Pennsylvania State University, the market size for semiconductor equipment is $\$ 200$ million worldwide and growing rapidly (Tressler, 2001). This market niche has not appeared in the periodic studies completed on advanced ceramics. The U.S. military has also been contributing to this market by its increased use of ceramic armor.

\section{Competitive Analysis}

More than 30 industry interviews were conducted by telephone. The phone contacts were derived from the ceramic industry publications. Any company involved in the manufacture or use of silicon carbide was included in the sampling frame.

In addition, numerous industry contacts were made by participation in two trade shows. EERC staff participated and collected marketing information from competitors at the American Ceramic Society meeting in April 2001 in Indianapolis, Indiana. They also participated in the American Ceramic Society Meeting in April 2002 in St. Louis, Missouri. At the second trade show, they served a dual marketing purpose by presenting marketing materials on the silicon carbide technology in addition to collecting competing marketing information.

The market leader in silicon carbide and advanced ceramics is St. Gobain whose family of companies now includes Carborundum, a former market leader. Although specific market share data were not obtained, respondents indicated that St. Gobain is a clear leader. In fact, one 
respondent referred to the company as a monopoly. The advanced ceramics industry is dynamic, with innovative start-up companies and industry consolidation as those companies mature.

\section{Who Is Perceived as Innovative in the Ceramics Industry}

One of the questions asked industry experts who they perceive as innovative in the ceramics industry. Smaller start-up and spinoff companies are perceived as innovative. For example, Starfire Systems is a company that was frequently mentioned in the research. Other sources of ceramics innovation are programs like the Small Business Innovation Research (SBIR) program and university research.

The Ceramics Corridor, located in New York along Interstate 86, was also frequently mentioned in the interviews as a source of innovation. The Ceramics Corridor Innovation Center, with both academic and industry links, has launched approximately 20 businesses, and 10 have graduated to off-site locations. Total sales since inception are approximately $\$ 900$ million, and 2700 jobs have been created in the region (Peterson, 2001).

\section{Commercialization of Technology - Licensing Technology}

Industry contacts were interviewed to learn about their reasons for licensing a technology. On the positive side, many reasons were given for licensing a technology. First, acquiring a technology drives innovation if the capability is not available in-house. Outsourcing from universities, national labs, and smaller firms can reduce the time required to market a technology, reduce the costs of research, and defray the risks associated with developing new technologies. Universities, national labs, and smaller firms are increasingly interested in commercializing the results of their research.

On the negative side, there are some reasons why technology is not licensed from universities. First, some companies rarely license in research from any source. This is also known as the "not invented here" problem. If a company is open to the idea of licensing a technology, a few reasons were stated as potential problems. The research may be at a stage of development too early to license. When asked how to overcome that problem, respondents suggested that there is a learning process as the company becomes familiar with the university and its researchers. This was expressed as "trial and error," "building relationships," and getting to know each other. Much awareness can be gained by active participation in trade shows and technical meetings. Relationship building takes more time and energy. In addition, there may be difficulty in reaching agreement and problems with intellectual property issues; however, these are typical problems in any licensing situation.

When asked how to facilitate the commercialization process, interviewees provided several ideas. First, they expressed the need to build awareness and relationships as previously mentioned. For example, Alfred University was mentioned by several respondents as associated with ceramics development. Respondents stated the need to make connections at technical meetings and trade shows. Sometimes they notice publications and patents if actively searching for a technology. They also suggested that providing them one-page technical briefs describing new technologies that present clear benefits and advantages is important to them. 


\section{What Factors Interest Industry}

From the literature, five perceptual characteristics of innovations that help explain differences in adoption rates were identified: relative advantage, compatibility, complexity, trialability, and observability. From the interviews, two primary market drivers are cost and performance which both fall within the realm of competitive advantage. There is often a tradeoff between these two important factors. In the interviews, the most important factor of the two appeared to be cost. Performance is more relevant in very specific high-end applications such as radiant burner tubes.

Another consideration in technology adoption is product life cycle. Silicon carbide as a product market category could be considered in the mature phase of its life cycle in that it has been available for many years and end-use applications have been identified. To extend the life cycle, new applications for the material (e.g., advanced power systems) or significant cost reductions are needed.

Silicon carbide or, more generally, advanced ceramics are described as in a state of either extension of the product life cycle or, possibly, introduction of new technology innovation. There is expectation. The market has not taken off as anticipated in the 1980s and 1990s. This can be explained by the perceptual characteristics of Rogers (1995). Ceramics are perceived as complex. They are the material of "last resort," as mentioned in a few of the interviews. It should also be noted that the idea of complexity may be more of a perception than a reality. In addition, the compatibility of advanced ceramics with existing technology was mentioned. Even though performance advancements may be achieved, if the new technology is perceived as a significant change that is not compatible with existing infrastructure, the diffusion process may be delayed. The product life cycle, consisting of four stages - introduction, growth, maturity, and declineis a well-documented phenomenon. Attempts are made in the maturity stage to extend the cycle.

Five customer types are related to the product life cycle: innovators, early adopters and opinion leaders, early majority, late majority, and laggards. Reaching the innovators and early adopters/opinion leaders is key to diffusion of technology. Thus interviewees were questioned on innovative companies in the ceramics industry.

\section{Market Opportunities}

One of the primary objectives of the marketing research was to identify market opportunities. For the joining technique, two market opportunities were discovered. The most market-ready application is joining radiant burner tubes. The potential industry partner is Schunk-Inex. A packet of information was provided to the inventor to describe the company and its existing technologies in order to provide background business information and foster future conversations.

In addition, a "general need" for joining in the ceramic industry was identified. For example, Kanthal has expressed interest in the joining technique. This general market demand establishes market potential for future applications once marketing barriers in the industry are overcome. 
In addition to the joining technique, use or the novel process for producing reactionbonded silicon carbide provides several potential market advantages. The key benefit of interest to industry is if the process is potentially of significantly lower cost. In addition, if other potential advantages of interest are lighter-weight and "tougher." The cost advantage was of interest to virtually all the interviewees, so there are several potential industry partners.

The greatest near-term market potential for the reaction-bonded silicon carbide material is in armor applications. This is very timely because personnel, vehicle, and building protection have become very important for both the defense and private sector since the events of September 11, 2001 (Brown, 2001). Ceradyne and Simula are leaders in this area. Information on their market environment, including company information such as annual reports, was collected. With this information, technology and market development may be driven to meet or exceed existing industry standards.

Dr. James McCauley, Senior Research Scientist, U.S. Army Research Laboratory, presented advanced materials needs in defense applications at the 2002 American Ceramic Society meeting in St. Louis. He stressed the importance of lightweight material for armor and vehicle and building protection (McCauley, 2002). Follow-up contact was made with Dr. McCauley to obtain more technical details.

\section{Barriers to Entry}

From the marketing data collected in the industry interviews via telephone and in person at the American Ceramic Society meetings, several barriers to market entry were identified:

- Time to build industry recognition and relationships

- New technologies expected to be proven and tested

- Engineering issues with ceramics - heating and cooling large structures

- Viewed as expensive material

- Spectacular sales growth of advanced structural ceramics predicted in the 1980 s and 1990s, but growth rates did not materialize

Addressing and overcoming these marketing barriers are keys to successful market entry.

\section{Industry Leads}

Several industry leads were identified in both the phone and in-person interviews. In addition, each participant was asked (if they did not readily volunteer the information) to offer additional contacts. This was a very effective way to find the right contacts in each company.

Contacting the ceramics companies in most cases was a first contact by the EERC, so it was essentially a "cold call," setting the stage for further marketing communications. Most of the companies contacted represent potential leads. If not useful for this specific technology, industry contact is a useful marketing strategy for the EERC to provide this industry network with ongoing information about other technologies. This communication will build awareness of EERC capabilities in technology development. 


\section{Recommendations for Marketing Strategies}

The following recommendations are based on the contacts with industry. First, a technical brief that includes material properties when data are available would be very useful in marketing technologies. Respondents indicated interest in knowing more specifics about the material. Second, follow-up through personal contacts and e-mail with potential industry partners from interviews, trade shows, and technical meetings) is suggested. Having ongoing conversations and an industry feedback process is important to drive the innovation of technology.

Companies that have expressed interest in further conversations are Schunk-Inex, Kanthal, Blasch Ceramics, and Superior Graphite. Both technical and marketing contacts were made at these companies, which provide good insight for both technology and market development. Also, follow-ups should be made with St. Gobain, because of its position as market leader.

In addition, a regional Native American-owned and operated corporation, Sioux Manufacturing, is interested in pursuing the development of the technology with the EERC. Sioux Manufacturing is a subcontractor to both Ceradyne and Simula, ceramics companies that have large defense contracts for armor and other personnel protection products. Ceradyne, Inc., recently announced it has received a $\$ 5.3$ million order for lightweight ceramic inserts for use in armor to protect U.S. Army forces. The order was issued by the U.S. Defense Logistics Agency.

Finally, new follow-up funding and business opportunities should be pursued. There is potential for a business spin-off from the EERC to manufacture the ceramic tiles utilized in personnel protection. The Advanced Technology Program has been identified as a funding source to facilitate the development of either a spin-off business or a joint venture between the EERC and Sioux Manufacturing. Sioux Manufacturing has also expressed interest in submitting a joint proposal to the SBIR program.

To evaluate this potential opportunity, silicon carbide tiles are being prepared this summer for ballistic testing by Sioux Manufacturing. This activity is being done as a direct consequence of this study and verifies that marketing research conducted during product development influences innovation.

\section{REFERENCES}

Allen, M.F. A Review of Best Practices in University Technology Licensing Offices. The Journal of the Association of University Technology Managers 2001, 13.

Brown, A.S. Response to Terrorist Attacks. Performance Materials 2001, 16 (20).

Ceradyne Receives \$5.3 Million Order, Ceramic Industry 2001.

Jaffe, A.B.; Lerner, J. Reinventing Public R\&D: Patent Policy and the Commercialization of National Laboratory Technologies. RAND Journal of Economics 2001, 32 (1), 167. 
McCauley, J.W. A Design-Based Approach to Ceramics Research - Friedberg Memorial Lecture. Presented at theAmerican Ceramics Society Meeting, St. Louis, MO, April 30, 2002.

Peterson, R. Ceramics Corridor: A Secret No More. The American Ceramic Society Bulletin. 2001.

Rogers, E.M. Diffusion of Innovations, 4th edition; Free Press: New York. 1995.

Tressler, R. Commercialization of Advanced Structural Ceramics and Ceramic Matrix Composites: Successes and Challenges, Friedberg Memorial Lecture. Presented at theAmerican Ceramics Society Meeting, Indianapolis, IN, April 24, 2001. 
APPENDIX B

\section{MERCURY MEASUREMENT IN COMBUSTION FLUE GASES SHORT COURSE}



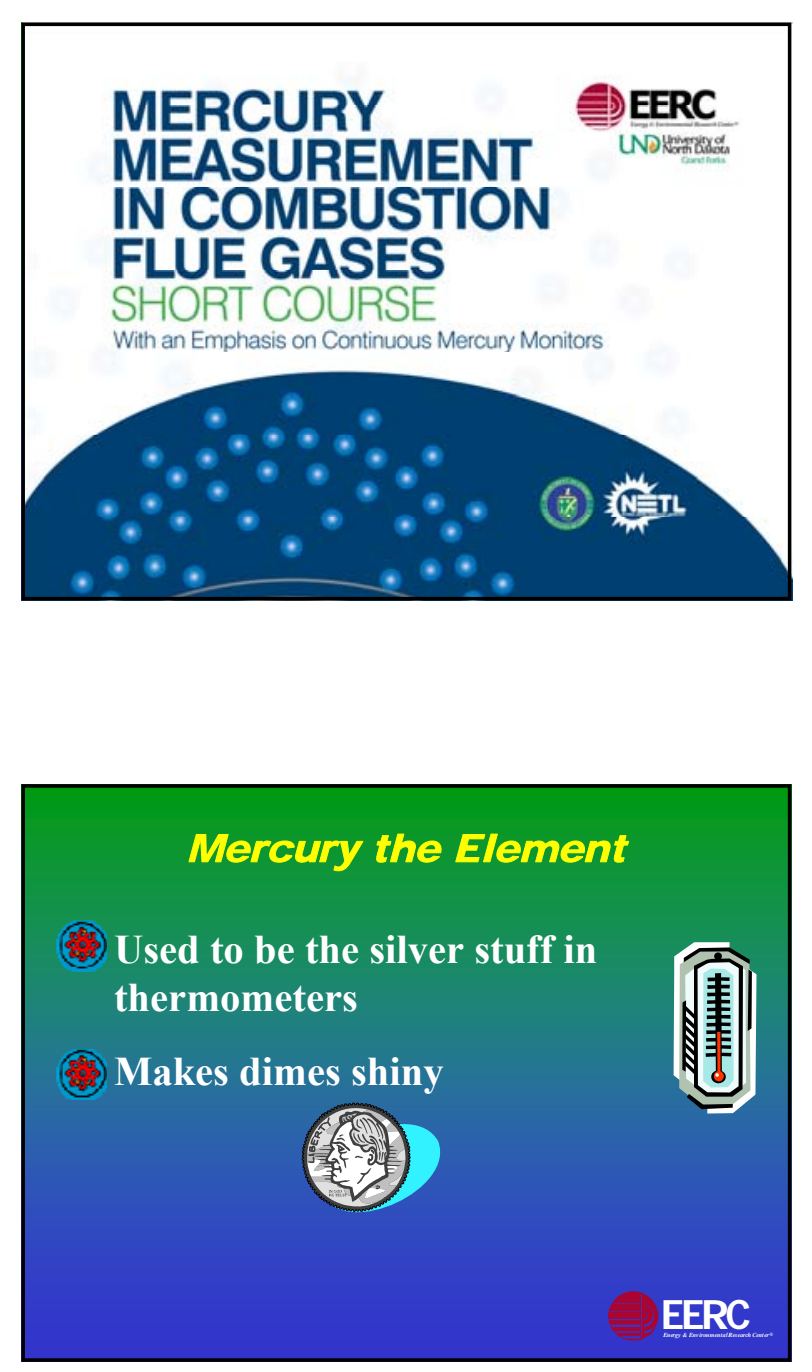

\section{The Science}

The science of mercury, its chemistry and its impact on health and the environment, is extremely complex, and our knowledge is still limited.
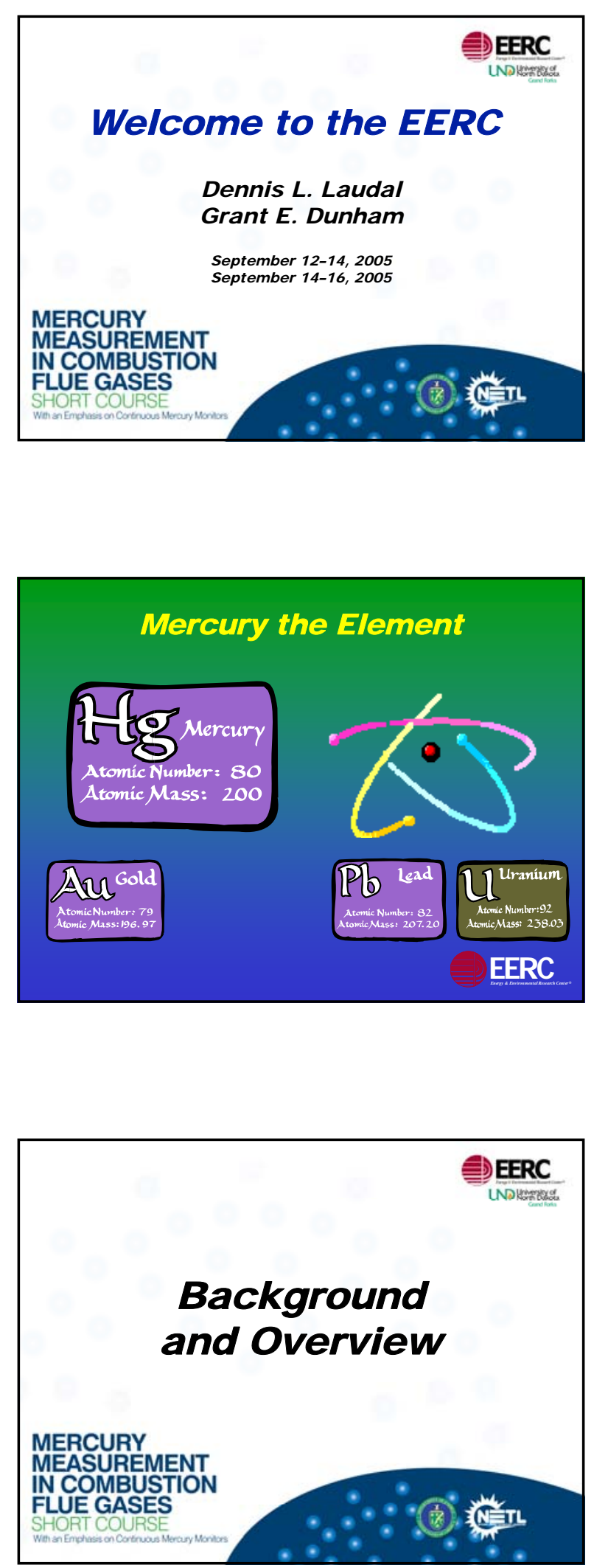


\section{Presentation Outline}

- Introduction and background

Health

Emissions

Regulations

- Mercury measurement planning

Wet-chemistry methods

$>$ U.S. Environmental Protection Agency (EPA) Method 101A

EPA Method 29

Ontario Hydro (OH) mercury speciation method

- Sorbent trap methods (Code of Federal Regulations [CFR], Part 75, Appendix K)

QuickCEMs ${ }^{\mathrm{TM}}$

Flue gas adsorbent mercury speciation (FAMS ${ }^{\mathrm{TM}}$ )

E.ON dry sampling method

EERC

\section{Why Regulate Mercury?}

Short Answer: Health Concerns
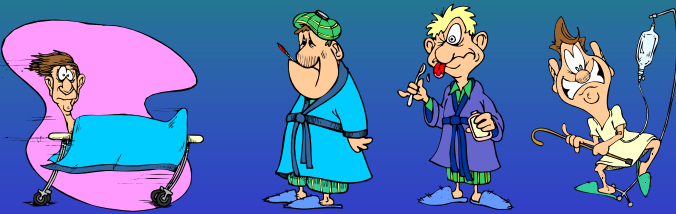

EERC

\section{Presentation Outline}

- Continuous mercury monitors (CMMs)

$>$ Terminology

> PS 12A and 40CFR, Part 75 (regulatory requirements)

$>$ Quality assurance/quality control

$>$ How they work

$>$ Advantages and limitations

Vendors

> Pretreatment/conversions systems

$>$ Calibration systems

$>$ Ash-handling systems

$>$ Demonstrations

- Wrap-up

EERC

\section{Mercury Toxicity}

- All forms of mercury are toxic especially to the fetus, as mercury readily crosses the placenta.

- Organic mercury compounds are the most toxic.

- Mercury is secreted very slowly (half life of 65 days).

- It exhibits high lipid solubility.

- Mercury accumulates in brain, kidneys, liver, hair, and skin.

EERC

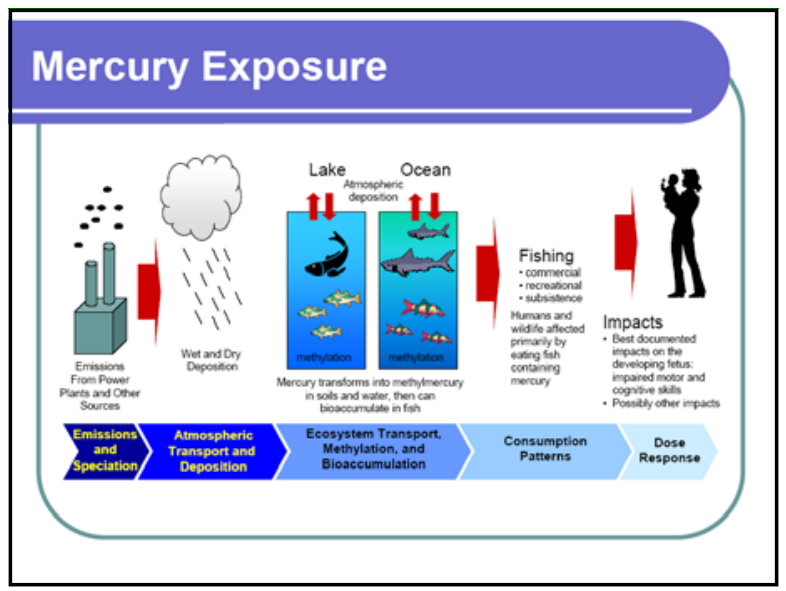




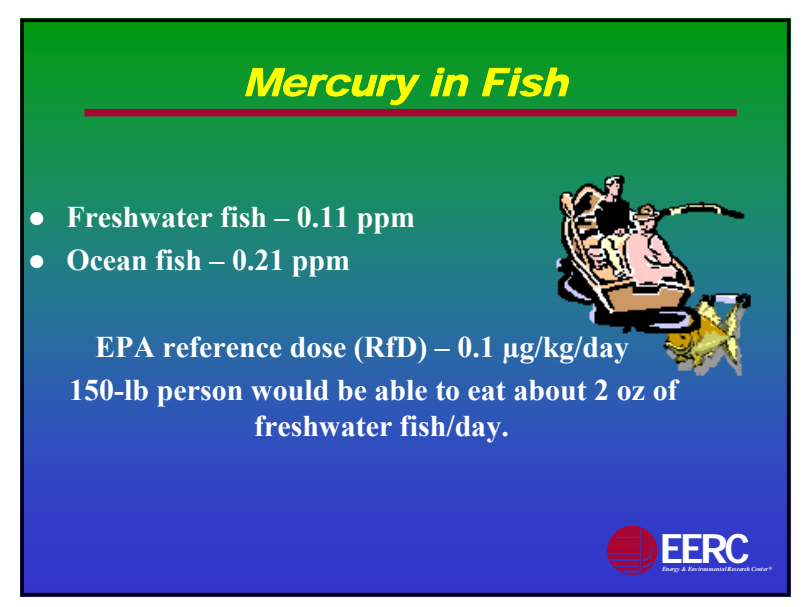

\section{Three Important Forms of Mercury in the Environment}

- Elemental Mercury $\left(\mathrm{Hg}^{\mathbf{0}}\right)$

> Dominant species in atmosphere, most pollution sources.

- Ionic or Oxidized Mercury $\left(\mathrm{Hg}^{2+}\right)$

$>$ In air, reactive gaseous mercury (RGM). Dominant species in rainfall, water, sediments, soil, some pollution sources (notably incinerators).

- Methylmercury (MeHg)

> Dominant species in fish and loons; produced by naturally occurring bacteria (especially sulfate-reducing bacteria in anoxic zones of wetlands and lake sediments).

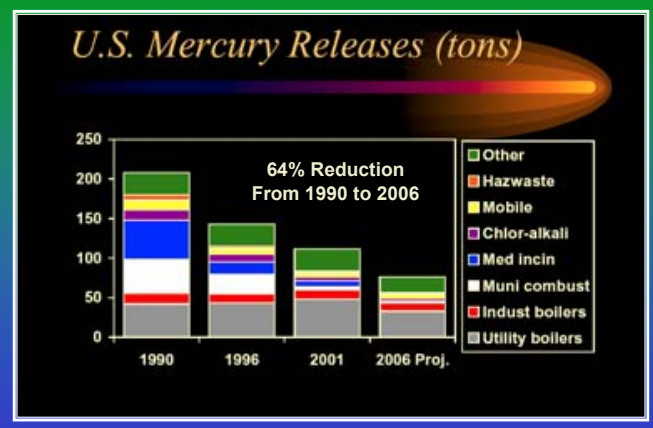

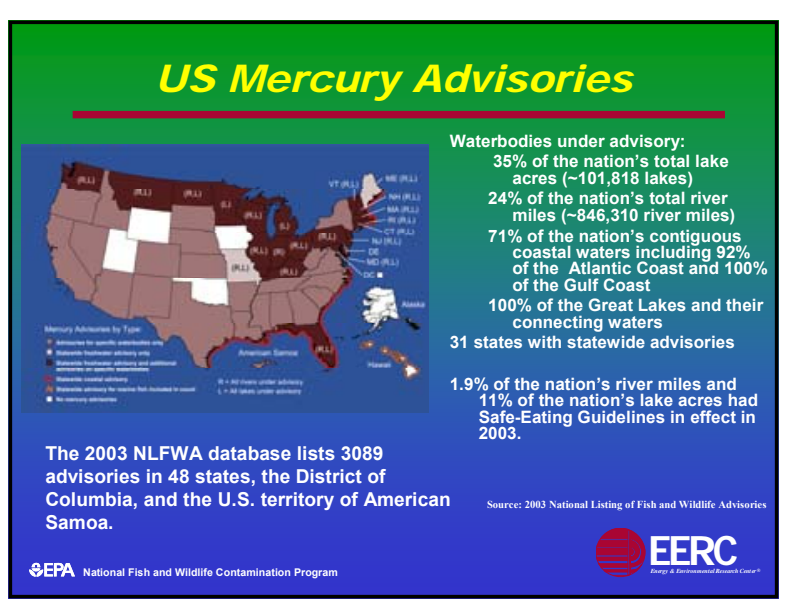

\section{Methylmercury Formation}

$$
\text { (2. }\left(\mathrm{CH}_{3}\right)_{2} \mathrm{Hg} \text { (2) }
$$

- Inorganic mercury settles to the sediments of the water body where microbiological activity converts it to MeHg.

- $\mathrm{MeHg}$ is easily passed up to animals at the top of the food chain (bioaccumulated).

\section{ERC}

\section{Power Plant Mercury Emissions}

- Power plants emit inorganic forms of mercury to the air as a result of the combustion of coal, which contains trace amounts of mercury.

- Power plant mercury emissions may be in several forms (none are MeHg):

$>\mathrm{Hg}^{\mathbf{0}}$

$>\mathrm{Hg}^{2+}$

$>$ Particulate-bound mercury $\left(\mathbf{H g}^{\mathrm{P}}\right)$ 

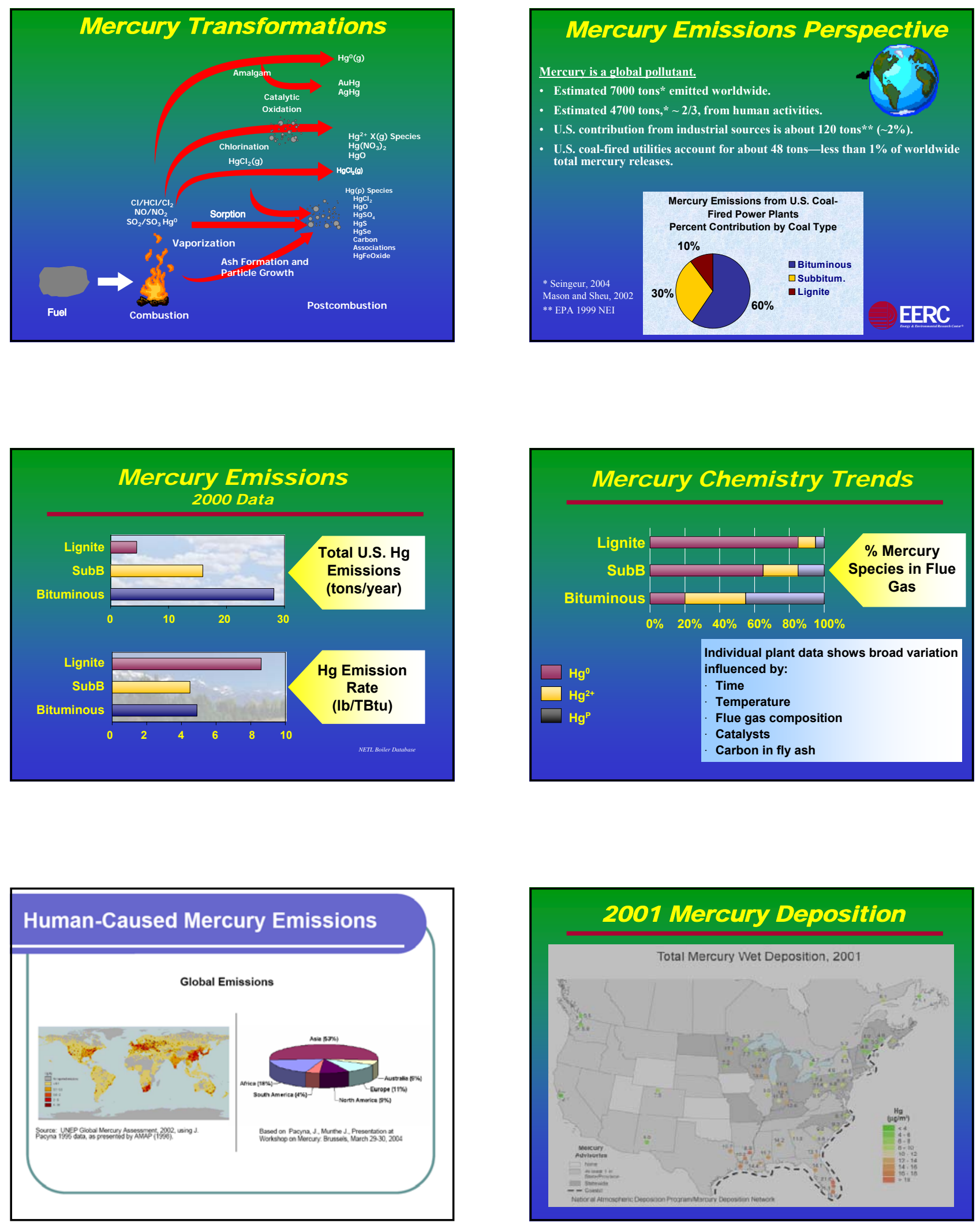


\section{Mercury Deposition}

- $\quad \mathrm{Hg}^{\mathrm{P}}$ and $\mathrm{Hg}^{2+}$ emissions create localized or regionalscale deposition as a result of the action of gravity and precipitation.

- $\quad \mathrm{Hg}^{0}$ emissions create global-scale deposition and have an atmospheric lifetime of approximately 1 year.

- Air deposition of the inorganic mercury contributes to mercury loading of water bodies either by direct air deposition or by indirect deposition on the watershed of the water body.

\section{Electronic CFR}

www.gpoaccess.gov/cfr/index.html

\section{CAMR}

- Under Section 111 of the 1990 Clean Air Act

- Provides for cap-and-trade structure

- Power plants $>25$ MW net will be regulated

- Two implementation phases: 2010 and 2018

- Works in concert with the Clean Air Interstate Rule (CAIR) for $\mathrm{SO}_{2}$ and $\mathrm{NO}_{\mathrm{x}}$

- Controversial and being challenged in court by 10 states and a number of environmental groups

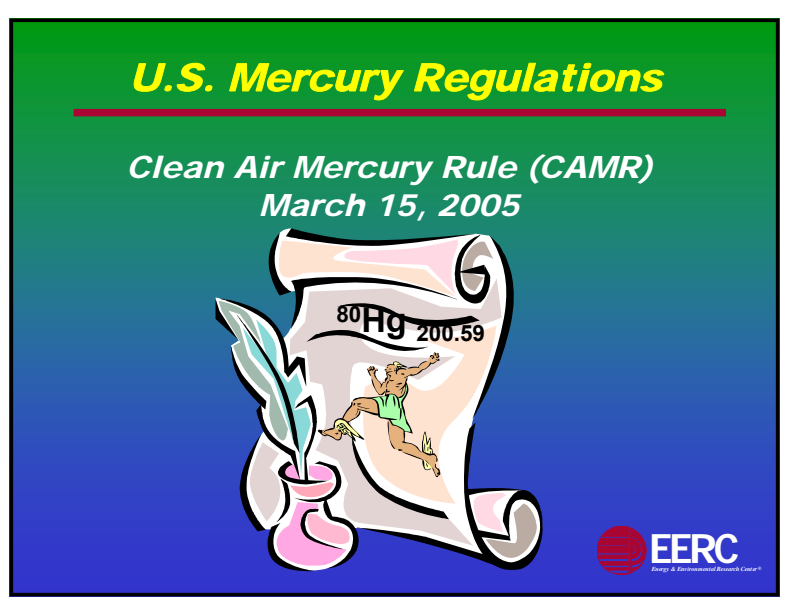

The Regulatory Process for Mercury

- Title III of the Clean Air Act Amendments of 1990 required EPA to conduct special studies of hazardous air pollutant (HAP) emissions from electric utilities to determine if regulation was necessary.

- In December 2000, EPA determined that mercury from coal and nickel from oil-fired electric utilities presented a health hazard and should be regulated under the Maximum Achievable Control Technology (MACT) regulatory program (Section 112).

- In the final rule, the previous EPA determination was rescinded and the decision was made to regulate under a cap-and-trade structure (Section 111).

\section{EERC}

\section{CFR Amendments}

- Part 60 - "Standards of Performance for New and Existing Stationary Sources: Electric Utility Steam-Generating Units"

- Part 63 - "Air Programs"

- Part 72 - "Air Programs Permits Regulation"

- Part 75 - "Continuous Emission Monitoring" 

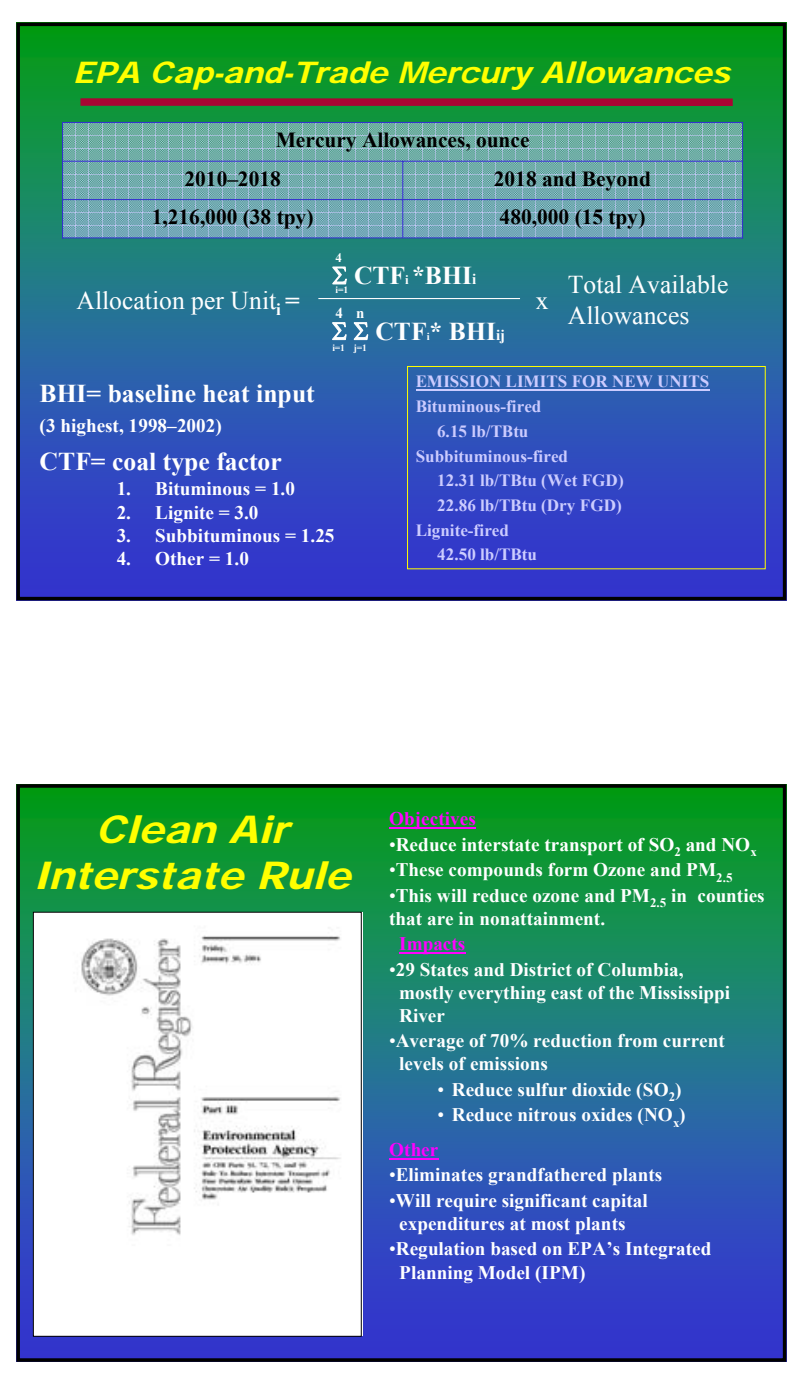

\section{States Regulated by CAIR}

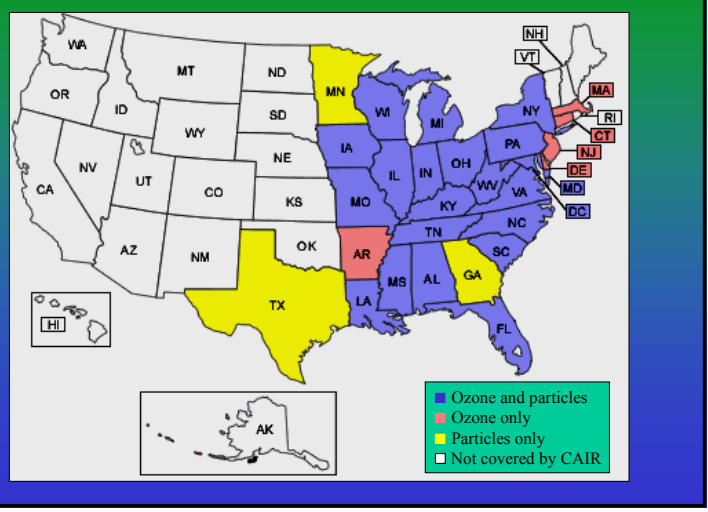

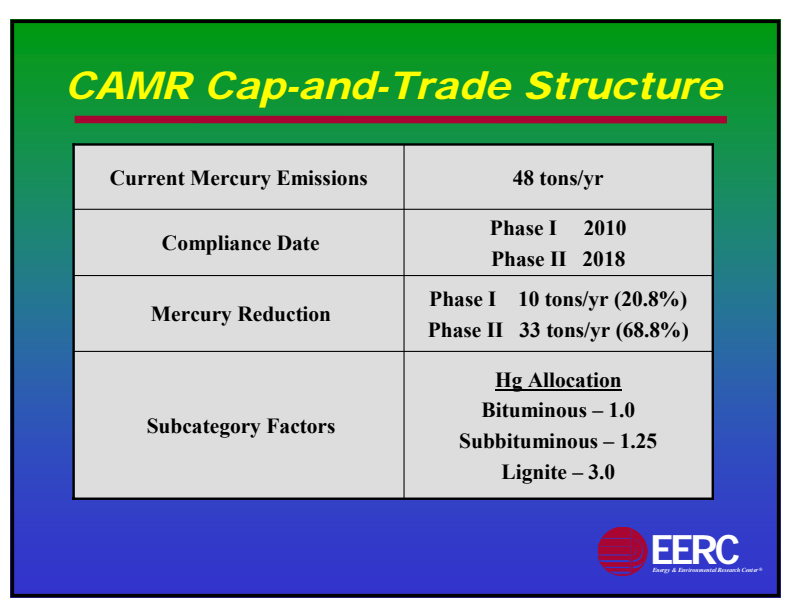

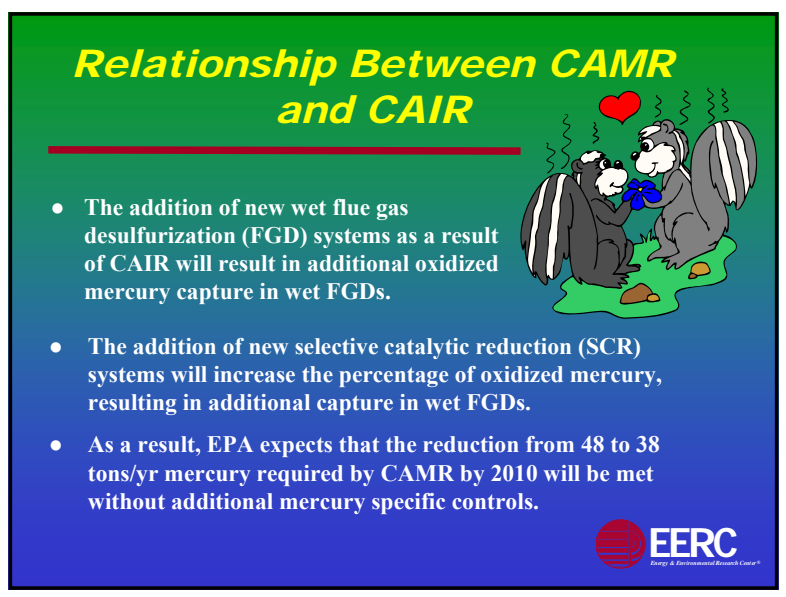

\begin{tabular}{|c|c|c|c|c|}
\hline \multicolumn{5}{|c|}{$\begin{array}{c}\text { Summary of Emissions Reductions } \\
\text { Using Cap-and-Trade Approach }\end{array}$} \\
\hline Year & 2009 & 2010 & 2015 & 2018 \\
\hline Hg & & $\begin{array}{l}\text { Cap at } 38 \text { tpy, a } \\
21 \% \text { reduction } \\
\text { from } 48 \text { tpy } \\
\end{array}$ & & $\begin{array}{l}\text { Cap at } 15 \text { tpy, a } \\
69 \% \text { reduction } \\
\text { from } 48 \text { tpy }\end{array}$ \\
\hline $\mathrm{SO}_{2}{ }^{*}$ & & $\begin{array}{l}\text { Reduce } 4.3 \text { Mtpy, } \\
\text { a 45\% reduction } \\
\text { from } 2003 \text { levels }\end{array}$ & $\begin{array}{l}\text { Reduce an additional } \\
1.1 \text { Mtpy for a } 57 \% \\
\text { reduction from } 2003 \\
\text { levels } \\
\end{array}$ & \\
\hline $\mathrm{NO}_{\mathrm{x}}{ }^{*}$ & $\begin{array}{l}\text { Reduce } 1.7 \\
\text { Mtpy, a 53\% } \\
\text { reduction from } \\
\text { 2003 levels }\end{array}$ & & $\begin{array}{l}\text { Reduce an additional } \\
0.3 \text { Mtpy for a } 61 \% \\
\text { reduction from } 2003 \\
\text { levels }\end{array}$ & \\
\hline
\end{tabular}



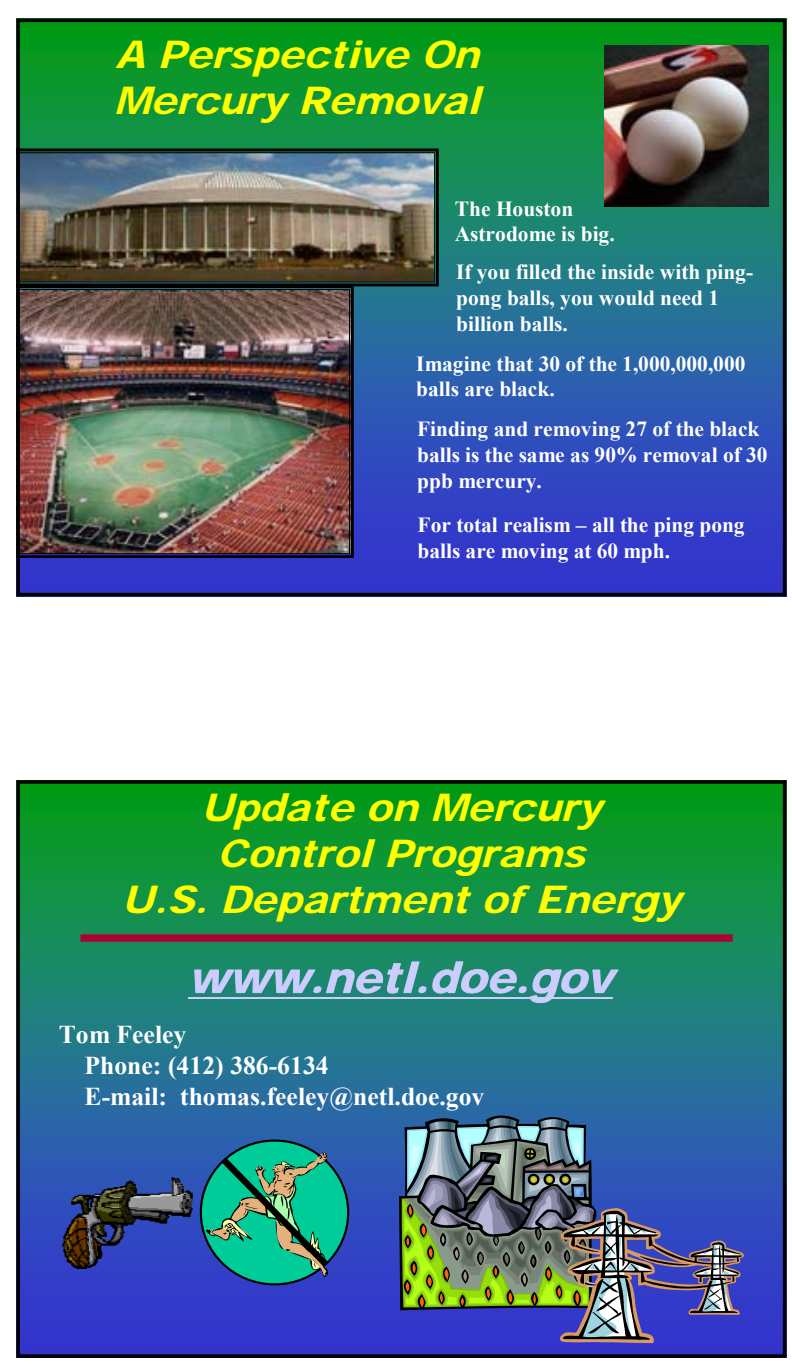

\section{EERC Mercury Measurement Experience}

- Validated OH mercury speciation method, ASTM International Method D6784-02.

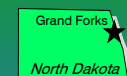

- Has over 17 years of experience in characterization and measurement of mercury.

- Has done extensive mercury sampling at $\mathbf{4 0}$ different power plants over the past 7 years.

- Has more than 10 years of experience with CMIMs.

E쿨
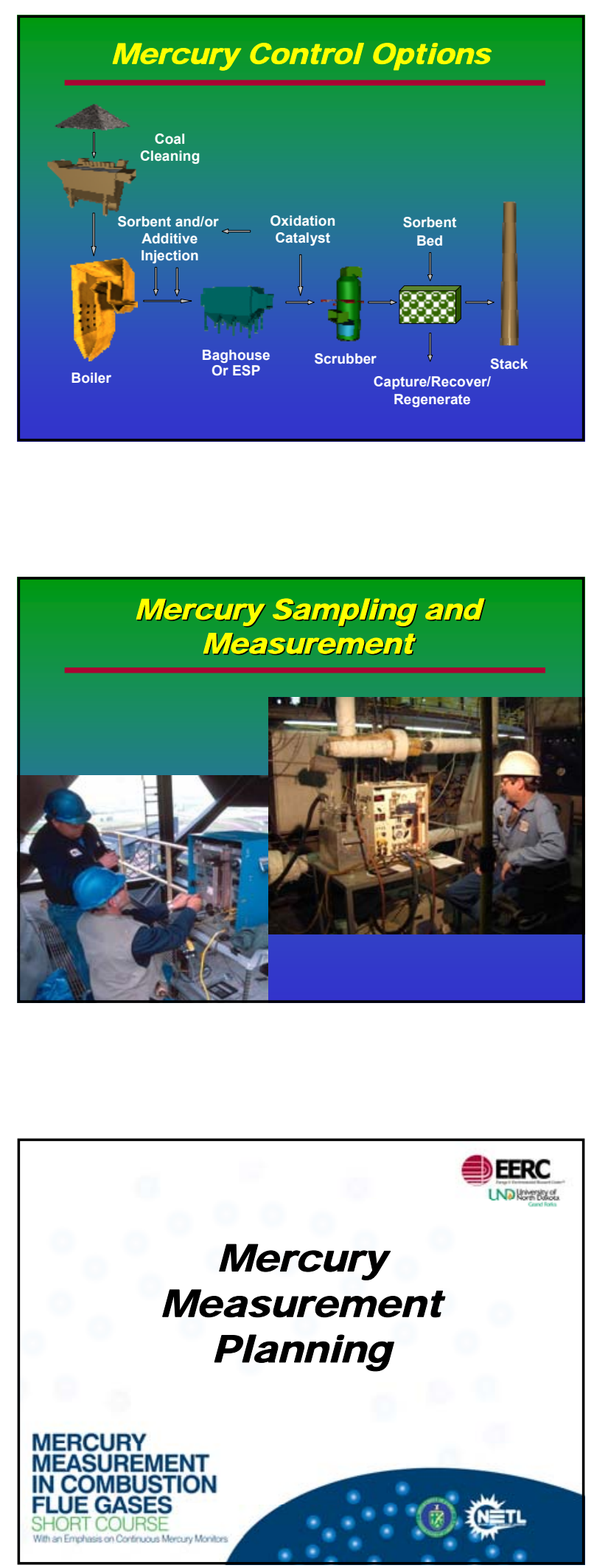


\section{Sample Collection for Mercury Measurement}

- Coal

- ESP or baghouse hopper ash

- Wet scrubber

- Dry scrubber

- Flue gas

\section{Project Planning}

- Defining overall objectives

$>$ Define purpose for measuring mercury

$>$ Determine measuring methods

- Determining the data needed to be taken to meet objectives

- Managing results

- Preparing a quality assurance plan (QAP)

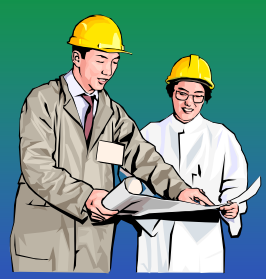

EERC

\section{Purpose for Doing Mercury Measurement}

- Research

- Control

- Regulations

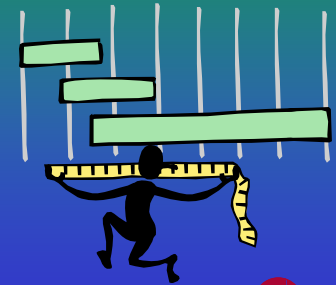

EERC

\section{Mercury Control Purposes}

- Mercury measurement method must be highly automated and with minimal maintenance.

- Method must be reliable and rugged.

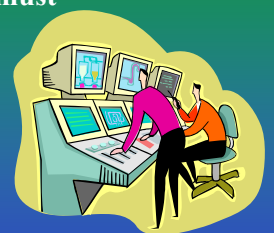

- Method must be flexible enough to be used for a variety of control options.

\section{Research Purposes}

- Measurements methods usually need to be very flexible (complex hardware and software are usually the result).

- Measurements are often done at multiple locations under difficult conditions.

- Research tests are usually short(er) term.

- Highly trained engineers and technicians are needed to do the measurements.

\section{ERC}

\section{Regulatory Purposes}

- Sampling must follow detailed procedures:

40 CFR, Part 75, for continuous emission monitoring

PS 12A for CMM specifications

ASTM and/or EPA procedures for wet-chemistry methods

> 40 CFR, Part 75, Appendix K for sorbent trap methods Any additional state procedures

- The simpler the better (cheaper the better!).

- For instrumentation methods, maintenance must be minimal.

- Data must be acceptable to the regulatory body (EPA and/or the states).

$>$ High level of $\mathrm{QA} / \mathrm{QC}$ required.

Missed data may be costly.

Detailed documentation is necessary.

- Sampling is done only at one location, usually the stack. 
Flue Gas Mercury Measurements as a Function of Plant Processes

- Other mercury measurements Coal, ash, scrubber liquor, etc. Additional sampling locations

- Plant operational effects

$>$ Load changes, plant upsets, plant start-up, etc.

Balance-of-plant impacts associated with mercury control technologies

$>$ Additional plant data needed to document mercury emissions (i.e., flue gas flow rates, flue gas moisture, $\mathrm{O}_{2}$ and $\mathrm{CO}_{2}$ concentrations)

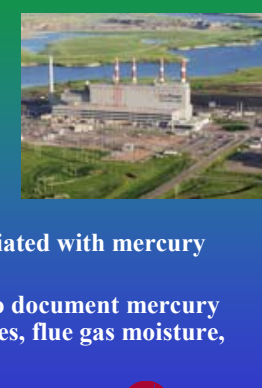

트를

\section{Quality Assurance (QA) Plan}

- Program definition

- Identification of test methodology

- Project organization

- Description of the project and schedule

- Quality objectives and criteria for data

- Assessment and oversight

- Planned corrective action if QA objectives not obtained

- Safety issues

- Documentation

EERC

\section{Management of Results}

- May be defined by a regulatory body

- Program management

- Documentation requirements

- Handling missing and/or poor data

EERC

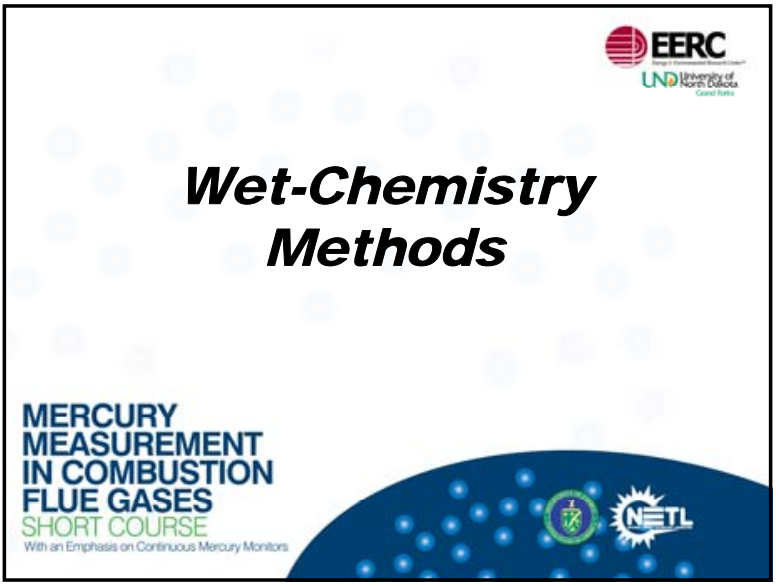

\section{Wet-Chemistry Methods}

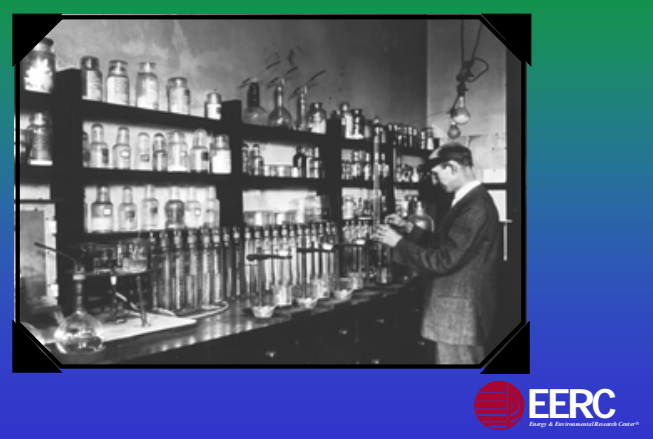

\section{Wet-Chemistry Methods Outline}

- Advantages and disadvantages

- Planning

- Methods
$>$ EPA Method 101A
$>$ EPA Method 29
$>\mathrm{OH}$ mercury speciation method 


\section{Advantages}

- Proven at a number of sites and under a wide variety of conditions.

- Provides good results with a high level of sensitivity, $<0.5 \mu \mathrm{g} / \mathrm{Nm}^{3}$.

- Currently, the only mercury measurement method considered to be a reference method by EPA.

\section{Up-Front Planning}

Factors to consider when evaluating a sampling contractor:

$>$ Experience and training

$>$ Prequalification requirements

$>$ Frequency of equipment calibration

$>$ Chain-of-custody procedures

$>$ Collection and handling of reagent and field blanks

$>$ Whether or not they routinely do field spikes

$>$ Procedures for handling glassware

\section{Up-Front Planning}

- Factors to consider when evaluating an analytical laboratory:

Is there currently a good working relationship with the laboratory that will be doing the analysis?

> Have they met all prequalification requirements?

- What are the laboratory's sample-handling, storage, and preservation procedures?

Are the analytical techniques used appropriate for the particular sample type and analysis quality desired?

> Are rigorous procedures for blanks, spikes, calibrations, and replicates implemented?

> Is an independent auditor needed?

\section{Limitations}

- But ...

> A high level of QA/QC and well-trained personnel required.

$>$ A 2-week or more turnaround time for results; in other words, no real-time data.

$>$ Particulate matter can cause biases in speciation data (total mercury data is still valid).

$>$ It is expensive.

\section{Up-Front Planning}

- Factors to consider when doing a site visit:

$>$ Is there adequate access to sampling locations and ports?

$>$ Is power available at each location for sampling equipment that will be used?

$>$ Has there been assigned a plant contact who will be on-site during testing?

$>$ What data, assistance, or information will be needed from the plant?

- Most importantly, involve representatives of the plant for all processes that will be impacted by the project.

\section{EERC}

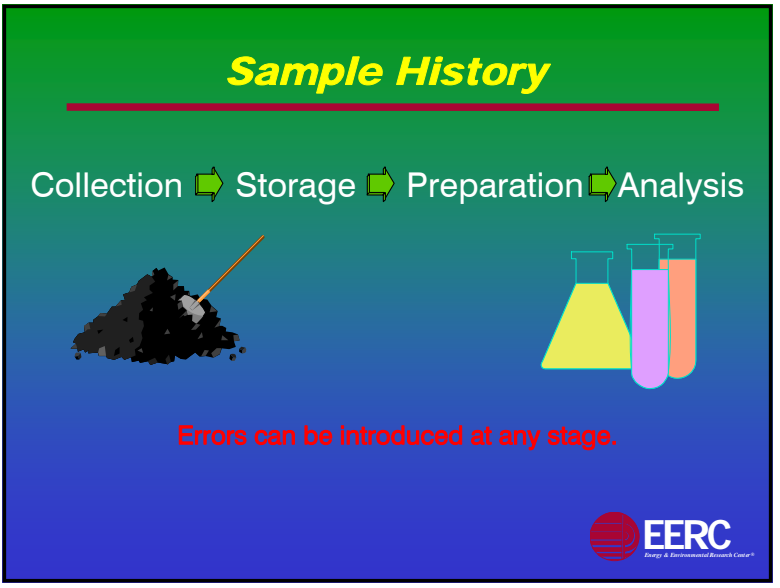




\section{Accuracy}

How well the measured concentration represents the true value.

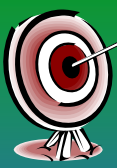

\section{Precision}

To what degree an analysis of the "same" sample can vary

based on the error associated with the analysis method.

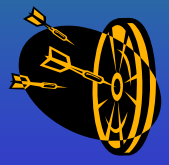

\section{Sample Blanks}

It is clear that obtaining good blank samples is critical to success of a mercury measurement project. In almost every case, bad data is associated with bad blanks.

- Reagent blanks

- Field blanks

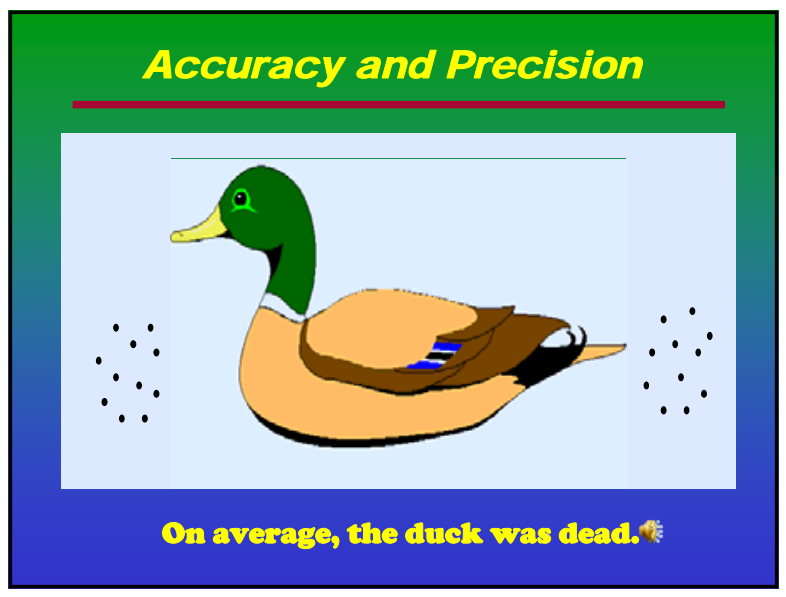

\section{Glassware}

Wet-chemistry methods are extremely glassware-intensive.

- Proper cleaning is essential (SW-846-0060)

$>$ Wash thoroughly with soap and water

Rinse with tap water

Rinse three times with distilled or deionizer water

$>$ Soak 4 hours in a $10 \%$ nitric acid bath

$>$ Rinse with distilled or deionized water

$>$ Air-dry glassware in a clean area

- There are two ways to ensure clean glassware in the field:

$>$ Set up wash stations to clean the glassware in the field

Bring enough glassware to complete the field test

\section{EERC}

\section{Sample Spikes}

A known quantity of mercury is added to a solution.

Hey, aren't the methods designed to remove all the mercury? So why go to all this trouble?

Answer:

People make mistakes. If all of the mercury is not removed, not only will the results for that sample be erroneous but so will the next one done with that glassware. If the bottles are cleaned each time, a mistake only affects one sample.

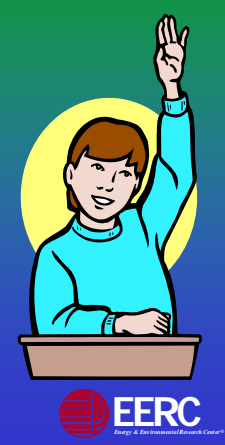

- Laboratory spikes

- Instrument spikes

- Field spikes

$>$ Not specifically required as part of ASTM D6784-02 but necessary nonetheless.

$>$ Spiked train is set up and torn down as if it was a used sample train.

EERC 

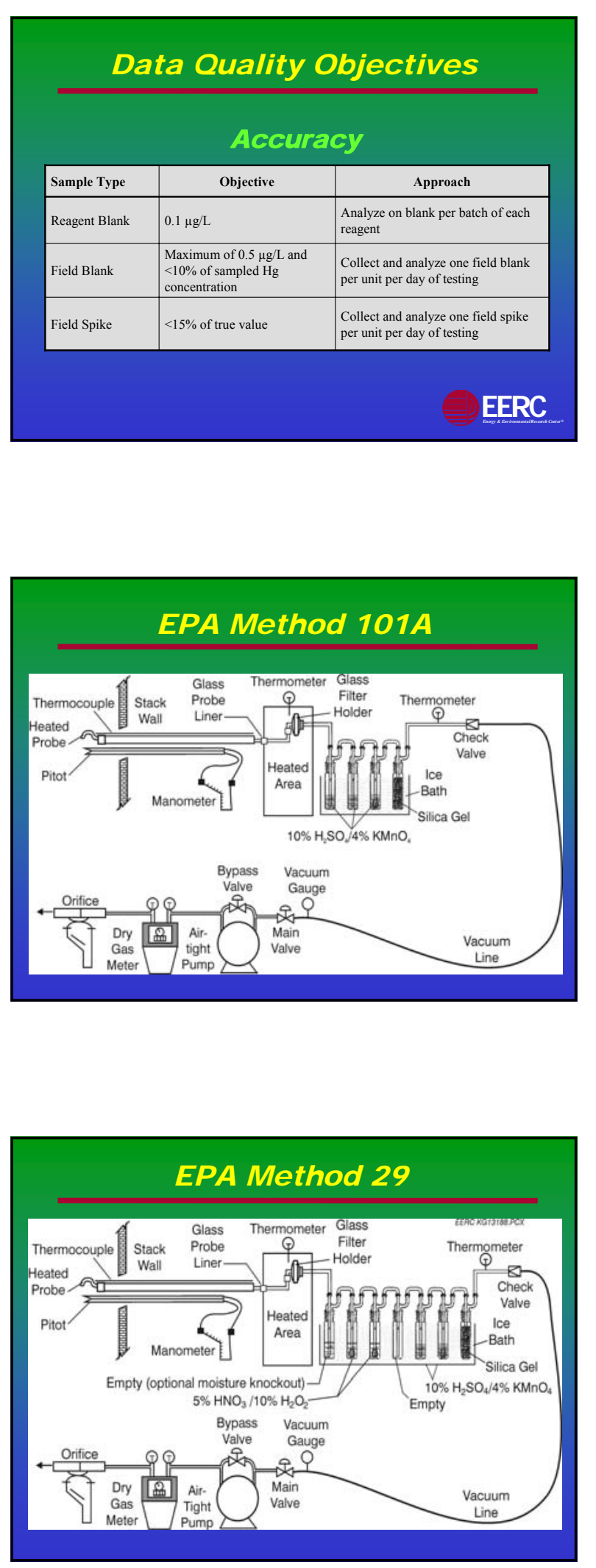

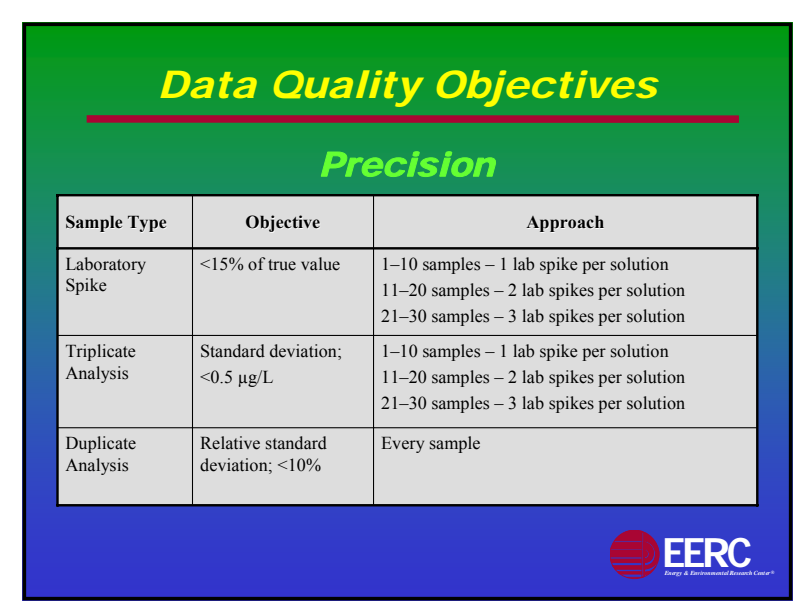

\section{EPA Method 101A}

- Simplest of the mercury measurement methods (only four bottles).

- Use may be limited by $\mathrm{SO}_{2}$ concentration in the flue gas.

- Only measures total mercury.

- Not accepted by the EPA as a reference method.

\section{EERC}

\section{EPA Method 29}

- Complex method; requires seven bottles and two different solutions.

- Not only measures mercury but is a multimetals sampling train.

- Requires a high level of QA/QC.

- Only measures total mercury. 


\section{OH Mercury Speciation Method}

\section{AST'MI D6784-02}

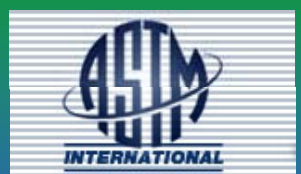

Standard Test Method for Elemental, Oxidized, Particle-Bound, and Total Mercury in Flue Gas Generated from Coal-Fired Stationary Sources (Ontario Hydro Method)

www.astm.org

EERC

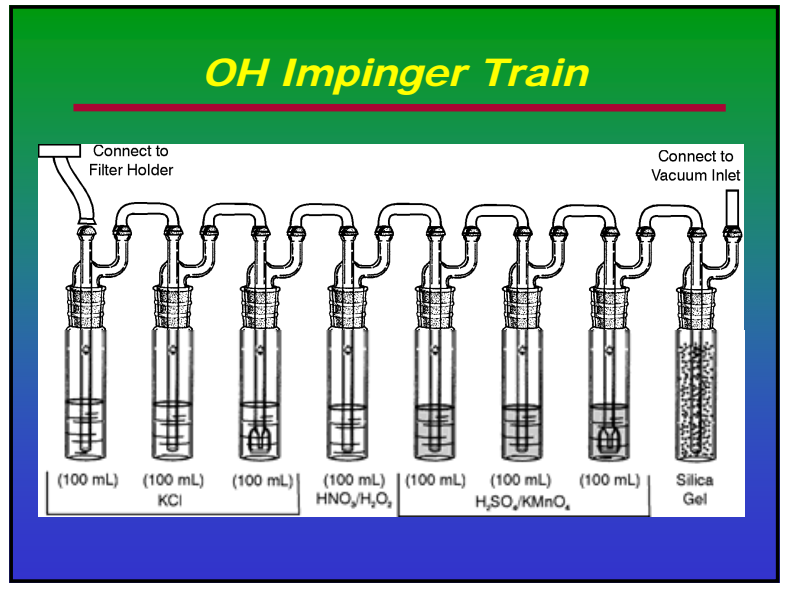

\section{OH Method for Regulatory Purposes}

- The only method currently recognized by EPA as a reference method for CAMR for the relative accuracy test audit (RATA).

- One of EPA's highest priorities is developing or determining an instrumental reference method.

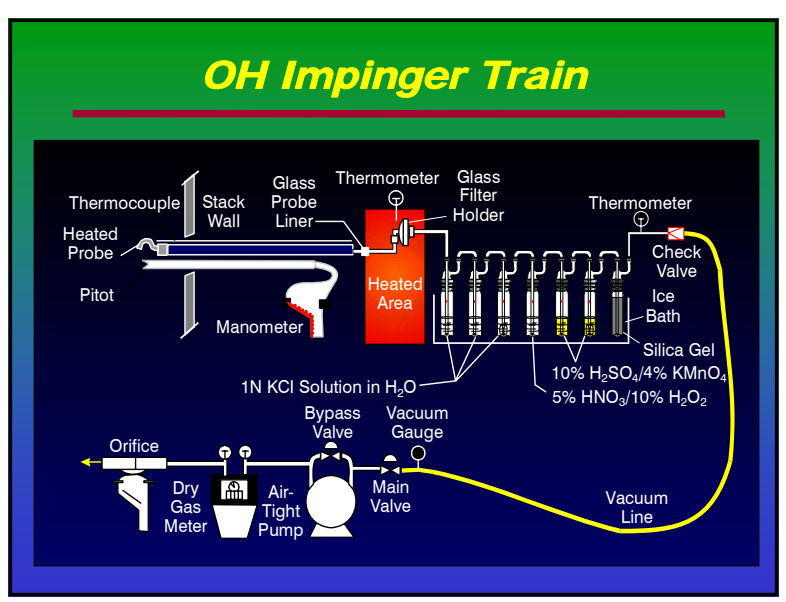

\section{$\mathrm{OH}$ Method}

- Complex method; requires eight bottles and three different solutions.

- Requires a high level of QA/QC.

- Able to speciate mercury $\left(\mathrm{Hg}^{0}, \mathrm{Hg}^{2+}, \mathbf{H g}^{\mathrm{P}}\right)$.

- Speciation may be biased at high-dust locations because of interaction of mercury and the ash collected on the filter.

\section{EERC}

OH Method as a Reference Method

- Conducted once during initial setup of the CMM.

$>$ Minimum of nine paired sample trains (averaged) required

$>$ Relative standard deviation (RSD) must be within $10 \%$

- Annual RATAs are required once CMMs have been set up and verified $(<20 \%$ or $\pm 1.0 \mu \mathrm{g} / \mathrm{dscm})$.

- For the sorbent traps method only annual RATAs are required. 


\section{Isokinetic Traversing}

Based on experience, traversing at the stack is not recommended for the $\mathrm{OH}$ method.

- Traversing was designed to ensure an accurate representation of dust loading in a duct (EPA Method 5/17). Mercury is in the gas phase at the stack.

- The OH method is very complex, and moving this train between traverse points is asking for trouble.

- The $\mathrm{KCl}$ impingers can offgas mercury if agitated.

- CAMR does not require traversing for CMMs or $\mathrm{OH}$ method for RATAs.

EERC

\section{Appendix $\mathrm{K}$}

- January 2004, published in CFR as Proposed Method 324 - Determination of Vapor-Phase Flue Gas Mercury Emissions from Stationary Sources Using Dry Sorbent Trap Sampling.

- In the final rule, published in March 2005, the concept of a dry sorbent trap method was retitled CFR, Part 75, Appendix K.

- For regulatory purposes, a method that meets the requirements of Appendix $K$ can be an alternative to CMMs.

트룯

\section{Duel-Trap Probe Design}

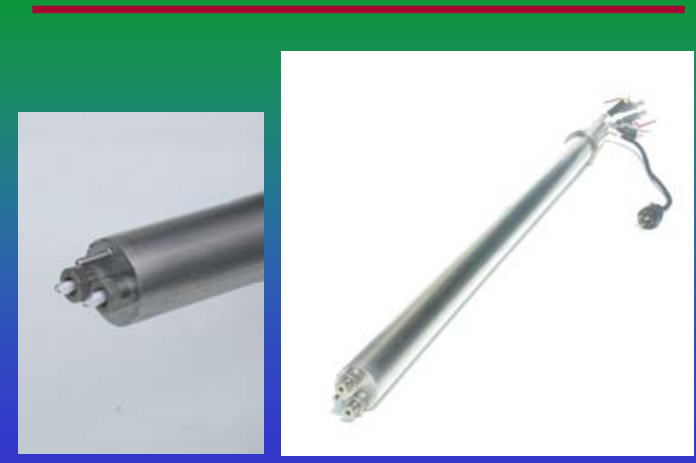

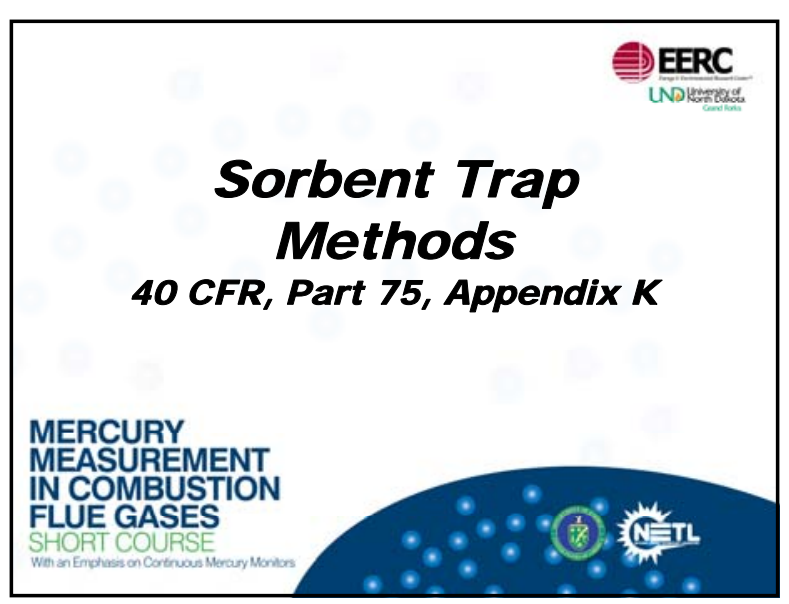
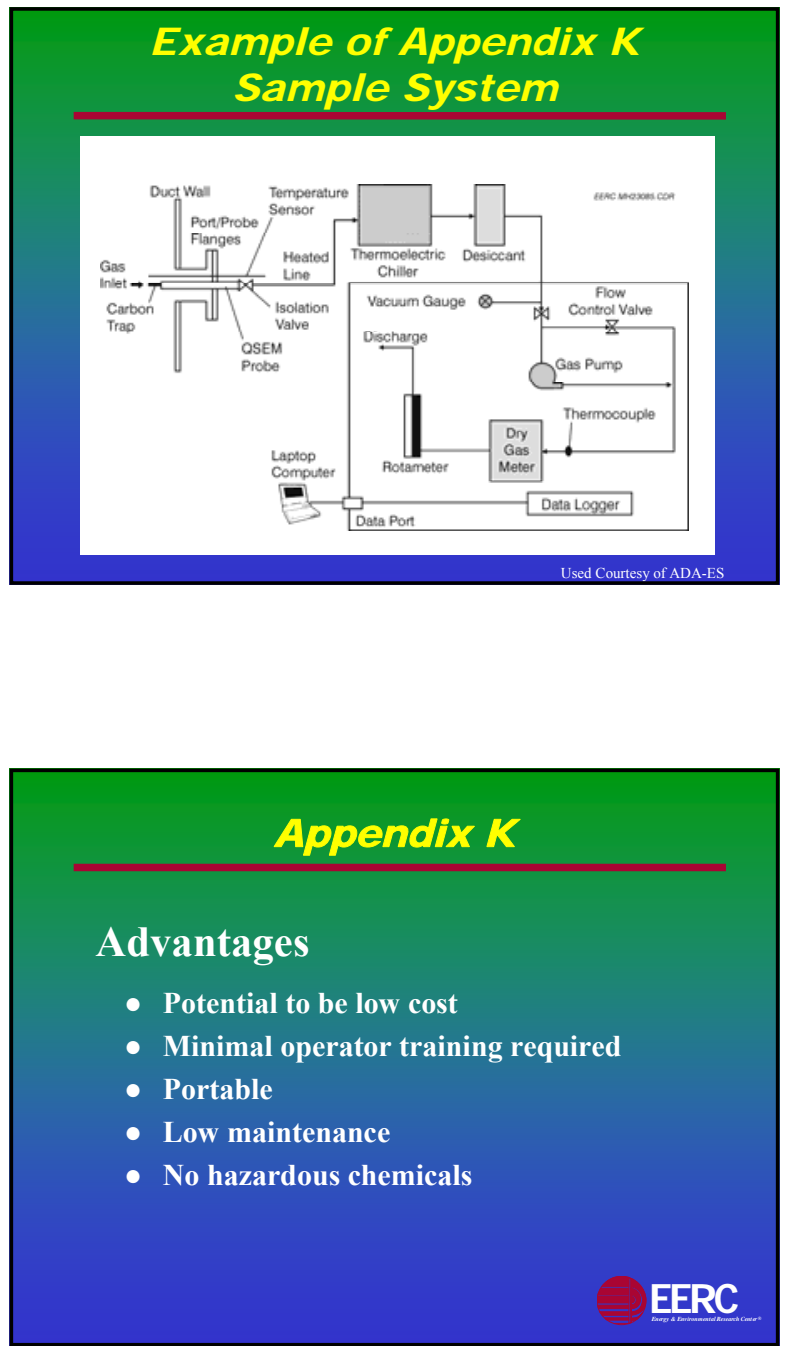


\section{Appendix K}

\section{Disadvantages}

- Gives no real-time data.

- Can only be used in low-dust conditions.

- Needs to be validated for different coals and plant configurations.

- Few vendors manufacture traps.

- Currently, analysis costs are high.

\section{Question:}

How is Appendix $\mathrm{K}$ different from proposed EPA Method 324?

\section{Answer:}

EPA will not promulgate Method 324; however, the method titled QuickCEMs ${ }^{\mathrm{TM}}$ (after some modification) may be used to meet Appendix $\mathrm{K}$ requirements.

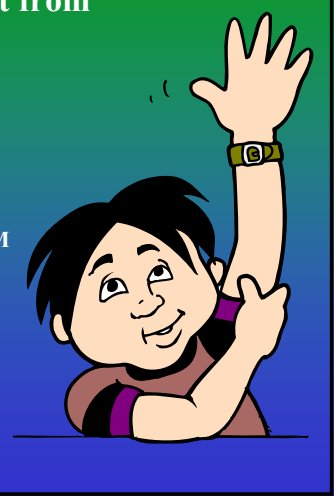

\section{Appendix K Requirements}

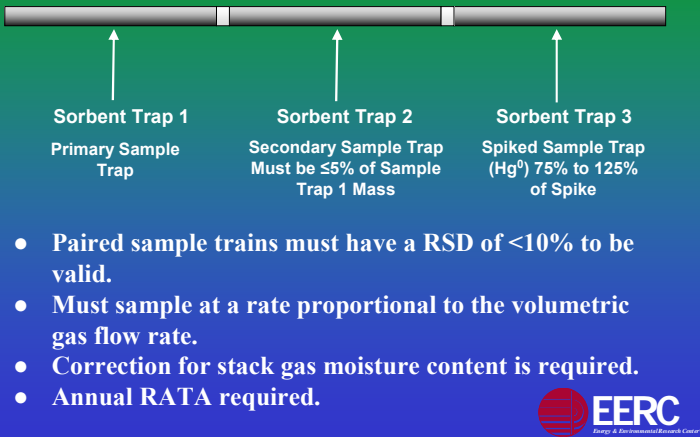

\section{Question:}

What is 40 CFR, Part 75, Appendix K?

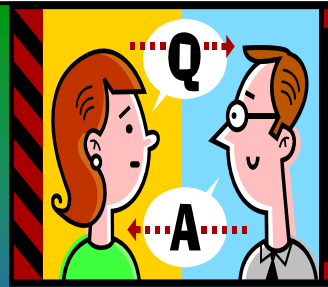

Answer:

Appendix $K$ is a procedure, which, if met, allows mercury sorbent traps to be used to measure mercury to meet CAMR.

\section{EERC}

\section{Question:}

Does Appendix $\mathrm{K}$ specify what sorbent is to be used or what analytical procedures need to be done?

\section{Answer:}

No. If the sorbent and/or analytical methods can pass the requirements as laid out in Appendix K, they can be used.

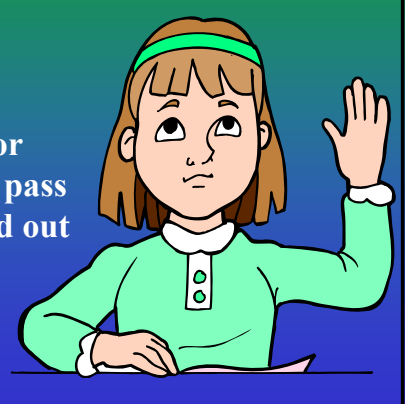

\section{Appendix K}

- Relative accuracy test.

Currently, the OH method is the only acceptable reference method.

$>$ A minimum of nine valid paired sample trains are required.

$>$ The sorbent trap results must meet a $\leq \mathbf{2 0} \%$ relative accuracy compared to the reference method.

Alternately, if the mercury concentration is $\leq \mathbf{5} \mu \mathrm{g} / \mathrm{scm}$, the results are acceptable if the mean difference does not exceed $1.0 \mu \mathrm{g} / \mathrm{scm}$. 

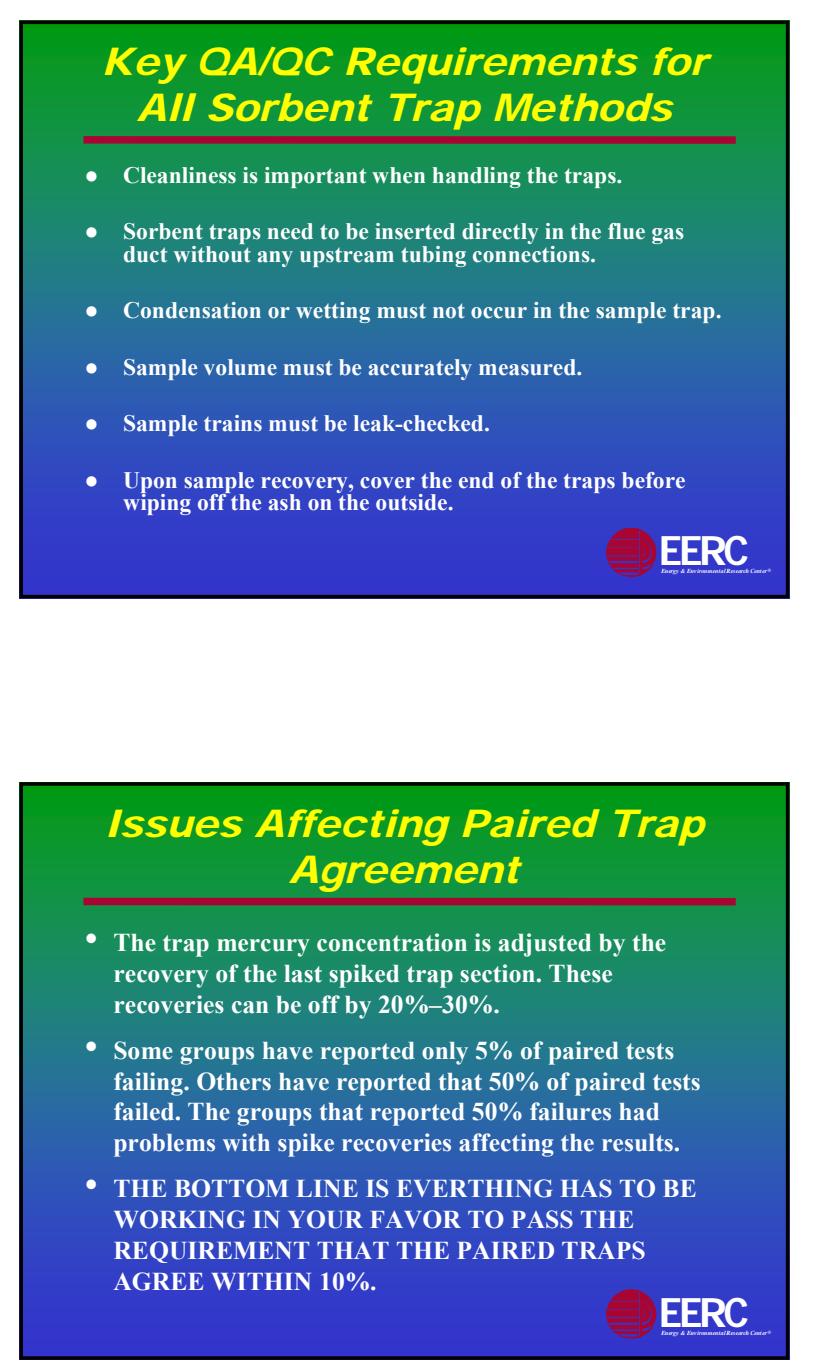

\begin{tabular}{|c|c|c|c|c|c|}
\hline \multirow{5}{*}{$\begin{array}{c}\text { Sorbent Trap } \\
\text { Results from } \\
\text { an EPRI } \\
\text { RATA Test }\end{array}$} & Run & Date & $\begin{array}{c}\text { EPRI } \\
\text { Sorbent Trap, } \\
\mu \mathrm{g} / \mathrm{dscm}\end{array}$ & $\begin{array}{l}\text { Reference } \\
\text { Method, } \\
\mu \mathrm{g} / \mathrm{dscm}\end{array}$ & $\begin{array}{c}\text { Difference, } \\
\mu \mathrm{g} / \mathrm{dscm}\end{array}$ \\
\hline & 1 & $3 / 7 / 05$ & 5.65 & 7.07 & -1.42 \\
\hline & 2 & $3 / 7 / 05$ & 7.98 & 7.50 & 0.48 \\
\hline & 3 & $3 / 8 / 05$ & 6.20 & 5.22 & 0.98 \\
\hline & 4 & $3 / 8 / 05$ & 4.94 & 4.44 & 0.50 \\
\hline \multirow{8}{*}{$\begin{array}{l}\text { Criteria: } \\
\mathrm{RA} \leq \mathbf{2 0} \% \text { or } \leq 1 \mu \mathrm{g} / \mathrm{m}^{3} \\
\text { absolute value of the } \\
\text { mean difference, if } \\
\text { mean } \mathrm{RM} \text { is }<5 \mu \mathrm{g} / \mathrm{m}^{3}\end{array}$} & 5 & $3 / 8 / 05$ & 5.49 & 4.48 & 1.01 \\
\hline & 6 & $3 / 9 / 05$ & 6.99 & 6.03 & 0.97 \\
\hline & 7 & $3 / 9 / 05$ & 5.92 & 5.55 & 0.37 \\
\hline & 8 & $3 / 9 / 05$ & 5.32 & 4.83 & 0.49 \\
\hline & 9 & $3 / 10 / 05$ & 4.27 & 3.31 & 0.95 \\
\hline & 10 & $3 / 10 / 05$ & 3.34 & 2.71 & 0.63 \\
\hline & 11 & $3 / 10 / 05$ & 3.06 & 2.55 & 0.51 \\
\hline & 12 & $3 / 11 / 05$ & 7.54 & 6.76 & 0.78 \\
\hline \multirow{2}{*}{$\begin{array}{l}\text { Calculated from } \\
11 \text { valid runs (2-12) }\end{array}$} & Mean & & 5.55 & 4.85 & 0.70 \\
\hline & RA, $\%$ & & & & 18.14 \\
\hline \multirow{2}{*}{$\begin{array}{r}\text { Calculated from } \\
\text { best nine runs }(1,5,9 \text { omitted })\end{array}$} & Mean & & 5.70 & 5.07 & 0.63 \\
\hline & RA, \% & & & & 15.87 \\
\hline
\end{tabular}

\section{Issues Affecting Paired Trap Agreement}

- Each control module has a dry gas meter that is calibrated to within $5 \%$. This means that paired trap agreement could be off by $5 \%$.

- Leak checks need to be within $4 \%$ of total flow rate. This can affect paired trap agreement by up to $4 \%$.

- Each trap has its own analytical uncertainty. This depends on the lab but it could easily be $2 \%-5 \%$.

EERC

\section{Relative Accuracy Test*}

Criteria: Relative accuracy (RA) $\leq 20 \%$ or $\leq 1 \mathrm{ug} / \mathrm{m}^{3}$ absolute value of mean difference, if mean reference method ( $R M)$ is $<5 \mu \mathrm{g} / \mathrm{m}^{3}$.

\begin{tabular}{|c|c|c|}
\hline Test & $\begin{array}{c}\text { Absolute Mean } \\
\text { Difference, } \mu \mathrm{g} / \mathrm{m}^{3}\end{array}$ & $\begin{array}{c}\text { Relative Accuracy, } \\
\%\end{array}$ \\
\hline EPA RATA Site 1 & 0.79 & 28.2 \\
\hline EPA RATA Site 2 & 0.09 & 9.4 \\
\hline
\end{tabular}

*The reference method was nine paired $\mathrm{OH}$ sample trains.

EERC

\section{Dry Sorbent Trap Methods}

- QuickCEMs ${ }^{\mathrm{TM}}$

Designed to measure total gas-phase mercury for lowdust conditions.

$>$ Uses impregnated activated carbon.

> To meet Appendix K criteria, the original specification needed to be modified by adding a third spiked QA/QC trap.

- FAMSTM

> Designed as a speciation method (includes particulatebound mercury).

> Uses two types of traps: $\mathrm{KCl} / \mathrm{quartz}$ followed by a chemically treated carbon trap.

$>$ Currently, only Frontier Geosciences provides the traps and does the analysis. 


\section{Dry Sorbent Trap Methods}

- E.ON dry sampling method

$>$ Designed as a speciation method for gas-phase mercury.

$>$ Uses an adsorber resin followed by a chemically treated carbon trap.

\section{Mercury Calculations}

- Flue concentrations

- Coal, hopper ash, and wet scrubber mercury concentrations

- Emission factors

- Mercury removal based on coal mercury

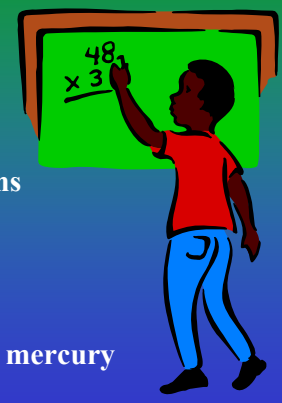

Continuous Mercury Monitors

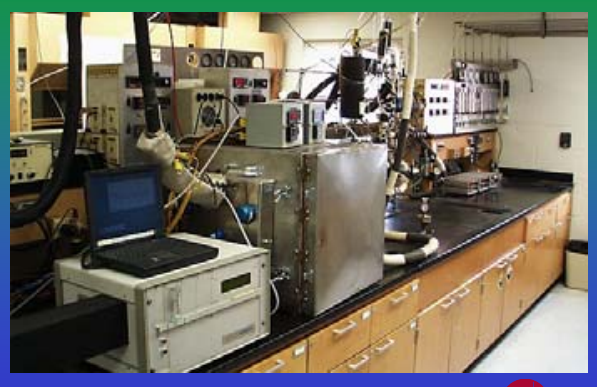

EERC Mercury Lab

EERC

\section{Costs Associated with Sorbent Trap Method}

- Sampling Equipment

Sample box (pump, dry gas meter, etc.)

Duel-sample probe

- Sample Traps

Chemically impregnated carbon traps (traps 1 and 2)

Spiked carbon trap

- Sample Analyses

Sending to outside laboratory (may take up to 2 weeks to obtain data)

$>$ Use instrumental method (i.e., Ohio Lumex)

- Personnel Costs

$>$ Training

$>$ Replacing traps on a regular basis

> Equipment maintenance

EERC

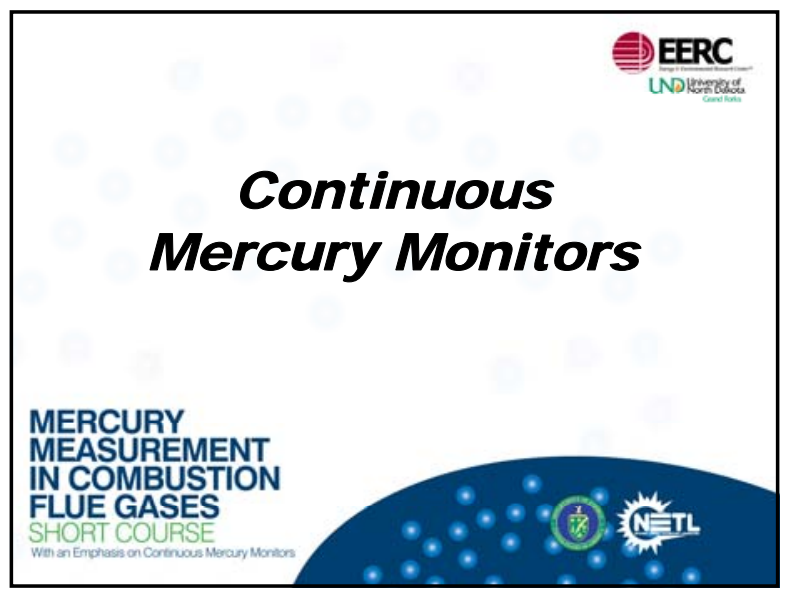

\section{Definition}

- Continuous Emission Monitor (CEM)

$>$ Refers to just the mercury analyzer

- Continuous Mercury Monitor (CMM)

$>$ Refers to entire mercury measurement system 


\section{Advantages of CMMs}

- Give real- or near-real-time results

- Able to assess process variability

- May be used for system optimization

- Provide feedback for $\mathrm{Hg}$ control strategies

- Have the potential to be less costly

- Allow direct measure of pollutants

- Critical to a cap-and-trade $\mathrm{Hg}$ control scenario

- May provide better public relations

\section{Challenges of CMMs}

- Low Hg concentrations

- $\mathrm{SO}_{3}$ and other acid gases and aerosols

- Moisture condensation (i.e., wet stacks)

- Other trace elements

- Interaction with ash

- Sample transport

- Long-term reliability

\begin{tabular}{|c|c|c|c|c|}
\hline Vendor & Product & $\begin{array}{l}\text { Analysis } \\
\text { Method }\end{array}$ & $\begin{array}{l}\text { Pretreatment/ } \\
\text { Conversion }\end{array}$ & Web Site \\
\hline Durag & HM-1400 & CVAA $^{1}$ & $\begin{array}{l}\text { Thermal } \\
\text { catalytic }\end{array}$ & durag.net \\
\hline Horiba/NIC & DM-6B & $\begin{array}{l}\text { Duel beam } \\
\text { CVAA }\end{array}$ & $\begin{array}{l}\text { Thermal } \\
\text { catalytic }\end{array}$ & $\begin{array}{l}\text { environ.hii. } \\
\text { horiba.com }\end{array}$ \\
\hline $\begin{array}{l}\text { Cooper } \\
\text { Envir. }\end{array}$ & $\begin{array}{c}\text { Xact } \\
\text { MM -EM }\end{array}$ & $\begin{array}{l}\text { Filter tape } \\
\text { with } \mathrm{XRF}^{2}\end{array}$ & None needed & $\begin{array}{c}\text { Cooperenvironment } \\
\text { al.com }\end{array}$ \\
\hline Ohio Lumex & RA-915+ & $\begin{array}{l}\text { CVAA with } \\
\text { Zeeman }\end{array}$ & None & ohiolumex.com \\
\hline \multicolumn{5}{|c|}{${ }^{\top}$ cold-vapor atomic absorption. } \\
\hline
\end{tabular}

Commercially Available CMMs (cont.)

\begin{tabular}{|c|c|c|c|c|}
\hline Vendor & Product & $\begin{array}{c}\text { Analysis } \\
\text { Method }\end{array}$ & $\begin{array}{c}\text { Pretreatment/ } \\
\text { Conversion }\end{array}$ & Web Site \\
\hline $\begin{array}{c}\text { Thermo } \\
\text { Electron }\end{array}$ & $\begin{array}{c}\text { Mercury } \\
\text { Freedom } \\
\text { System }\end{array}$ & CVAF & $\begin{array}{c}\text { Thermal catalytic } \\
\text { with dilution }\end{array}$ & $\begin{array}{c}\text { thermo.com/ } \\
\text { com }\end{array}$ \\
\hline $\begin{array}{c}\text { SICK UPA } \\
\text { GmbH }\end{array}$ & MERCEM & $\begin{array}{c}\text { Au- } \\
\text { CVAA }\end{array}$ & Wet chemistry & cemsi.on.ca \\
\hline $\begin{array}{c}\text { EcoCem } \\
\text { Analytics }\end{array}$ & Hg MKII & CVAA & $\begin{array}{c}\text { Thermal } \\
\text { catalytic }\end{array}$ & ecochem.biz \\
\hline $\begin{array}{c}\text { ST }^{2} \\
\text { Technologies }\end{array}$ & SM-3 & CVAA & Thermal catalytic & st2-service.com \\
\hline
\end{tabular}

EERC

\begin{tabular}{|c|c|c|c|c|}
\hline \multicolumn{5}{|c|}{ Commercially Available CMMs (cont.) } \\
\hline Vendor & Product & $\begin{array}{l}\text { Analysis } \\
\text { Method }\end{array}$ & $\begin{array}{c}\text { Pretreatment/ } \\
\text { Conversion }\end{array}$ & Web Site \\
\hline Opsis AB & $\mathrm{HG} 200$ & CVAA & Dilution system & opsis.se \\
\hline PS Analytical & $\begin{array}{c}\text { Sir } \\
\text { Galahad }\end{array}$ & $\mathrm{Au}-\mathrm{CVAF}{ }^{1}$ & $\begin{array}{l}\text { Wet chemistry and } \\
\text { Thermal Catalytic }\end{array}$ & $\begin{array}{c}\text { psanalytical. } \\
\text { com }\end{array}$ \\
\hline Envimetrics & $\begin{array}{c}\text { Argus- } \\
\mathrm{Hg} 1000\end{array}$ & $\begin{array}{c}\text { Au-plasma } \\
\text { emission }\end{array}$ & $\begin{array}{l}\text { Thermal } \\
\text { catalytic }\end{array}$ & $\begin{array}{l}\text { envimetrics. } \\
\text { com }\end{array}$ \\
\hline $\begin{array}{c}\text { Semtech } \\
\text { Metallurgy AB }\end{array}$ & Hg 2010 & $\begin{array}{l}\text { CVAA with } \\
\text { Zeeman }\end{array}$ & Wet chemistry & semtech.se \\
\hline Tekran, Inc. & 3300 & Au-CVAF & $\begin{array}{c}\text { Dry dilution } \\
\text { system }\end{array}$ & tekran.com \\
\hline \multicolumn{4}{|c|}{${ }^{1}$ cold-vapor atomic fluorescence. } & EERC \\
\hline
\end{tabular}

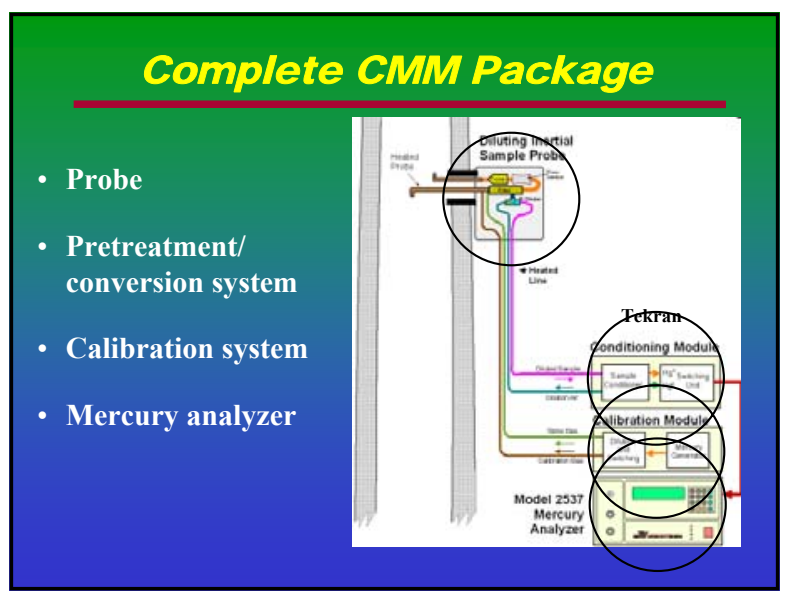



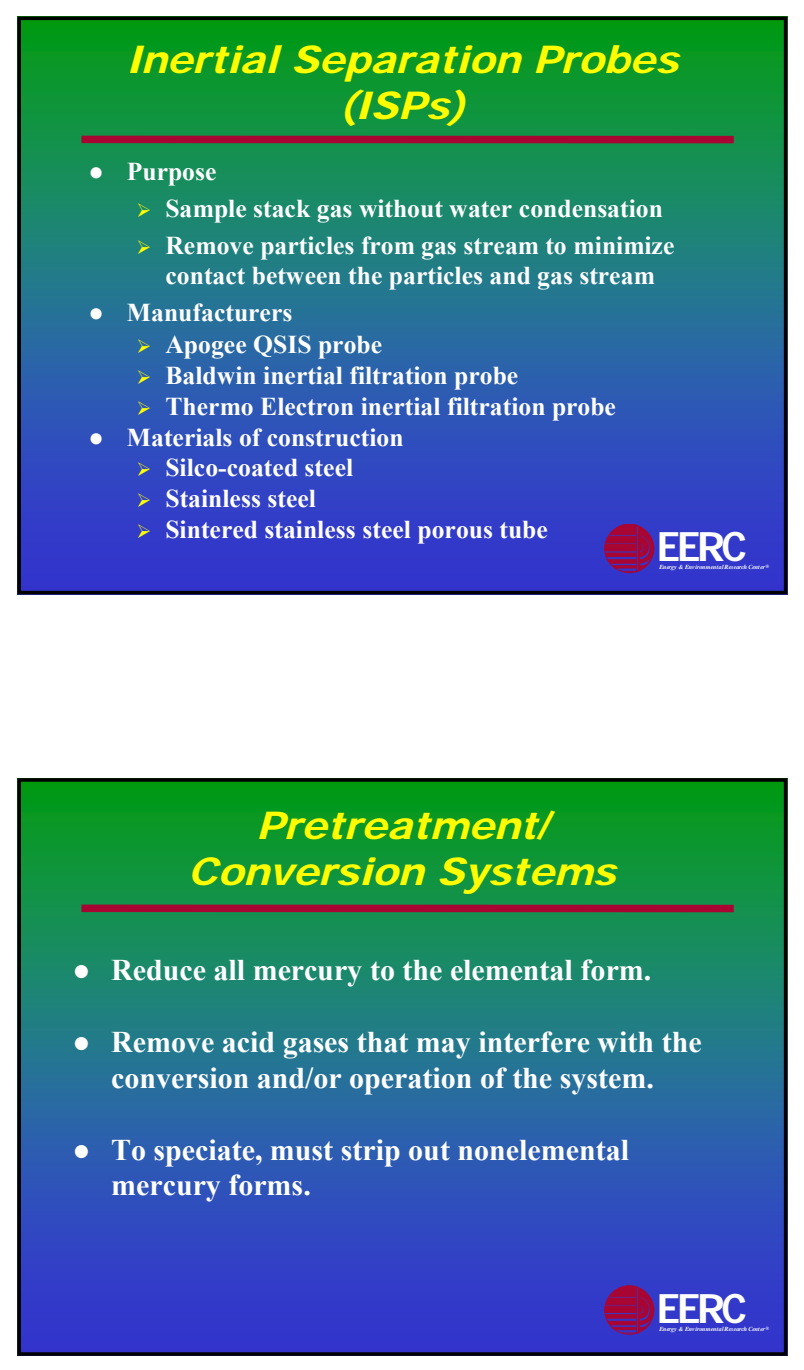

\section{Pretreatment/Conversion Wet-Chemistry Systems}

- Use a $\mathrm{SnCl}_{2}$ solution with $\mathrm{Hg}^{0}$ to reduce all mercury.

- Use a separate solution to strip out oxidized mercury.

- Solutions also remove acid gases.

- Chilled gas-liquid separator removes moisture from sample gas.

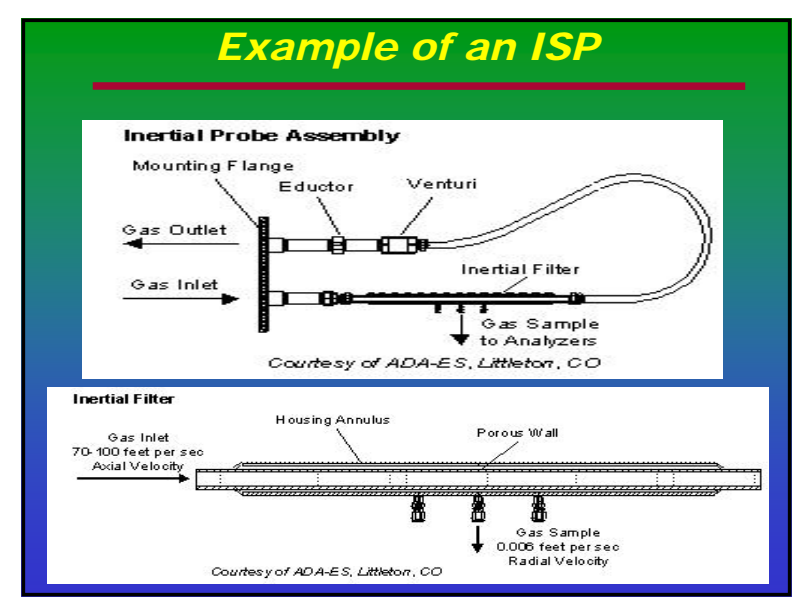

\section{Types of Pretreatment/ Conversion Systems}

- Wet chemistry

- Thermal catalytic

- Thermal catalytic with dilution

- Thermal dilution

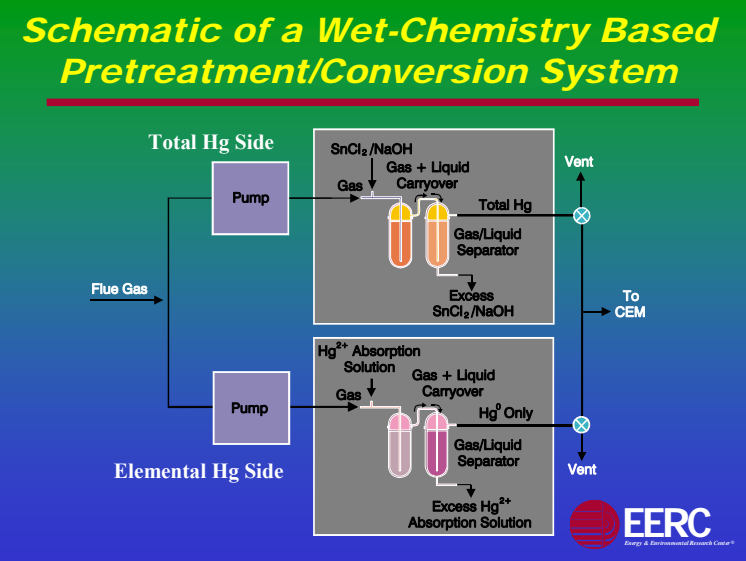




\section{Wet Conditioning/ Conversion Units}

- They have worked well for research but are not suited to long-term compliance monitoring.

- Extensive engineering or technician support is required.

- The solutions may remove $\mathrm{CO}_{2}$ from the sample gas.

- Tin plating and crystallization of solutions can cause problems.

- Cold spots.
Pretreatment/Conversion Thermal Catalytic Systems

- May or may not use wet chemicals to remove acid gases and moisture.

- Use a catalyst to reduce all mercury forms to $\mathrm{Hg}^{0}$.

- Removal of acid gases prevents conversion back to nonelemental forms during cooling.

- Speciated mercury is obtained using dual detectors or pretreatment systems.

- Life span of the catalyst has been a concern.

\section{Schematic of the PSA Dry-Based Speciation Module}

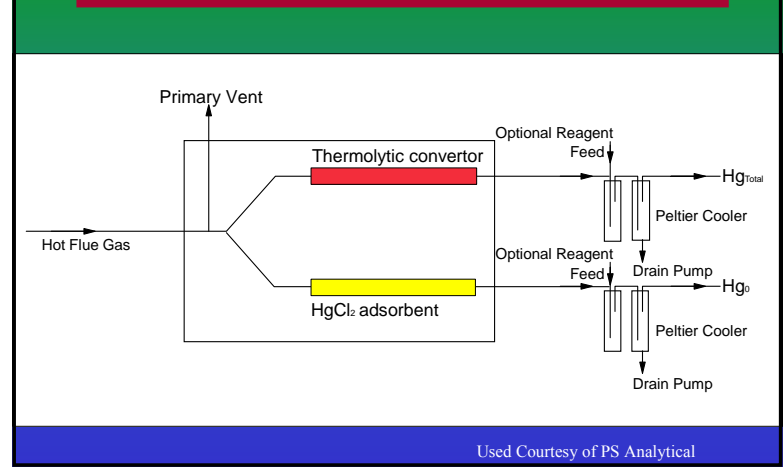

\section{Example of a Thermal Dilution System}

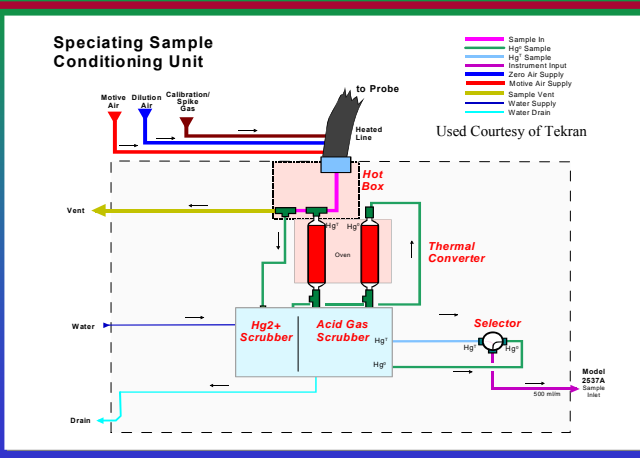

\section{Thermal Dilution Systems}

- Use little or no wet chemicals.

- Sample is diluted for transport.

- No catalyst is needed to reduce all forms of mercury to $\mathrm{Hg}^{0}$.

- Scrubbing of acid gases prevents conversion back to nonelemental forms during cooling.

- Must have a highly sensitive instrument such as atomic fluorescence (AF).

- Reduces problems with poisoning of gold traps with AF systems.

EERC

\section{Mercury Analyzers}

- CVAA spectroscopy with and without Zeeman modulation

- CVAF spectroscopy

- Differential optical emission spectroscopy (DOAS)

- Plasma emission spectroscopy

- Two-photon adsorption with wavelength modulation
PS Analytical

Sir Galahad

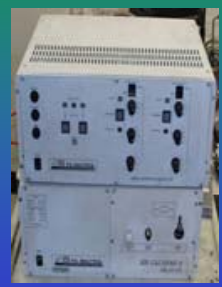

EERC 


\begin{tabular}{|l} 
Cold-Vapor Atomic Absorption \\
S pectroscopy \\
\multicolumn{3}{|c|}{$\begin{array}{l}\text { Measures mercury using UV light at } \\
\text { a spectra of 253.7 nm }\end{array}$} \\
\begin{tabular}{|l|l|l|}
\hline \multicolumn{1}{|c|}{ How it works } & \multicolumn{1}{c|}{ Example } \\
\hline $\begin{array}{l}\text { Type } \\
\text { Gold }\end{array}$ & $\begin{array}{l}\text { Uses gold trap to preconcentrate } \\
\text { Hg and remove interferents. }\end{array}$ & SICK MERCEM \\
\hline $\begin{array}{l}\text { CVAAS - } \\
\text { Dual Beam }\end{array}$ & $\begin{array}{l}\text { Measures gas with and without } \\
\text { Hg. SO }{ }_{2} \text { may be scrubbed. }\end{array}$ & Horiba/NIC DM-6 B \\
\hline $\begin{array}{l}\text { CVAAS - } \\
\text { Zeeman Shift }\end{array}$ & $\begin{array}{l}\text { Uses Zeeman shift to } \\
\text { compensate for interferents. }\end{array}$ & Ohio Lumex \\
\hline
\end{tabular} \\
\hline
\end{tabular}
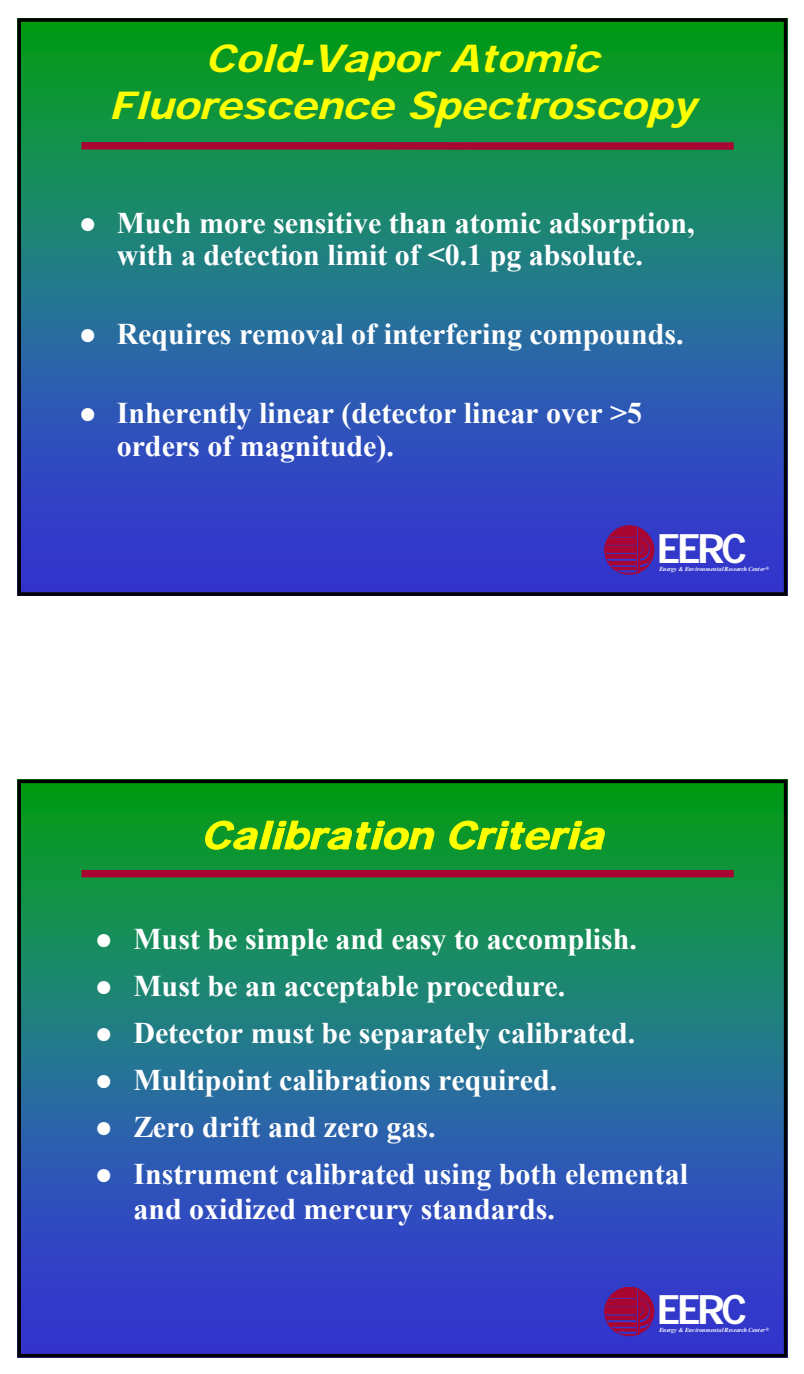
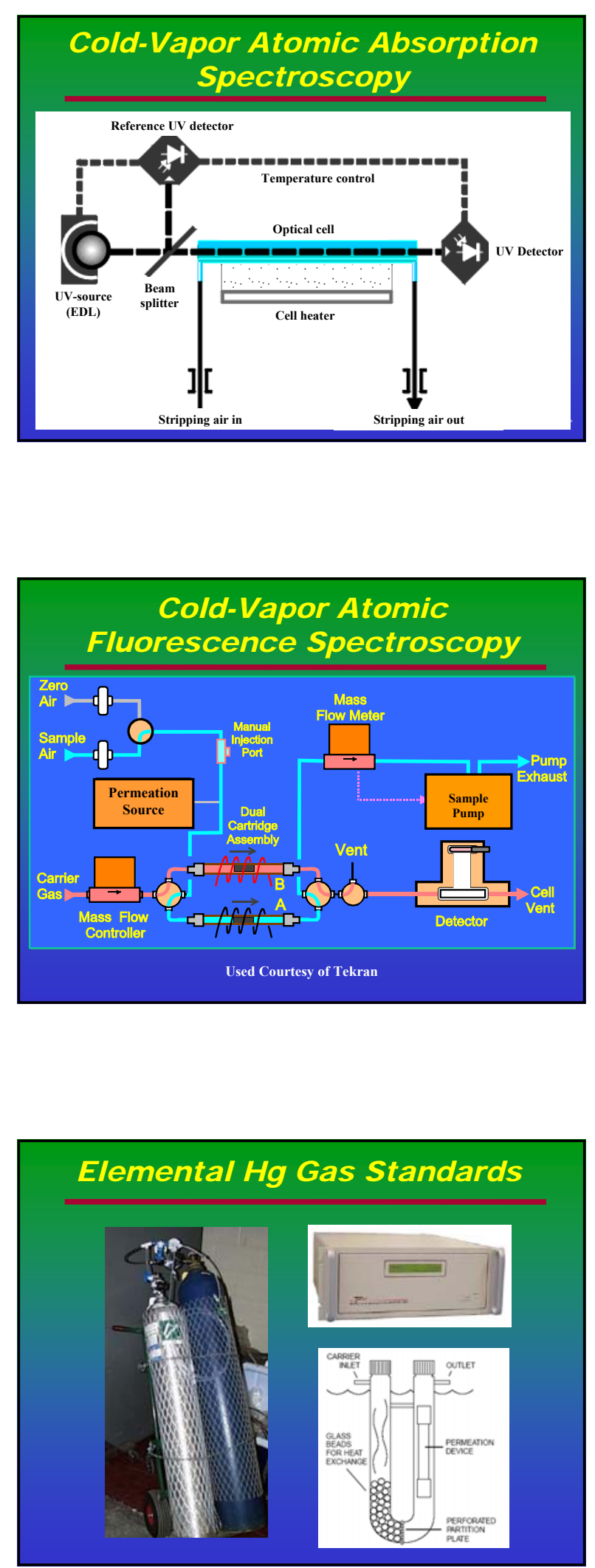

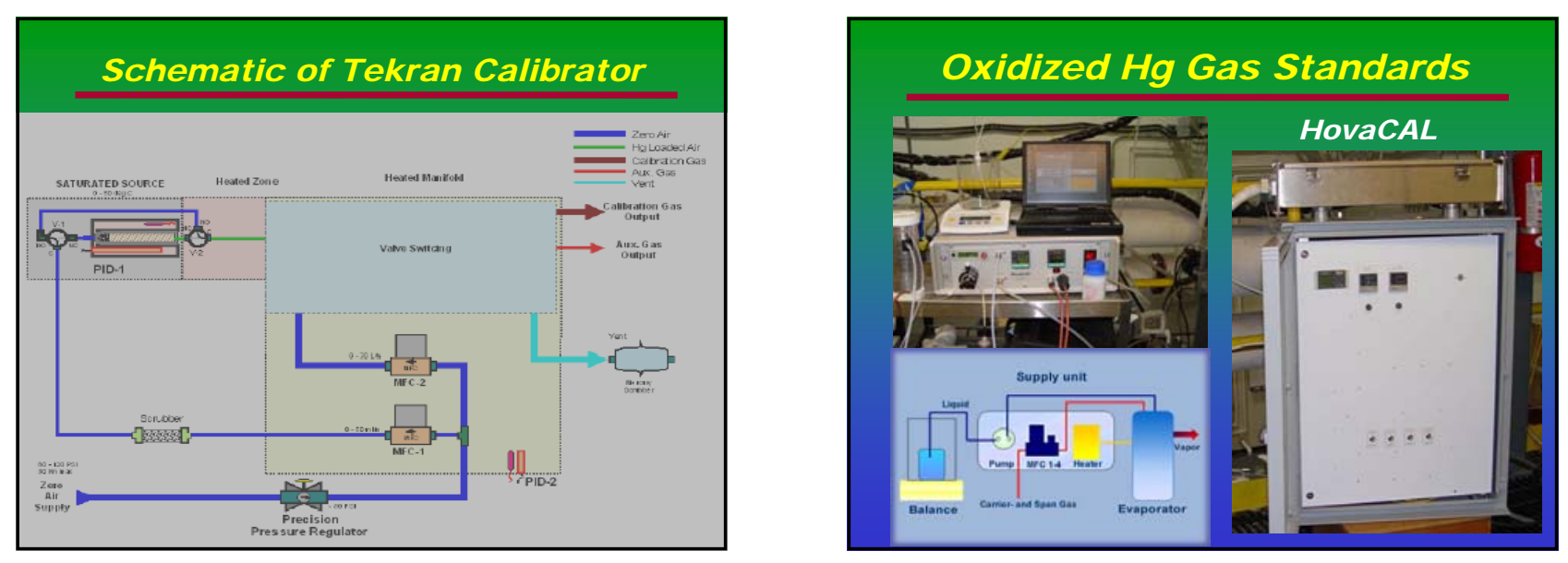

\section{Costs Associated with CMMs}

- Capital costs

- Cost of supplies

- Training costs

- Costs associated with certification (PS 12A)

- Costs associated with on-going QA/QC

$>$ Calibration

$>$ Regular maintenance

$>$ Troubleshooting

$>$ Cost for RATA

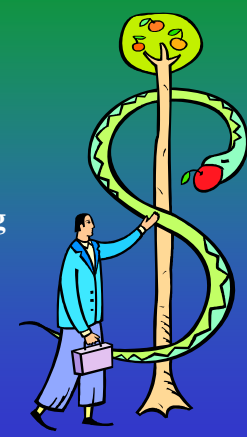

Performance Speciation (PS) 12A (Amended to Appendix B Part 60)

- "Specification and Text Procedures for Total VaporPhase Mercury Continuous Emission Monitoring Systems in Stationary Sources"

- PS 12A used for evaluating acceptability of total vaporphase CMMs at time of or soon after installation

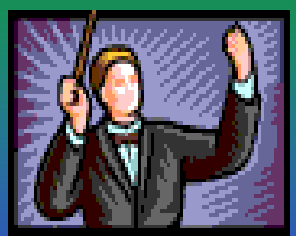

EERC

\section{Time Lines}

- Time lines associated with federal mandates (monitors required by

January 2009)

- Time lines associated with instrument development

- Time line associated with instrument operation

$>$ Purchase

$>$ Installation

> Certification (12 months)

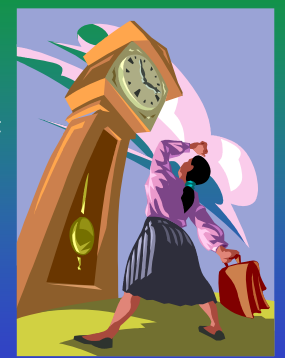

EERC

\section{PS 12A}

- Amended to CFR, Part 60, as Appendix B.

- Provides details as to the acceptability of a CMM for an affected site.

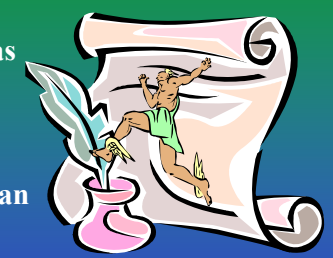

- Does not include ongoing calibration procedures. 


\section{PS 12A}

- PS 12A is not:

> Intended for long-term evaluation of CMMs.

$>$ Intended to identify specific calibration techniques or auxiliary procedures to asses CMM performance.

- Facilities subject to the requirements of Subpart I of Part 75, Chapter 1 of Title $\mathbf{4 0}$ may conduct performance evaluation of the CMMs according to $\$ \$ 75.20(c)(1)$ of Chapter 1 Title $\mathbf{4 0}$ and Section $\mathbf{6}$ of Appendix A to Part 75 in lieu of PS 12A.

EERC

\section{Reagents and Standards}

- Reference gases

$\begin{array}{ll}>\text { Zero-level } & 0 \% \text { to } 20 \% \text { of span } \\ >\text { Mid-level } & 50 \%-60 \% \text { of span }\end{array}$

Mid-level $\quad 50 \%-60 \%$ of span

- Span value is defined as the upper limit of the intended $\mathrm{Hg}$ concentration measurement range.

- Reference gas delivery system

Gas flow rate must be the same at all three challenge levels.

Gas flow must exceed the flow required by the CMMs.

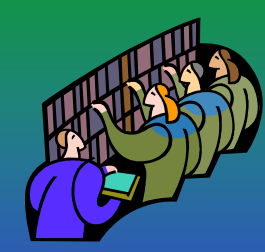

\section{PS $12 \mathrm{~A}$ \\ Measurement Error (ME)}

- Three-point check - low-, mid-, and high-level.

- National Institute of Standards and Technology (NIST) traceable $\mathrm{Hg}^{0}$ and $\mathrm{HgCl}_{2}$ must be used.

- The reference gas must be injected immediately after the sampling filter.

- ME test must be conducted with both $\mathrm{Hg}^{\mathbf{0}}$ and $\mathrm{HgCl}_{2}$ reference gases.

- For each reference gas, the absolute value of the difference cannot exceed $5 \%$ of the span value.

\section{PS 12A}

- Provides definitions (CEM, span value, etc.)

- Measurement location

- Measurement error (ME)

- Upscale drift (UD)

- Zero drift (ZD)

- Measuring RA

- Data acquisition

- Data reduction and documentation

EERC

\section{PS 12A Instrument Location}

- Assessable location downstream of all air pollution control devices

- Guidelines for determining location

$>\mathbf{2}$ equivalent diameters

downstream of the nearest control device

$>1 / 2$ equivalent diameters from the effluent exhaust

$>1$ meter from stack or duct wall

- Single-point extraction

$>$ Free from mercury stratification

Conduct a $\mathrm{NO}_{\mathrm{x}}$ and/or $\mathrm{SO}_{2}$ traverse prior to installation to determine stratification.

플

\section{PS 12A \\ Upscale Drift (UD) Tests}

- Challenge the entire CMM with an upscale reference gas $\left(\mathrm{Hg}^{0}\right.$ or $\mathrm{HgCl}_{2}$ ) once each day for 7 consecutive unit operating days.

- Conduct the tests immediately before any automatic zero and span operations.

- Unit operating at more than $\mathbf{5 0 \%}$ of normal load.

- NIST traceable $\mathrm{Hg}^{0}$ or $\mathrm{HgCl}_{2}$ standards used.

- The absolute value of the difference cannot exceed $5 \%$ of the span value for each day.

UD $=|\mathbf{R}-\mathbf{A}| / \mathrm{S} \times 100 \leq \mathbf{5 . 0} \%$ 


\section{PS $12 \mathrm{~A}$ \\ Zero Drift Tests (ZD)}

- Challenge the entire CMM once per day for 7 days $\mathrm{N}_{2}$ or air.

- Conduct the tests immediately before any automatic zero and span operations.

- Unit operating at more than $\mathbf{5 0 \%}$ of normal load.

- The absolute difference between the zero level and the instrument reading is expressed as \% of span gas.

\section{$\mathrm{ZD}=|\mathbf{R}-\mathbf{A}| / \mathrm{S} \times \mathbf{1 0 0} \leq \mathbf{5 . 0} \%$}

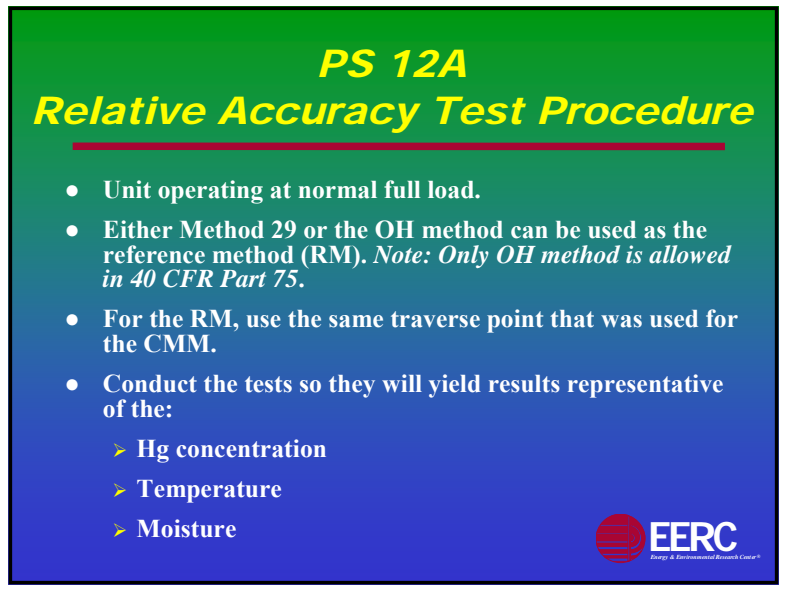

\section{Relative Accuracy Test Procedure}

- Use paired RM samples.

- Conduct a minimum of nine valid paired RM test runs.

- More than nine RM tests can be conducted but only a maximum of three sets of test results can be rejected.

- Report all data, including rejected data.

- Run RM long enough to ensure a sufficient mass of mercury is collected for analysis ( 2 hrs is suggested).

- RM data must meet relative deviation (RD) criteria.

\section{Relative Accuracy Test Procedure}

- The minimum performance criteria is:

$>\mathrm{RD} \leq 10 \%$ for $\mathrm{Hg}$ concentrations $>1.0 \mu \mathrm{g} / \mathrm{m}^{3}$

$>\mathrm{RD} \leq 20 \%$ for $\mathrm{Hg}$ concentrations $\leq 1.0 \mu \mathrm{g} / \mathrm{m}^{3}$

- Pairs of data that do not meet these criteria should be eliminated from the data set used to determine RA.

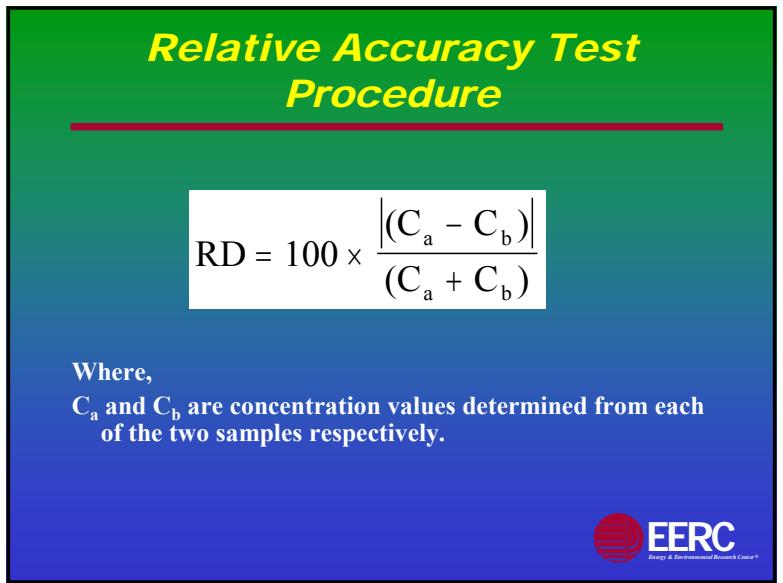

\section{Relative Accuracy Test Procedure}

- To correlate the RM and CMM data, confirm that they are reported on consistently:

$>$ Moisture

$>$ Pressure

$>$ Temperature

$>$ Diluent concentration basis

- Take into consideration response time of CMM

- Tabulate the paired data 


\section{Relative Accuracy Test Procedure}

Calculate relative accuracy using:

$$
\mathrm{RA}=\frac{|\overline{\mathrm{d}}|+|\mathrm{cc}|}{\mathrm{RM}} \times 100
$$

Where,

d = The sum of the difference between the RM values and the corresponding $\mathrm{CMM}$ values

cc $=$ The value of the confidence coefficient

$\mathbf{R M}=$ Arithmetic mean of the reference method values

\section{Relative Accuracy Test Procedure}

Calculate the confidence coefficient (one tailed) of a data sets using:

$$
c c=t_{0.025} \frac{S_{d}}{\sqrt{n}}
$$

Where,

$\mathbf{t}_{0.025}=$ Student $\mathbf{t}$ value (use statistical tables)

$\mathrm{S}_{\mathrm{d}} \quad=$ Standard deviation

n $\quad$ Number of data points

\section{Relative Accuracy Test Procedure}

The bias test is passed if:

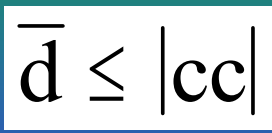

Where,

$\mathbf{d}=\quad$ The mean difference between the $\mathrm{RM}$ values and the corresponding CMM values

\section{Relative Accuracy Test Procedure}

Calculate d using:

$$
\overline{\mathrm{d}}=\sum_{\mathrm{i}=1}^{\mathrm{n}} \mathrm{d}_{\mathrm{i}}
$$

Where,
$\mathbf{n}=$ Number of data points
$\mathbf{d}_{\mathbf{i}}=$ The difference between a reference method value and the corresponding $\mathbf{C M M}$ 's value $\left(\mathbf{R M}_{\mathrm{i}}-\mathbf{C M M}_{\mathrm{i}}\right)$ at a given point in time $i$

\section{EERC}

\section{Relative Accuracy Test Procedure}

Standard deviation is calculated using:

$$
S_{d}=\sqrt{\frac{\sum_{i=1}^{n} d_{i}{ }^{2}-\frac{\left(\sum_{i=1}^{n} d_{i}\right)^{2}}{n}}{n-1}}
$$

\section{EDRC}

\section{Relative Accuracy Test Procedure}

The RATA data sets are evaluated for bias using:

$$
\mathrm{CMM}_{\mathrm{i}}{ }^{\text {Adjusted }}=\mathrm{CMM}_{\mathrm{i}}{ }^{\text {Monitor }} \times \mathrm{BAF}
$$

\section{Where,}

$\mathrm{CMM}_{\mathrm{i}}^{\text {Monitor }}=$ Data provided by the monitor at time $\mathbf{i}$

$\mathrm{CMM}_{\mathrm{i}}^{\mathrm{Adjusted}}=$ Data value, adjusted for bias, at time $\mathrm{i}$

BAF $=$ Bias adjustment factor, calculated to the nearest thousandth 


\section{Relative Accuracy Test Procedure}

BAF is defined by:

$$
B A F=1+\frac{|\bar{d}|}{C M M_{\text {avg }}}
$$

Where,

d $\quad=$ Arithmetic mean of the difference obtained during the failed bias test

$\mathrm{CMM}_{\mathrm{avg}}=$ Mean of the data values provided by the CMM during the failed bias test

EERC

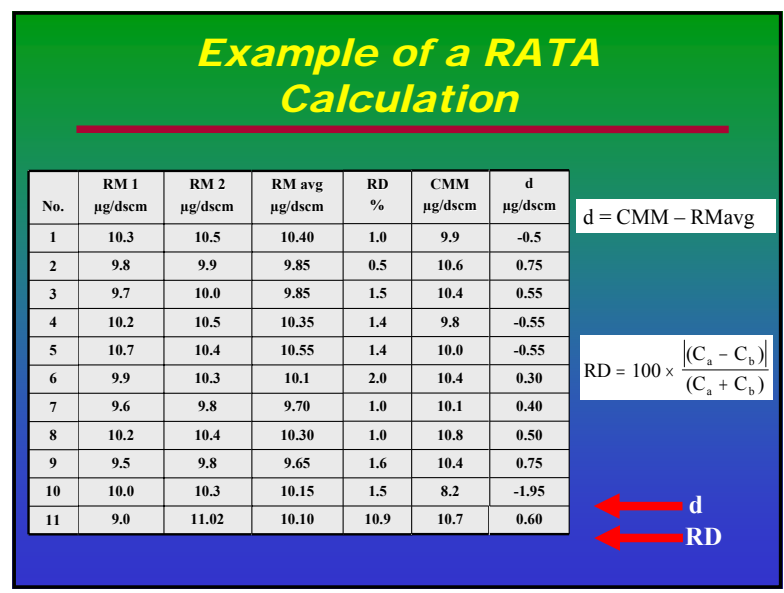

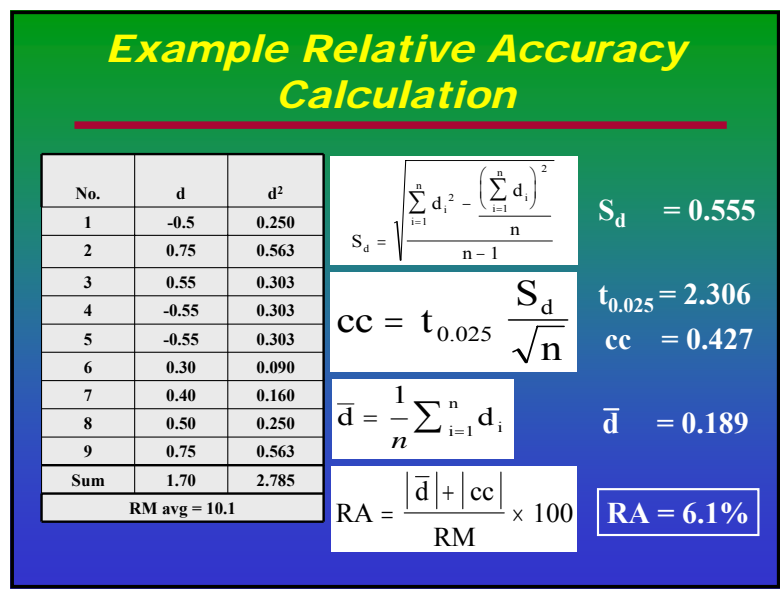

\section{Relative Accuracy Test Procedure}

If the mercury concentration is $<\mathbf{5 . 0} \boldsymbol{\mu \mathrm { g }} / \mathrm{dscm}$ during the RATA and the instrument meets the $20 \%$ RA or $1.0 \mu \mathrm{g} / \mathrm{scm}$ difference, but fails the bias test, the calculated BAF can be used or a default value of 1.250 .

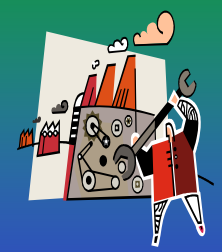

플

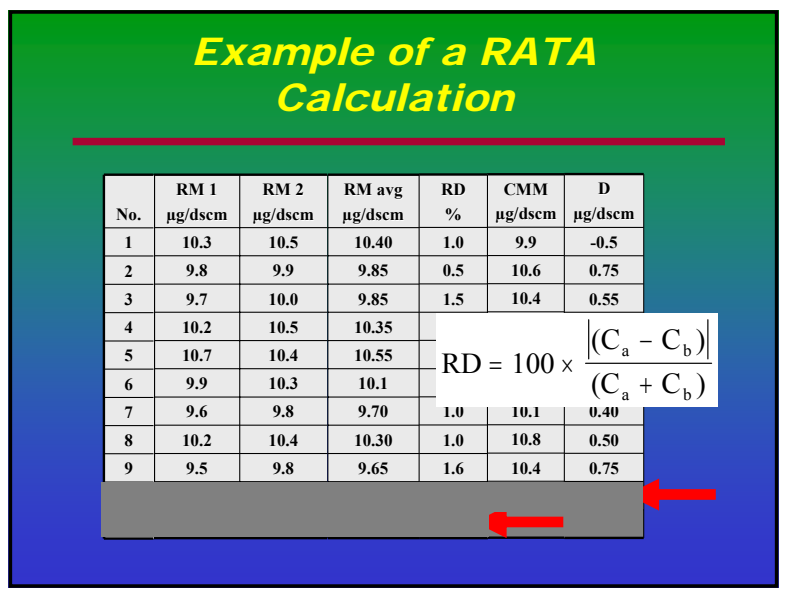

\section{Example Relative Accuracy} Calculation

\begin{tabular}{|c|c|c|c|c|c|c|c|c|}
\hline No & $\begin{array}{c}\text { RM 1 } \\
\mu \mathrm{g} / \mathrm{dscm}\end{array}$ & $\begin{array}{c}\text { RM } 2 \\
\mu \mathrm{g} / \mathrm{dscm}\end{array}$ & $\begin{array}{l}\text { RMavg } \\
\mu \mathrm{g} / \mathrm{dscm}\end{array}$ & $\begin{array}{c}\text { CMM } \\
\mu \mathrm{g} / \mathrm{dscm}\end{array}$ & d & $d^{2}$ & $\begin{array}{l}\text { RD } \\
\%\end{array}$ & $S_{d}=0.856$ \\
\hline 1 & 10.3 & 10.5 & 10.40 & 9.9 & -0.5 & 0.250 & 1.0 & $t_{0025}=2.226$ \\
\hline 2 & 9.8 & 9.9 & 9.85 & 10.6 & 0.75 & 0.563 & 0.5 & \\
\hline 3 & 9.7 & 10.0 & 9.85 & 10.4 & 0.55 & 0.303 & 1.5 & $c c=0.612$ \\
\hline 4 & 10.2 & 10.5 & 10.35 & 9.8 & -0.55 & 0.303 & 1.4 & \\
\hline 5 & 10.7 & 10.4 & 10.55 & 10.0 & -0.55 & 0.303 & 1.4 & $=-0.025$ \\
\hline 6 & 9.9 & 10.3 & 10.1 & 10.4 & 0.30 & 0.090 & 2.0 & \\
\hline 7 & 9.6 & 9.8 & 9.70 & 10.1 & 0.40 & 0.160 & 1.0 & $\mathrm{RA}=6.4 \%$ \\
\hline 8 & 10.2 & 10.4 & 10.30 & 10.8 & 0.50 & 0.250 & 1.0 & \\
\hline 9 & 9.5 & 9.8 & 9.65 & 10.4 & 0.75 & 0.563 & 1.6 & \\
\hline 10 & 10.0 & 10.3 & 10.15 & 8.2 & -1.95 & 3.803 & 1.5 & \\
\hline & \multicolumn{2}{|c|}{ Average $=10.1$} & & & $\sum=-0.25$ & $\sum=6.588$ & & \\
\hline
\end{tabular}




\section{Example Relative Accuracy Calculation}

In both cases, the Bias Adjustment Factor (BAF) test is passed as:

\section{$\overline{\mathbf{d}} \leq|\mathbf{c c}|$}

$$
\begin{aligned}
& \overline{\mathbf{d}}=\mathbf{0 . 1 8 9}<|\mathrm{cc}|=\mathbf{0 . 4 2 7} \\
& \overline{\mathbf{d}}=\mathbf{0 . 0 2 5}<|\mathrm{cc}|=\mathbf{0 . 6 1 2}
\end{aligned}
$$

CFR 40, Part 75

\section{Continuous Emission Monitoring}

- Requirements for $\mathrm{SO}_{2}$ and $\mathrm{NO}_{\mathrm{x}}$ monitoring

- Changed to include requirements for monitoring mercury

- Includes detailed specifications for initial certification of CMMs and ongoing QA/QC requirements

- Includes detailed specifications for monitoring using sorbent traps
CFR Part 75, Appendix A Ongoing CMM QA/QC Required

- Daily calibration

- Weekly system integrity check

- Quarterly 3-point linearity check

- Annual RATA

EERC
40 CFR, Part 75, Changes as a Result of CAMR

- 75.2 Applicability

- 75.10 General operating requirements

- 75.15 Special provisions for measuring mercury mass emissions using the sorbent trap monitoring methodology

- 75.20 Initial certification and recertification

- 75.21 Quality assurance and quality control requirements

- 75.22 Reference methods

\section{EERC}

\section{CFR, Part 75, Changes as a Result of CAMR}

- 75.24 Out-of-control periods and adjustment for system bias

- 75.31 Initial missing data procedures

- 75.32 Determination of monitor data availability for standard missing data procedures

- 75.33 Standard missing data procedures for $\mathrm{SO}_{2}, \mathrm{NO}_{\mathrm{x}}$, and flow rate

- 75.38 Standard missing data procedures for CMMs
40 CFR, Part 75, Changes as a Result of CAMR

- 75.53 Monitoring plan

- 75.39 Missing data procedures for sorbent trap monitoring systems

- 75.57 General record-keeping provisions

- 75.58 General record-keeping provisions for specific situations

- 75.59 Certification, quality assurance, and quality control record provisions

EERC 


\section{CFR, Part 75, Appendix Changes}

- Appendix A Specifications and test procedures

- Appendix B Quality assurance and quality control procedures

- Appendix F Conversion procedures

- Appendix K Quality assurance and operating procedures for sorbent trap monitoring systems

\section{Equipment Specifications}

- A maximum potential concentration (MPC) must be determined by using:

$>$ A predetermined fixed-value based on coal type.

$>$ Site-specific emissions testing.

> 720 or more hours of CMM data or sorbent trap data.

- A high span for the Hg monitor should be set by rounding the MPC upward to the next highest multiple of $10 \mu \mathrm{g} / \mathrm{scm}$.

E풀

\section{Data Acquisition and Handling Systems}

- Read and record full range of mercury concentrations.

- Provide a permanent continuous record of all data.

- Capable of converting readings to emission rates or mass emissions in appropriate units.

- Compute and record monitor calibration error, bias adjustments, mercury emission rate and all missing data procedure statistics.

\section{Equipment Specifications}

- The CMM must be setup such that:

> Known concentrations of elemental $\mathrm{Hg}$ and $\mathrm{HgCl}_{2}$ can be injected.

> There is an injection point immediately preceding the sample extraction filtration system.

> The entire measurement system can be checked.

> A cycle time test must pass with a maximum allowable of 15 minutes.

- Select a measurement range such that the majority of readings are between $20 \%$ and $80 \%$ of full scale.

EERC

\section{Equipment Specifications}

- At a minimum, an annual evaluation of the MPC, span, and range may need adjustment because of:

$>$ Change in fuel type.

$>$ Change in unit operations.

$>$ Installation or removal of emissions control.

\section{EERC}




\section{Weekly System Integrity Checks}

- Single point system check

- Use NIST-traceable source of $\mathbf{H g}^{2+}$

- Use mid- or high-level gas concentration

- Do not have to be performed if a NISTtraceable source of $\mathrm{Hg}^{2+}$ is used for daily calibration error tests

\section{Quarterly 3-point Linearity Check}

- NIST-traceable $\mathrm{Hg}^{0}$ reference gas

- Must meet a specification of $10 \%$ of standard at three gas levels (low-, mid-, high-level)

- Alternately, specification can be $<1.0 \mu \mathrm{g} / \mathrm{scm}$ absolute difference

EERC

\section{Quarterly 3-point Linearity Check}

- Linearity check is passed if:

or

$$
\mathrm{LC}=\frac{|\mathrm{R}-\overline{\mathrm{A}}|}{\mathrm{R}} \times 100 \leq 10.0 \%
$$

$$
|\overline{\mathrm{R}}-\overline{\mathrm{A}}| \leq 1.0 \mu \mathrm{g} / \mathrm{scm}
$$

- Must pass for each of the three reference gas levels

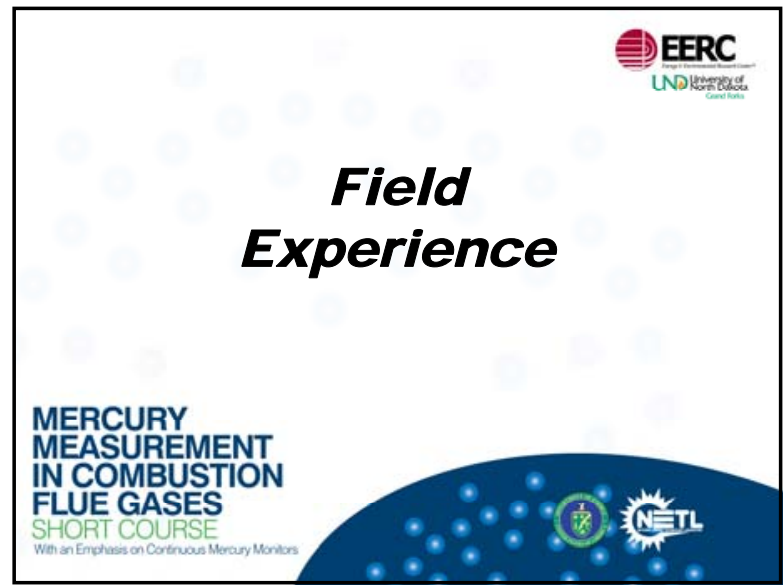

Relative Accuracy Test Audit (RATA)

- Same procedures used as discussed for PS 12A

> CMM must meet 20\% RA.

$>$ Alternately, if mercury concentration is $\leq \mathbf{5} \mathrm{g} / \mathrm{scm}$, results are acceptable if absolute mean difference between the RM and CMM does not exceed $1.0 \mu \mathrm{g} / \mathrm{scm}$.

\section{EERC}

\section{Mercury CMM Test Programs}

- DOE/EPA CMM Testing at Holly Hills, North Carolina

$>$ Tests done in 1997

> Unit is cement kiln

$>$ Substantial variation in flue gas

$>$ Tests largely unsuccessful

- European TUV certification test results

> Test primarily conducted on European waste-to energy systems.

A number of CMMs have obtained TUV certification. 


\section{Mercury CMM Test Programs}

- Batelle ETV program

$>$ Tests primarily done in 1999 and 2000.

Pilot-scale testing at EPA's facility.

$>$ Only several vendors participated with mixed results.

- RATA Tests at Site 1 (eastern bituminous coal)

$>$ Tekran

$>$ Horiba

$>$ Thermo Electron

$>$ Foney (Genesis)

$>$ Sorbent Traps

> The Tekran, Thermo Electron, and sorbent traps passed

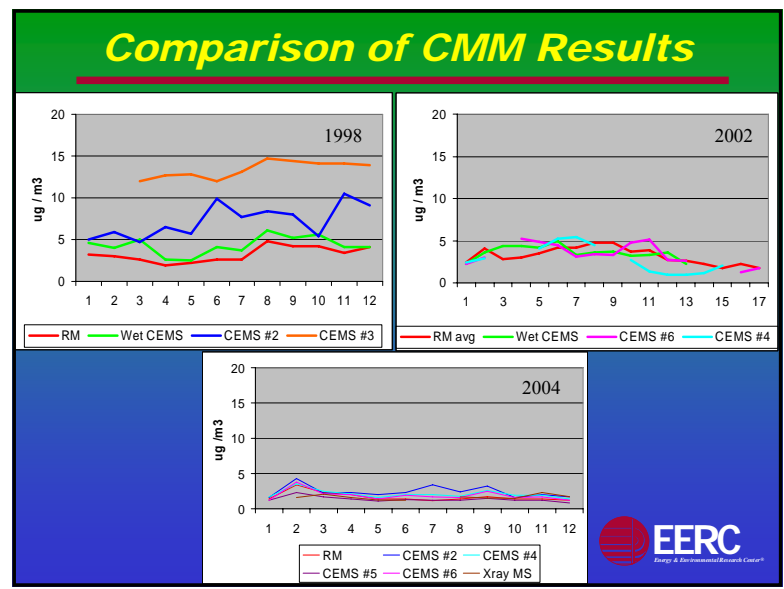

\section{EERC Field Experiences}

- Siting

- Filtration

- Conversion/ conditioning units

- Sample transport

- Calibration

- Spiking

- Instruments

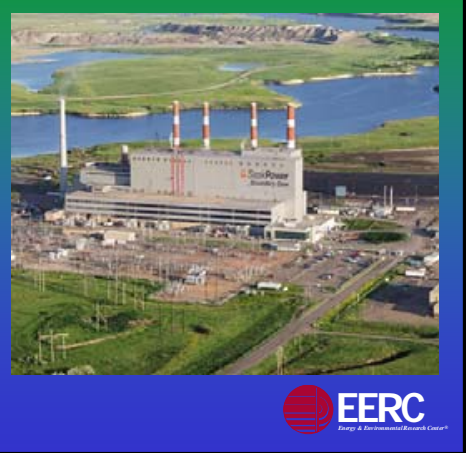

\section{Mercury CMM Test Programs}

- RATA Tests at Site 2 (eastern bituminous coal)

\section{$>$ Tekran}

$>$ Horiba

Sorbent traps

Tekran and sorbent traps passed

- EERC and other research groups

$>$ Primary instruments used are Tekran and PS Analytical

$>$ Used in field for research purpose

$>$ Substantial short-term data comparing results to OH method

EERC

\begin{tabular}{|c|c|c|c|c|}
\hline \multicolumn{5}{|c|}{$\begin{array}{l}\text { Relative Accuracy Test } \\
\text { Comparing Two CMMs* }\end{array}$} \\
\hline \multicolumn{5}{|c|}{$\begin{array}{l}\text { Criteria: } \mathrm{RA} \leq 20 \% \text { or } \leq 1 \mu \mathrm{g} / \mathrm{m}^{3} \text { absolute value } \\
\text { of mean difference, if mean } \mathrm{RM} \text { is }<5 \mu \mathrm{g} / \mathrm{m}^{3} \text {. }\end{array}$} \\
\hline Test & \multicolumn{2}{|c|}{ Site 1} & \multicolumn{2}{|c|}{ Site 2} \\
\hline Instrument & Tekran & Horiba & Tekran & Horiba \\
\hline $\begin{array}{l}\text { Mean Difference, } \\
\mathrm{ug} / \mathrm{m}^{3}\end{array}$ & 0.51 & 1.59 & 0.26 & 1.57 \\
\hline $\begin{array}{l}\text { Relative Accuracy, } \\
\%\end{array}$ & 18.9 & 51.5 & 10.5 & 49.3 \\
\hline *The reference method & nine pair & I sample & & \\
\hline
\end{tabular}

\section{Operational Manpower Requirements}

- Extensive initial training from vendor

- An instrument technician will be required to perform:

$>$ Daily calibration error tests

$>$ Weekly system integrity checks

$>$ Quarterly linearity checks

$>$ Annual RATA

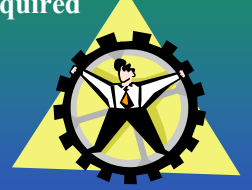

$>$ Maintenance as needed

- Coordination of RATA testing 

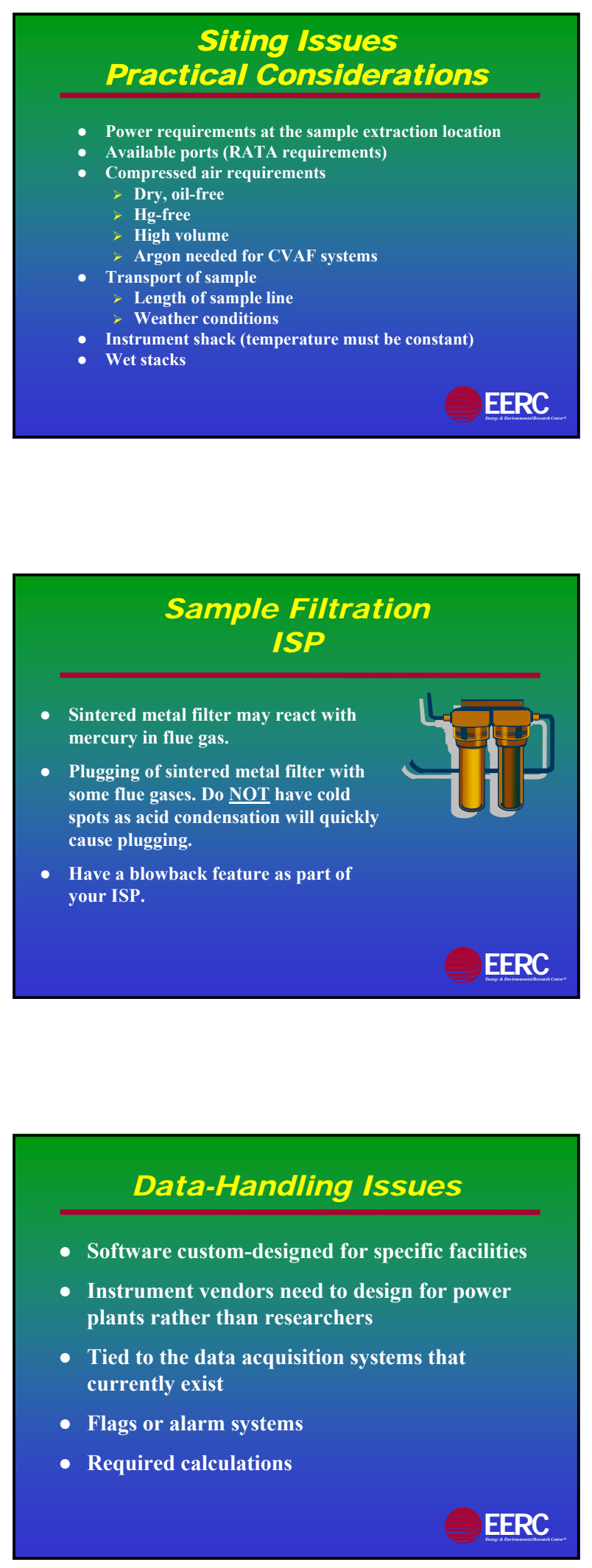
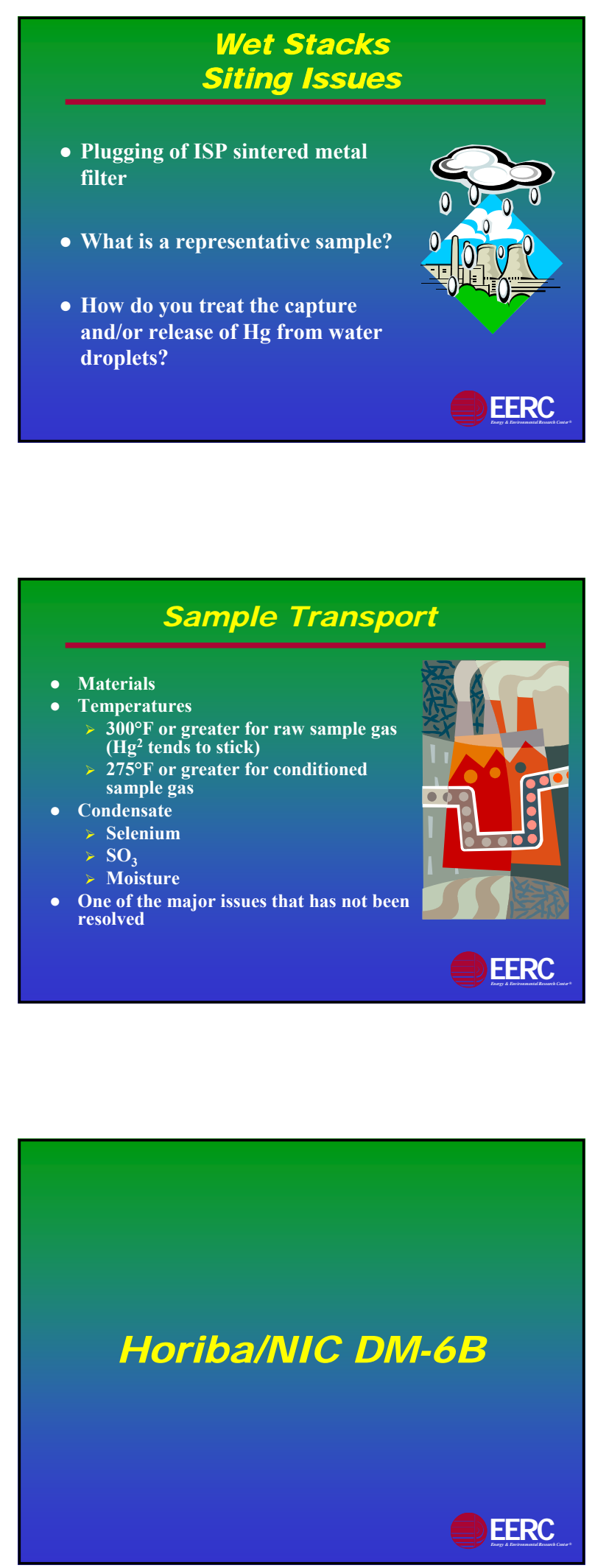


\section{Pretreatment/Conversion Thermal Catalytic Systems}

- Uses a catalyst to reduce all mercury forms to $\mathbf{H g}^{\mathbf{0}}$.

- Acid gases must be removed to prevent conversion back to nonelemental Hg forms during cooling; may or may not use wet chemicals to do this.

- Speciated mercury is obtained using dual detectors or pretreatment systems.

- Life span of the catalyst has been a concern.

\section{Summary of EERC Experience Using the Horiba/NIC CMM}

\section{Advantages}

- Uses CVAA for mercury analysis, which is generally simpler to use than AF-based systems.

- Costs somewhat less.

- Does not use a gold trap or argon.

- Is more portable.

- Has fewer power requirements.

\section{Summary of EERC Experience} Using the Horiba/NIC CMM

\section{Disadvantages}

- Is less versatile - catalyst life may limit its use to select plants (i.e., those using western coals).

- Catalyst is expensive (approx. \$750).

- May require the addition of $\mathrm{HCl}$ to zero gas in order to prevent $\mathrm{NO}_{\mathrm{x}}$-related loss of catalyst life.

- May require more wet chemistry than would be desired from a dry system.

- Has a selenium problem.

- Engineering layout is poor.

- Uses fragile glassware.

- Poor service from Horiba, which is trying to set up its distribution and service network.

Effect of Combustion Modifications on Hg Emissions

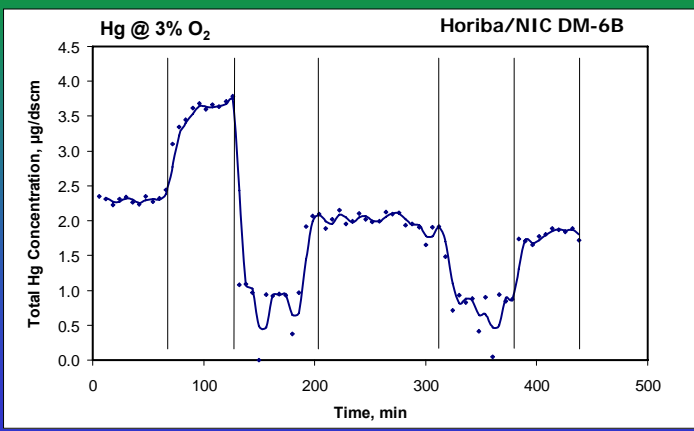

\section{Horiba/NIC - Current Research}

- Currently testing a higher-temperature catalyst.

- Using a water injection system to flush out selenium buildup in sample line.

- Providing new solenoid valve system so that HCl injection only goes through the total mercury side.

- Testing a new CVAF system (NIC AM-4).

EERC
Longer-Term CMM Data for a Lignite (hourly averages)

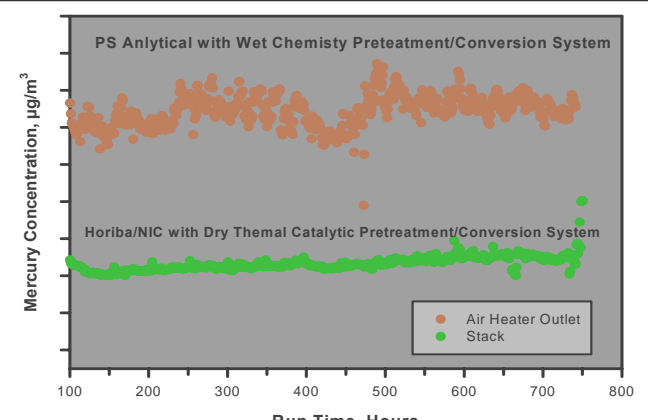

Run Time, Hours 


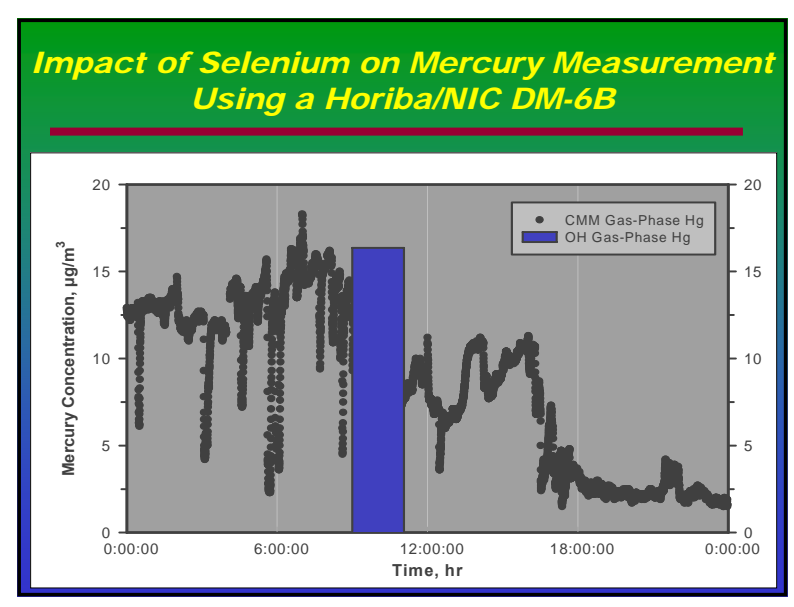

\section{Thermal Dilution Systems}

- Minimal wet chemicals are used.

- Sample is diluted for transport.

- All forms of mercury are thermally reduced to $\mathrm{Hg}^{0}$.

- Scrubbing of acid gases prevents conversion back to nonelemental Hg forms during cooling and eliminates gold trap poisoning problems.

- Must have a highly sensitive instrument such as AF.

- Must accurately calculate dilution ratio.

EERC

\section{Summary of EERC Experience} Using the Tekran CMM

\section{Disadvantages}

- Is a relatively large instrument.

- Is more costly.

- Dilution ratio has the potential to change.

- Requires argon.

- Has a gold trap that has the potential to be poisoned.

- Concentration is reported on a wet basis. Additional measurements will be needed to report on a dry basis.

- $\mathrm{SO}_{3}$ condensation may be a long-term maintenance issue.

- Is generally more complex than CVAA systems.

\section{Tekran Model 3300}

EERC

\section{Summary of EERC Experience Using the Tekran CMM}

\section{Advantages}

- Has the potential to be usable on a wide range of combustion systems.

- Has no catalyst limitations.

- Has demonstrated longer-term capabilities.

- Is an almost completely dry system.

Hg Data Collected at a Slipstream Pilot Unit Located at a Lignite Facility

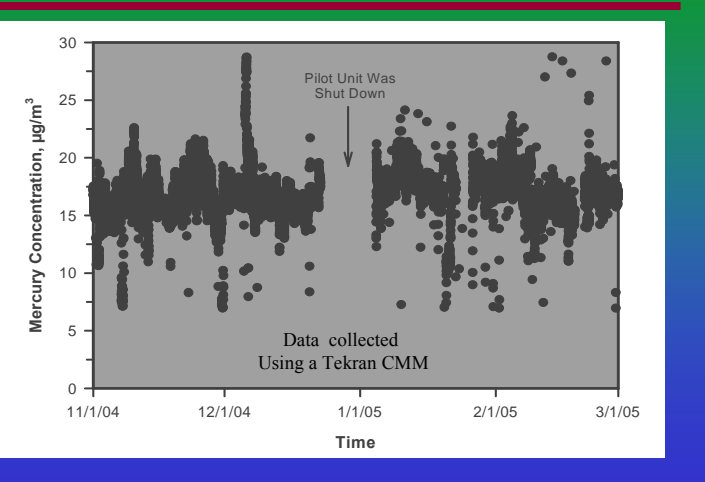




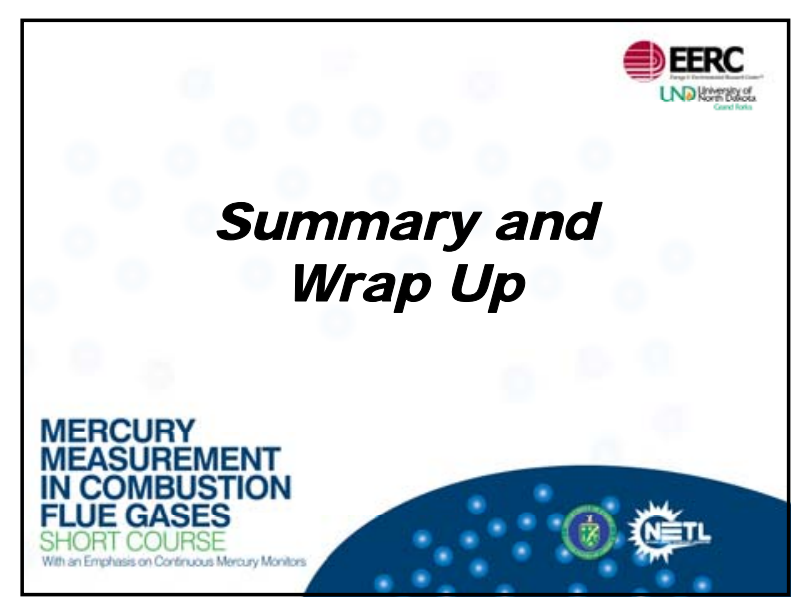

\section{CMM Advice}

- Substantial space is required as CMMs are relatively large and heavy; therefore, some type of pulley or trolley system is advisable.

- All CMMs require substantial power and more than one circuit.

- Some type of temperature-controlled area is needed for the analyzer portion of the system. The calibration will drift if the temperature changes.

- There are still unknowns as to the length of heat trace line that can be used between the sample probe and the instrument.

EERC

\section{EERC Conclusions and Recommendations}

- Currently, CMMs are difficult to use and require a substantial amount of engineering support to operate well. Remember KISS.

- More research is needed to provide effective, cheap, and simple pretreatment/conversion systems.

- PS 12A QA/QC procedures must be evaluated over time to determine what is necessary to ensure the high-quality data that is needed for a cap-and-trade structured rule to work properly.

\section{CMM Advice}

- Before purchasing an instrument, have the vendor test it at your facility; a dry catalytic system is simpler to operate and troubleshoot but cannot be used at all facilities.

- Be sure to plan all aspects of the purchase, including training of personnel. These instruments have a fairly steep learning curve.

- Understand all aspects of PS 12A. As currently written, the certification of the instrument, locating the instrument, and on going $\mathrm{QA} / \mathrm{QC}$ will be complex, costly, and time-consuming.

플

\section{CMM Advice}

- In high-acid flue gases or wet stacks, the ISP must be heated to $>260^{\circ} \mathrm{C}$ to prevent plugging.

- A source of dry, clean, compressed air is necessary, particularly for the Tekran.

- Have a Cav Kit or the equivalent on-site for troubleshooting.

- Become GOOD friends with your vendor.

\section{EERC}

Technologies Not Commercially Available - Many Under Development

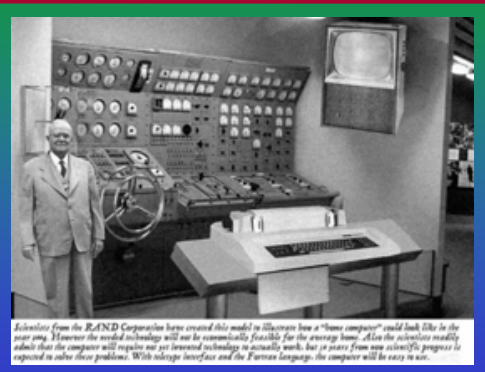

EERC 


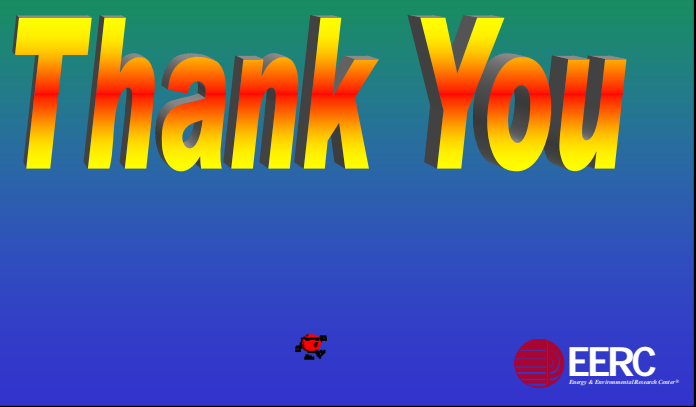

\begin{tabular}{|c|c|}
\hline Contact Information \\
Energy \& Environmental Research Center \\
University of North Dakota \\
15 North 23rd Street \\
PO Box 9018 \\
Grand Forks, North Dakota 58202-9018 \\
World Wide Web: www.undeerc.org \\
Telephone No. (701) 777-5000 \\
Fax No. (701) 777-5181
\end{tabular}


APPENDIX C

\section{FINAL REPORT FOR RESEARCH PROJECT ENTITLED DEVELOPMENT OF A NOVEL PETROLEUM BIOTECHNOLOGY}




\section{DEVELOPMENT OF A NOVEL PETROLEUM BIOTECHNOLOGY}

\section{INTRODUCTION}

This project is an effort to develop a novel biotechnology to mitigate production of hydrogen sulfide $\left(\mathrm{H}_{2} \mathrm{~S}\right)$ in the petroleum industry, to promote methane $\left(\mathrm{CH}_{4}\right)$ production in oil and gas fields, and to enhance oil recovery, based on a recently developed Energy \& Environmental Research Center (EERC) sulfide control additive capable of effectively controlling microbial $\mathrm{H}_{2} \mathrm{~S}$ production.

\section{Sulfate-Reducing Bacteria and Sulfide in the Petroleum Industry}

Production of sulfide in oil and gas fields is currently an unresolved issue for the petroleum industry. Sulfide is corrosive and toxic, and the overall economic impact of reservoir souring can be very significant. Sulfate-reducing bacteria (SRB) contribute to the production of sulfide. If $\mathrm{SRB}$ are inhibited, production of $\mathrm{H}_{2} \mathrm{~S}$ will subsequently be controlled.

In addition to causing the souring problem, SRB may also decrease methane production. It is well-documented that SRB are competitors of methanogenic bacteria. SRB compete with methanogens for hydrogen, the electron donor, in forming $\mathrm{H}_{2} \mathrm{~S}$ and $\mathrm{CH}_{4}$. In this competition, SRB always outcompete methanogens, resulting in more $\mathrm{H}_{2} \mathrm{~S}$ production and less methane formation. Methane is a major component of natural gas, and it is highly desirable to promote biogenic methane formation in oil and gas fields.

\section{Biodegradation of Residual Oil to Methane}

In recent years, the ability of anaerobic microorganisms to biodegrade a variety of hydrocarbons has been well-documented. In fact, gases of biological origin are believed to be primary by-products of anaerobic oil decomposition in petroliferous deposits. $n$-Alkanes, a major fraction of most crude oils, have recently been found to be biodegradable under methanogenic conditions, both as pure substrates and in oily mixtures, and could be a substantial source of methane in biodegraded oil resources. In the United States, energy recovery from marginal wells approximates 1 million barrels of oil per day, which equates to about $19 \%$ of domestic oil production (www.fossil.energy.gov/programs/oilgas/marginalwells/index.html). It may be possible to increase total energy production in marginal wells by converting a portion of the unrecoverable oil in marginal wells to methane.

\section{Recent Technologies in Oil Recovery}

Growing global demand for oil and gas could greatly increase demand for tertiary oil recovery. The National Institute of Petroleum and Energy Research estimate that $27 \%$ of oil reservoirs may be good candidates for microbial improved oil recovery. Currently, oil recovery techniques extract only about $45 \%$ of in-place oil resources, leaving the remainder stranded in mature fields. Developing new technologies to recover even a fraction of such a large energy pool is of great interest to help nations reduce reliance on foreign imports and increase the value of domestic reserves (www.fossil.energy.gov/programs/oilgas/marginalwells/index.html). 
Traditional methods of tertiary oil recovery are costly for widespread use in the oil industry. Recently, some new biotechnologies have been reported. The core of these microbial enhanced oil recovery (MEOR) technologies is to inject inorganic nutrients into an oil and gas well to stimulate some beneficial microorganisms (e.g., denitrifiers) that live in virtually every oil and gas reservoir. These bacteria grow rapidly, outcompeting harmful SRB for basic carbon and nutrients. As SRB are outcompeted, sulfide production is reduced and the by-products produced by the beneficial microorganisms mobilize residual oil trapped within the reservoir. It has been reported that this new technology is capable of significantly enhancing oil production at a reduced cost and prevents the production of poisonous and corrosive hydrogen sulfide in oil and gas reservoirs.

\section{Hypothesis of the Project}

Recently, the EERC developed a sulfide control additive that is capable of selectively killing SRB without adversely affecting other microorganisms. This additive (referred to as "EERC additive") is relatively nontoxic. In the U.S. Environmental Protection Agency's (EPA's) "National Recommended Water Quality Criteria," both "Priority Toxic Pollutants" and "Nonpriority Pollutants" are listed, and none of the EERC additive components is included in either of the lists. It is, therefore, possible to develop a formulation for an additive that may 1) prevent souring of oil, 2) potentially promote methanogens by inhibiting SRB, and 3) enhance total gas (including but not limited to methane) production to improve oil recovery.

Compared to current technologies, it is expected that if an EERC additive formulation is developed, the new formulation would be better than the current commercial ones for the following reasons:

1. Some current technologies only marginally suppress SRB by stimulating denitrification; the EERC additive, however, directly selectively kills SRB.

2. Killing SRB will subsequently promote methanogens because of reduced competition. An increase in methane not only mobilizes residual oil, but also directly increases production of natural gas.

\section{GOALS AND OBJECTIVES}

The goals and objectives of this subtask are to:

1. Test the hypothesis that the EERC additive may prevent souring of crude oil and may, potentially, promote methanogens.

2. Conduct preliminary experiments for future development of an EERC additive formulation that may mitigate hydrogen sulfide, enhance oil recovery, and increase methane production. 


\section{EXPERIMENTAL}

\section{Preliminary Experiment}

A preliminary experiment was undertaken to examine the effects of EERC additive on $\mathrm{H}_{2} \mathrm{~S}$ production. The experiment was conducted with $28-\mathrm{mL}$ anaerobic culture tubes. Since, at that time, a fresh crude oil and formation water sample could not be procured, a wastewater sample collected from a sugar production facility was used for this experiment. Sugar industry wastewater produces a significant amount of $\mathrm{H}_{2} \mathrm{~S}$ because of the presence of S-containing biochemical compounds (e.g., S-containing proteins) in the wastewater. To ensure a measurable effect, $\mathrm{Na}_{2} \mathrm{SO}_{4}$ was added to the wastewater sample at a final concentration of $3 \mathrm{~g} / \mathrm{L}$. The sample was then dispensed into the tubes, and each tube received $20 \mathrm{~mL}$ of the wastewater. EERC additive was then added at a final concentration of 0 (the control group), $0.5,1,2.5$, and $5 \mathrm{mM}$, respectively; each concentration group consisted of three tubes (triplicates). The tubes were then sealed with butyl rubber stoppers and aluminum crimpers and incubated at $30^{\circ} \mathrm{C}$ in the dark for 4 weeks.

After 4 weeks of incubation, headspace gas samples were analyzed for $\mathrm{H}_{2} \mathrm{~S}$. Gas samples from the tubes were analyzed using a gas chromatograph (GC) (Agilent GC 6890) equipped with a thermal conductivity detector (TCD). However, GC analytical results showed that TCD was not sensitive to detect $\mathrm{H}_{2} \mathrm{~S}$ in some samples since the $\mathrm{H}_{2} \mathrm{~S}$ levels in those samples were too low. The $\mathrm{H}_{2} \mathrm{~S}$ in the liquid phase was subsequently measured using a sulfide test kit, Model Kit P-7C, manufactured by LaMotte Company, Chestertown, Maryland. The liquid samples were first filtered through a $0.22-\mu \mathrm{m}$ syringe filter, followed by reacting with the test reagents, and then measuring absorbance at $664 \mathrm{~nm}$ using a Beckman DU 650 spectrophotometer.

The results are plotted in Figure 1. The \% sulfide reduction is calculated as follows:

$$
\% \text { sulfide reduction }=(\text { control }- \text { experimental }) / \text { control } \times 100 \%
$$

The control is the mean of the sulfide concentration in the triplicate 0 -mM samples. As shown in Figure 1, EERC additive effectively reduced $\mathrm{H}_{2} \mathrm{~S}$ production in all the experimental groups. Another experiment was then performed to further decrease the EERC additive concentrations to 0.25 and $0.1 \mathrm{mM}$. The experimental results are plotted in Figure 2. At these two lower concentration levels, EERC additive was still effective, and a $74.8 \%$ and $44.5 \%$ sulfide reduction was achieved, respectively. These results confirmed that EERC additive is able to effectively mitigate sulfide production, and the inhibitory effect is concentration-dependent.

\section{Crude Oil and Formation Water Experiment}

Sour crude oil and formation water samples were collected from the E.L. Gudvangen well, located in the McGregor Field, 4 miles west of the town of McGregor, North Dakota. Sterile (autoclaved) 0.5-gallon mason jars were used as the sample containers. The crude oil and formation water filled to the top of the jars and were sealed with the lids to ensure anaerobic conditions. The samples were then shipped to the EERC and immediately stored in a refrigerator at $4^{\circ} \mathrm{C}$. 


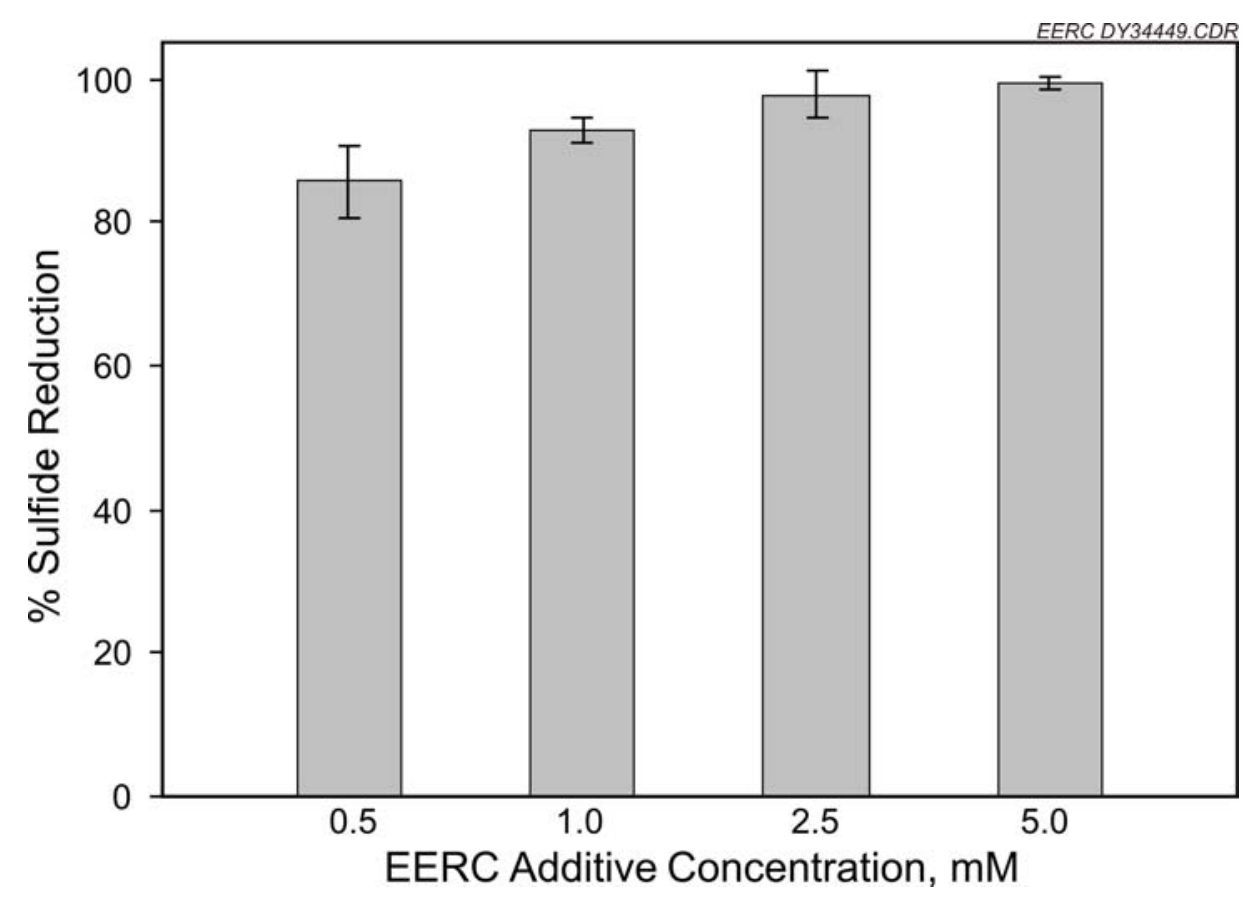

Figure 1. Effects of EERC additive on sulfide concentration (liquid phase) in a sugar industry wastewater (1). Error bars represent standard deviation of triplicate samples.

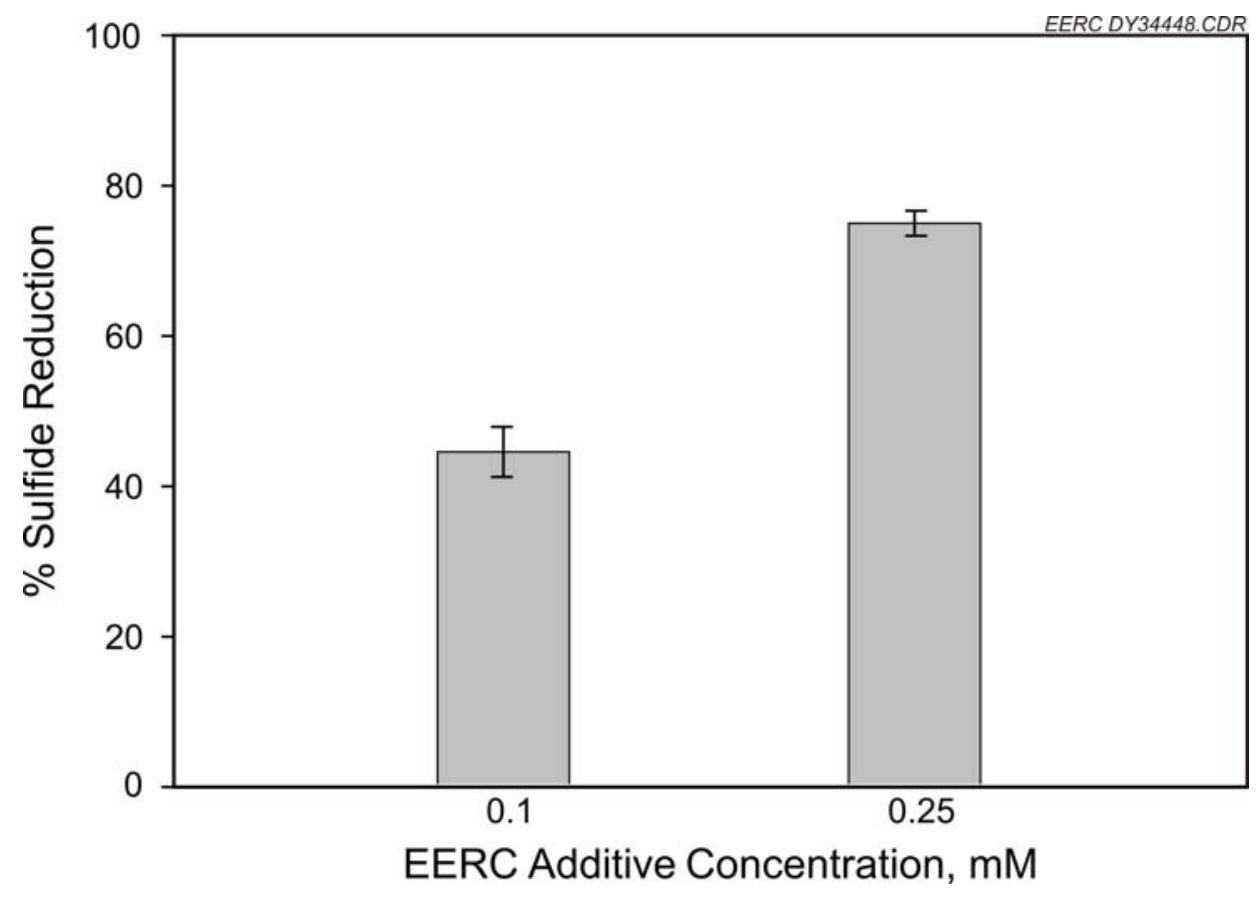

Figure 2. Effects of EERC additive on sulfide concentration (liquid phase) in a sugar industry wastewater (2). Error bars represent standard deviation of triplicate samples. 
Experiments were conducted to determine the optimal concentration of EERC additive for $\mathrm{H}_{2} \mathrm{~S}$ control. The experiments were set up in an anaerobic glove box (Coy Laboratory Products Inc. Grass Lake, Michigan). Serum bottles $(125 \mathrm{~mL})$ were used as the experimental vessels. Since the concentration of EERC additive that would be effective was unknown, once again, the experiments were started with a concentration profile experiment. There were five experimental groups amended with different concentrations of EERC additive: 0 (control), 0.5, 1, 5, and 10 $\mathrm{mM}$, respectively. Each group consisted of three bottles (triplicates), and each bottle received 70 $\mathrm{mL}$ of the oil-water (crude oil and formation water, 1:1) mixture. The bottles were then sealed with butyl stoppers and aluminum crimpers and incubated in the dark at $30^{\circ} \mathrm{C}$.

After 14 weeks of incubation, gas-phase samples from the bottles were analyzed using a GC (Agilent GC 7890) with a flame photometric detector (FPD), a selective detector for sulfur compounds with low detection-level capability and high sensitivity. As illustrated in Figure 3, EERC additive completely prevented $\mathrm{H}_{2} \mathrm{~S}$ production at 5 and $10 \mathrm{mM}$ and significantly reduced $\mathrm{H}_{2} \mathrm{~S}$ at 0.5 and $1 \mathrm{mM}$, suggesting that introducing EERC additive into an oil well could potentially prevent souring of the crude oil.

\section{Effects of EERC additive on Methane Production}

To determine whether EERC additive is capable of promoting methane formation by suppressing SRB, an experiment was conducted with $160-\mathrm{mL}$ serum bottles (Figure 4). Each bottle received $40 \mathrm{~mL}$ of 1:1 oil and formation water mixture, and $40 \mathrm{~mL}$ of anaerobic mineral growth medium containing $2 \mathrm{~g} / \mathrm{L}$ yeast extract (in replacement of vitamins) and methanol, acetate, formate $\left(2 \mathrm{~g} / \mathrm{L}\right.$ of each). The initial headspace gas was $\mathrm{H}_{2} / \mathrm{CO}_{2}(80 / 20)$. EERC additive was added to half of the bottles at a final concentration of $1 \mathrm{mM}$. The bottles were then sealed with butyl stoppers and aluminum crimpers and incubated at $30^{\circ} \mathrm{C}$ in dark. Gas-phase samples were taken and analyzed using GC with a flame ionization detector (FID). After 6 weeks of incubation, methane was detected in a culture with EERC additive, carbon, and $\mathrm{H}_{2} / \mathrm{CO}_{2}$. After another 4 weeks of incubation, methane was detected in several other cultures in the $\mathrm{C}-\mathrm{H}_{2}-$ EERC additive group; in contrast, no methane was detected in the cultures without EERC additive. However, after initial methane formation, the methane production stopped, and no further methane production was detected. We postulate that the methane might be converted from the limited-headspace hydrogen; and there may be lack of microorganisms in the culture that were able to degrade the crude oil to hydrogen or prolonged incubation time may be needed to allow the culture(s) to develop this degradation capability. Nevertheless, these results suggest that EERC additive seemed to have the potential to promote methane formation by suppressing SRB.

\section{Total Gas Production}

Gas production is an important issue in MEOR since the produced gases $\left(\mathrm{N}_{2}, \mathrm{CO}_{2}\right.$, etc.) mobilize residual oil trapped within the reservoir. Currently, MEOR is generally achieved by injecting nutrients and organic carbon into an oil and gas well to stimulate a microbial gas production, and the cost of organic carbon is among the major costs. To develop a potential formulation for MEOR, an experiment was set to determine whether organic carbon is necessary 


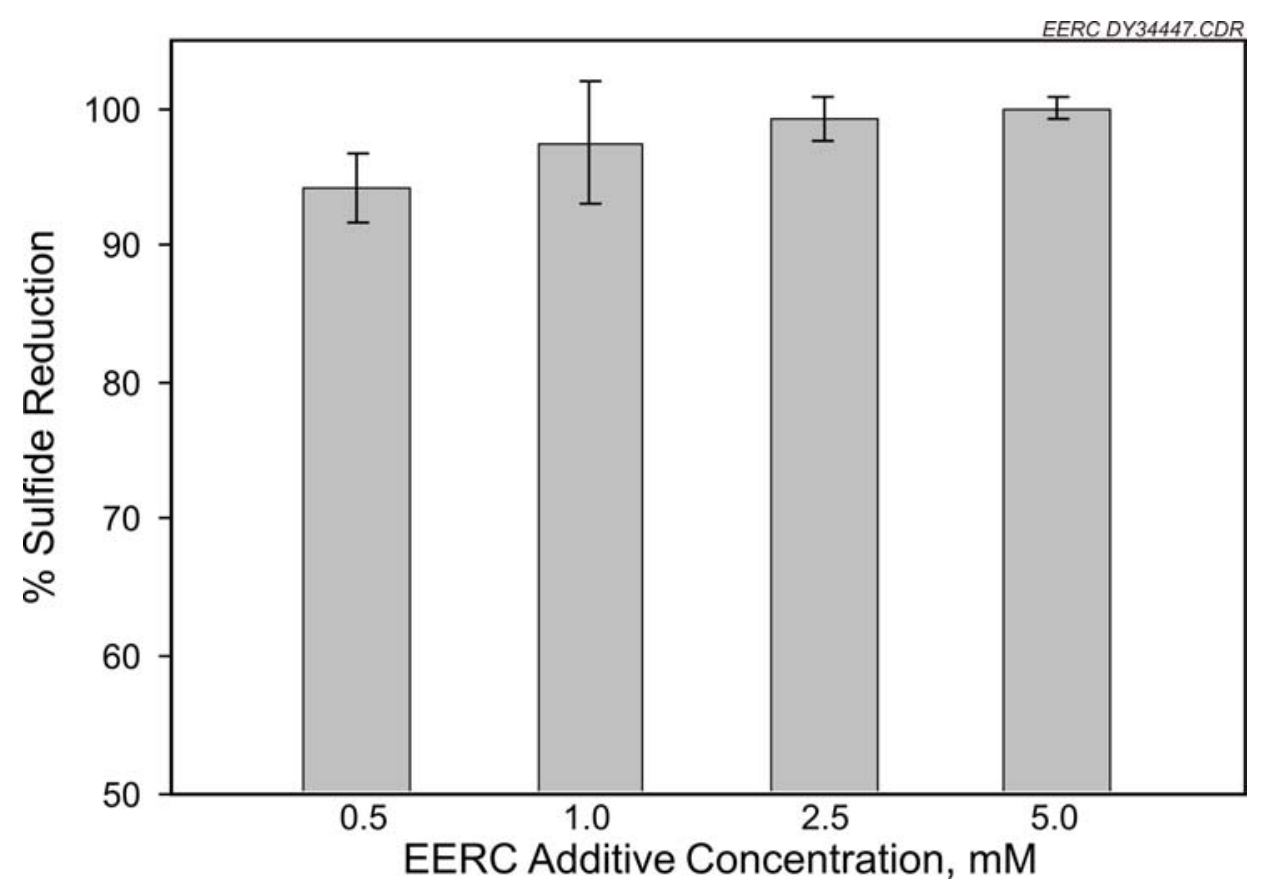

Figure 3. Effects of EERC additive on hydrogen sulfide (gas phase) produced in the oil and formation water experiment. Error bars represent standard deviation of triplicate samples.

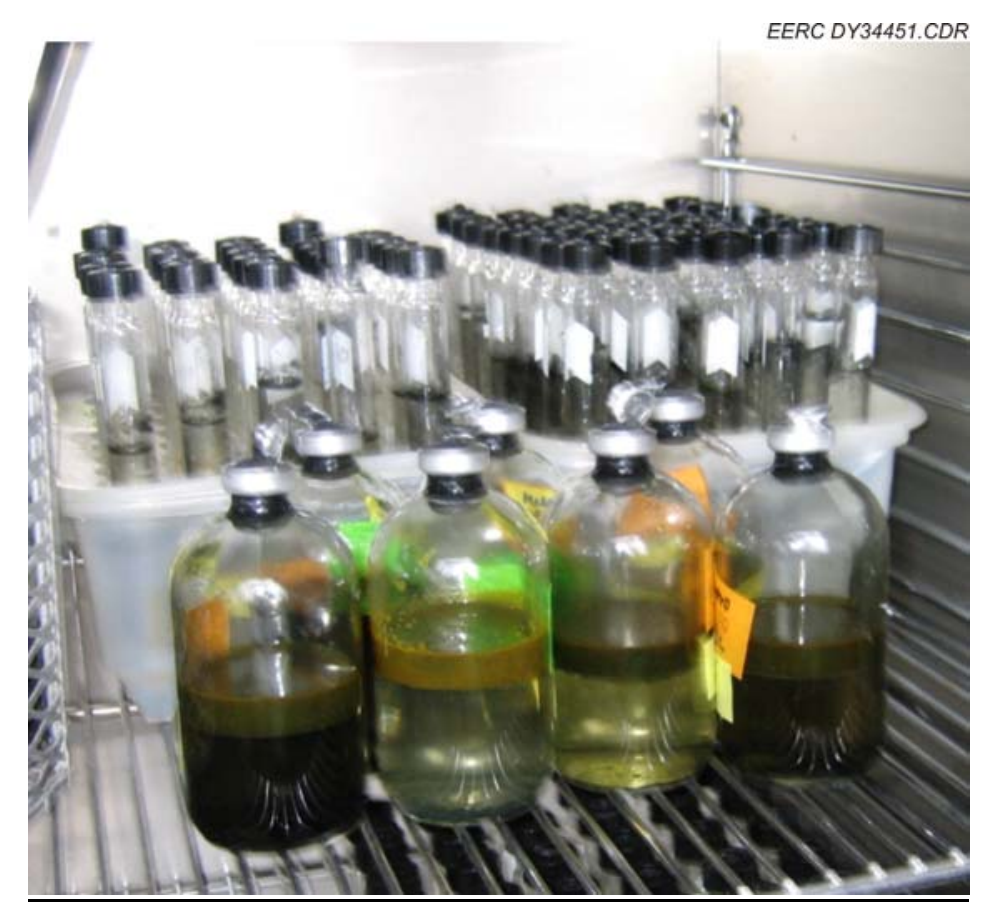

Figure 4. The $160-\mathrm{mL}$ serum bottles as the experimental vessels. The anaerobic tubes in the background were used for MPN enumeration on SRB. 
for gas production. The experiment was set up with $160-\mathrm{mL}$ serum bottles, and all bottles received $40 \mathrm{~mL}$ of the oil, the formation water, or both $(1: 1)$ and $40 \mathrm{~mL}$ of mineral medium containing $2 \mathrm{~g} / \mathrm{L}$ of yeast extract. The initial headspace gas was nitrogen. The bottles were divided into two experimental groups: with and without the addition of the organic carbon (methanol, acetate, formate; $2 \mathrm{~g} / \mathrm{L}$ of each). The bottles were then sealed with butyl stoppers and aluminum crimpers and incubated at $30^{\circ} \mathrm{C}$ in the dark. After 6 weeks of incubation, the total gas produced in each bottle was measured with a 50-mL glass syringe (B.D. Yale, Becton, Dickinson \& Company, New Jersey, Figure 5). The produced gas volume was certainly underestimated since the weight of the syringe plug $(65.8 \mathrm{~g})$ would more or less compress the gases. However, this would not significantly affect the relative comparison of the produced gas volume among these bottles since all bottles were measured in the same way. Regardless of whether the inocula were crude oil, formation water, or a mixture, both "with C" and "without C" groups produced comparable amounts of gases (Figure 6), suggesting that under our experimental conditions the added organic $\mathrm{C}$ played a minimal role in gas production; this observation would have practical application potential to significantly cut some material costs in MEOR.

As shown in Figure 6, there was little difference in total gas production between the "crude oil" and "crude oil + formation water" groups. The "formation water" group, in contrast, produced less than $1 / 4$ volume of the gas, indicating that the fermentative microorganisms in our sample were mainly present in the crude oil rather than the formation water.

\section{MPN Results}

The MPN number of SRB in the original 1:1 oil-water mixture was enumerated and the result was $2.3 \times 10^{2} \mathrm{MPN} / \mathrm{mL}$. After 2 months of incubation at $30^{\circ} \mathrm{C}$ with the mineral medium, yeast extract, organic carbon, and headspace hydrogen, the MPN of the culture without EERC additive amendment was $9.6 \times 10^{5} / \mathrm{mL}$, while the MPN of the culture amended with $1 \mathrm{mM}$ EERC additive was $5.1 \times 10^{3} / \mathrm{mL}$. The results of the SRB MPN determinations are listed in Table 1 . These results provide direct evidence that EERC additive effectively reduced the SRB number in the amended culture.

\section{CONCLUSIONS}

Experimental results of this project proved that under our experimental conditions, EERC additive was able to mitigate $\mathrm{H}_{2} \mathrm{~S}$ production in the oil-water mixture, suggesting that introducing EERC additive into an oil well may potentially prevent souring the crude oil. The MPN results further provided direct evidence that EERC additive effectively reduced the

Table 1. Results of SRB MPN Determinations

\begin{tabular}{lcc}
\hline Experimental Group & MPN/mL & SRB Reduction \\
\hline Original 1:1 Oil-Water Mixture & $2.3 \times 10^{2}$ & \\
After 2 Months at $30^{\circ} \mathrm{C}$ & & \\
Without EERC Additive & $9.6 \times 10^{5}$ & \\
With EERC Additive & $5.1 \times 10^{3}$ & $99.4 \%$ \\
\hline
\end{tabular}




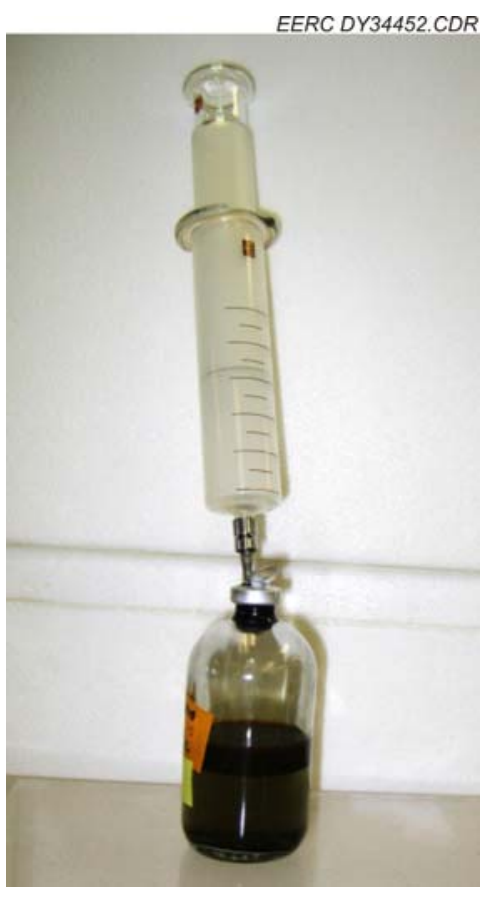

Figure 5. The total gas produced in each bottle was measured with a 50-mL glass syringe.

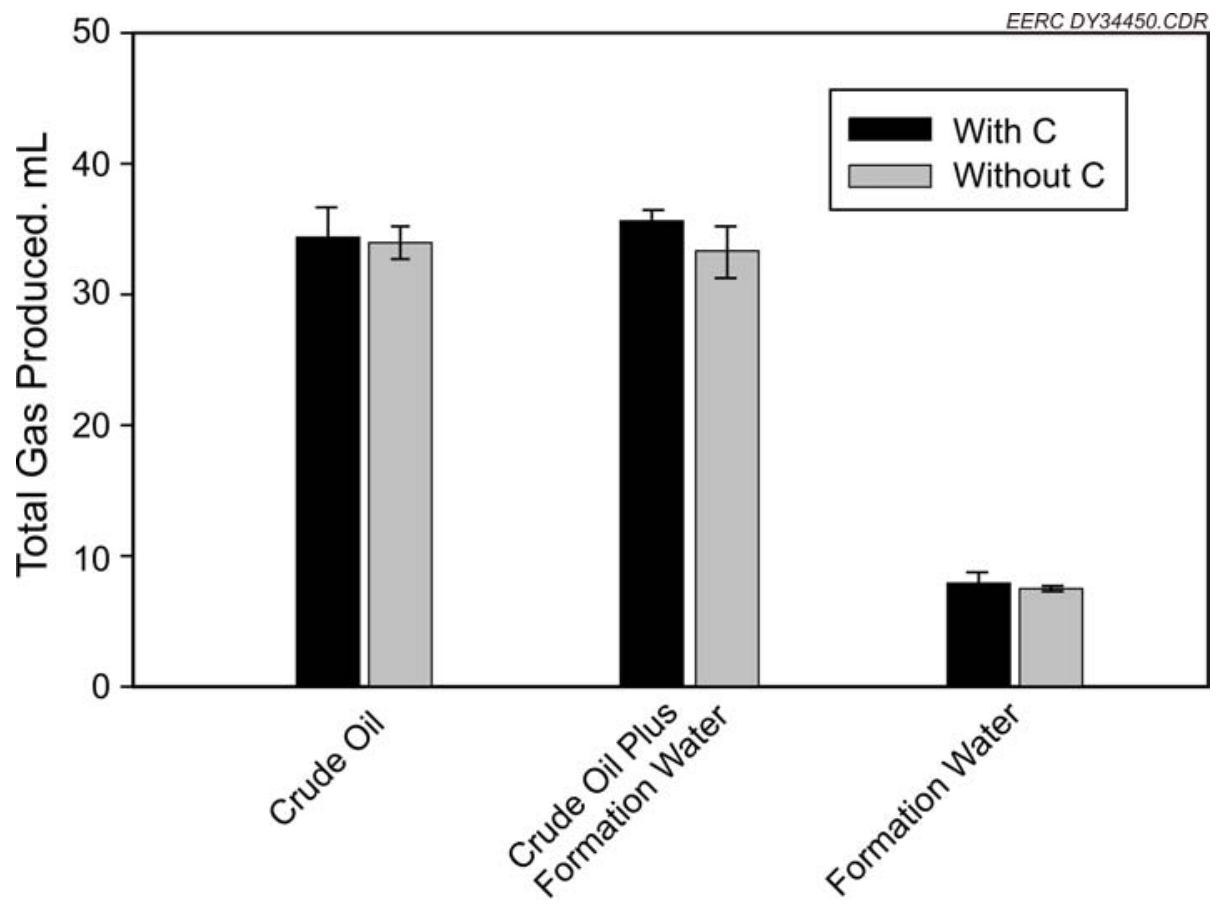

Figure 6. Results of the total gas measurement. Error bars represent standard deviation of triplicate samples 
population of SRB in the amended cultures. Analysis of methane production suggested that EERC additive might have the potential to promote $\mathrm{H}_{2}$-utilizing methanogens by inhibiting SRB. Measurement of the total gas production revealed that under our experimental conditions, the added organic $\mathrm{C}$ played no apparent role in gas production; this observation would have practical application potential to significantly cut some material costs in MEOR. Results of the gas production experiment also indicated that the fermentative microorganisms in our sample were mainly present in the crude oil rather than the formation water.

\section{ACKNOWLEDGMENTS}

This work was supported by the U.S. Department of Energy (under Subtask 7.1 - Strategic Studies; Cooperative Agreement No. DE-FC26-98FT40320, Fund 9065; and the author appreciates this support.

\section{BIBLIOGRAPHY}

Aitken, C.M.; Jones, D.M.; Larter, S.R. Anaerobic Hydrocarbon 8 Biodegradation in Deep Subsurface Oil Reservoirs. Nature 2004, 341, 291-294.

Bryant, R.S.; Lindsey, R.P. Worldwide Applications of Microbial Technology for Improving Oil Recovery. Presented at the SPE/DOE Improved Oil Recovery Symposium, Tulsa, OK, April 21-24, 1996; SPE Paper 35356.

Bryant, R.S.; Burchfield, T.E. Review of Microbial Technology for Improving Oil Recovery. SPE Reservoir Eng. (Society of Petroleum Engineers) 1989, 4 (2), 151-154.

Clesceri, L.S.; Greenberg, A.E.; Eaton. A.D. Standard Methods for the Examination of Water and Wastewater, 20th Edition; American Public Health Association: Washington, DC, 1998.

Gieg, L.M.; Duncan, K.E.; Suflita, J.M. Bioenergy Production via Microbial Conversion of Residual Oil to Natural Gas. Appl. Environ. Microbiol. 2008, 74 (10), 3022-9.

Kleikemper, J.; Pombo, S.A.; Schroth, M.H.; Sigler, W.V.; PEERC additivero, M.; Zeyer, J. Activity and Diversity of Methanogens in a Petroleum Hydrocarbon-Contaminated Aquifer. Appl. Environ. Microbiol. 71 (1), 149-58.

Kowalewski, E.; Rueslatten, I.; Gilje, E.; Sunde, E., Bødtker, G., Lillebø, L.P.; Torsvik, T.; Strand, K.A. Interpretation of Microbial Oil Recovery from Laboratory Experiments. In 13th European Symposium on Improved Oil Recovery; Budapest, Hungary, April 25-27, 2005.

Head, I.M.; Jones, D.M.; Larter, S.R. Biological Activity in the Deep Subsurface and the Origin of Heavy Oil. Nature 2003, 426, 344-352. 
Jones, D.M.; Head, I.M.; Gray, N.D.; Adams, J.J.; Rowan, A.K.; Aitken, C.M.; Bennett, B.; Huang, H.; Brown, A.; Bowler, B.F.; Oldenburg, T.; Erdmann, M.; Larter, S.R. Crude-Oil Biodegradation via Methanogenesis in Subsurface Petroleum Reservoirs. Nature 2008, 10; 451 (7175), 176-80.

Lee, D. Microbiology in the Oil Patch: A Review. In 47th Annual Technical Meeting of the Petroleum Society; The Petroleum Society, Calgary, AB, June 10-12, 1996; pp 96-109.

Maudgalya, S.; Knapp, R.M.; McInerney, M.J. Microbial Enhanced Oil Recovery Technologies: A Review of the Past, Present, and Future. In Proceedings of the SPE Production and Operations Symposium; 2007; pp 524-534.

Ollivier, B.; Magot, M., Eds. Petroleum Microbiology; ASM Press: Washington, DC, 2005.

Rauf, M.A.; Ikram, M.; Tabassum, N. Enhanced Oil Recovery Through Microbial Treatment. J. Trace Microprobe Techniques 2003, 21 (3), 533-541.

Taylor, B.F.; Oremland, R.S. Depletion of Adenosine Triphosphate in Desulfovibrio by Oxyanions of Group VI Elements. Current Microbiol. 1979, 3, 101-103.

Zengler, K.; Richnow, H.H.; Rossello-Mora, R.; Michaelis, W.; Widdel, F. Methane Formation from Long-Chain Alkanes by Anaerobic Microorganisms. Nature 1999, 401, 266-269. 


\title{
APPENDIX D
}

\author{
FINAL REPORT FOR RESEARCH PROJECT \\ ENTITLED ENGINEERING OPPORTUNITIES \\ AND CHALLENGES OF $\mathrm{CO}_{2}$ MITIGATION USING \\ MICROALGAE IN FOSSIL FUEL-FIRED POWER \\ PLANTS
}




\title{
ENGINEERING OPPORTUNITIES AND CHALLENGES OF $\mathrm{CO}_{2}$ MITIGATION USING MICROALGAE FROM FOSSIL FUEL POWER PLANTS
}

\author{
Ye Zhuang and Dennis Laudal \\ Energy \& Environmental Research Center
}

\subsection{BACKGROUND}

Public concerns over global climate change due to anthropogenic emissions of greenhouse gases such as $\mathrm{CO}_{2}$ has resulted in significant pressure on all industries to seek effective ways to reduce $\mathrm{CO}_{2}$ emissions. Because coal-fired electric utilities are one of the largest sources of $\mathrm{CO}_{2}$ emissions, the pressure has been more intense. All fossil fuels originate from biomass produced by photosynthetic fixation of $\mathrm{CO}_{2}$, the process which green plants produce sugar from sunlight, $\mathrm{CO}_{2}$, and water, with oxygen as a waste product. Photosynthesis is essentially nature's way of recycling $\mathrm{CO}_{2}$. However, the process of indirect $\mathrm{CO}_{2}$ capture by planting forests and other agricultural crops has been deemed to be an inadequate solution to the accumulation of greenhouse gases in our atmosphere. The potential $\mathrm{CO}_{2}$ capture by planting agricultural crops is expected to result in only a $3 \%-6 \%$ reduction compared to the $\mathrm{CO}_{2}$ generated burning fossil fuels (1). The one possible exception is to utilize microalgae for the direct treatment of flue gas. Microalgae have the ability to fix $\mathrm{CO}_{2}$ using solar energy, with an efficiency 10 times greater than that of terrestrial plants (2). In addition it grows rapidly and can be incorporated into engineered systems, such as photobioreactors. It has been found that the high $\mathrm{CO}_{2}$ content of power plant flue gas, $\sim 14 \%$ compared to only $350 \mathrm{ppm}$ in the atmosphere, greatly enhanced algae growth (3). It is estimated that algae produce between $73 \%$ and $87 \%$ of the net global production of oxygen (4).

Algae cultivation has been done since the early 1970s for the production of biofuels and is considered an environmentally friendly process. Essentially the only components needed to grow algae are sunlight, $\mathrm{CO}_{2}$, nitrates, and water. Even the water can be low quality, including most wastewaters and saline water. Although the maximum oil content of microalgae is only about $40 \%$ compared to $55 \%$ for sunflower seeds, microalgae's very high growth rate and photosynthetic efficiency mean it has the potential to sequester substantially more $\mathrm{CO}_{2}$ and produce a lot more biofuel than any other crop. Table 1 shows the typical yields of biodiesel for various crops. Algae are the only biofeedstock that can theoretically replace all our current and future petrofuel needs and do not compete with agriculture food products.

The growth in the number of companies directly involved in producing biofuel from algae is quite impressive, as shown in Table 2. The most prominent companies are listed below:

- Aquaflow Bionomic

- Cellana

- GreenFuel

- OriginOil
- PetroAlgae

- PetroSun

- Sapphire Energy
- Seambiotic

- Solazyme

- Valcent 


\begin{tabular}{lc}
$\begin{array}{l}\text { Table 1. Oil Production Potential for } \\
\text { Various Crops (4) }\end{array}$ \\
\hline Crop & Biodiesel, gallon/acre \\
\hline Algae & $1600-8550$ \\
Corn & 13 \\
Soy & 47 \\
Safflower & 83 \\
Sunflower & $80-100$ \\
Castor & 150 \\
Canola & 171 \\
Jojoba & 192 \\
Coconut & 290 \\
Palm & 640 \\
Chinese Tallow & $500-1000$ \\
Peanut & 90 \\
\hline
\end{tabular}

Table 2. Number of Companies Directly Involved in Producing Fuels from Algae (4)

\begin{tabular}{lc}
\hline Year & No. of Companies \\
\hline 2001 & 1 \\
2002 & 2 \\
2003 & 4 \\
2004 & 5 \\
2005 & 10 \\
2006 & 15 \\
2007 & 25 \\
2008 & 50 \\
\hline
\end{tabular}

A discussion of the status of each of these companies is provided in the Oilgae Digest (3).

This report will focus on the status and research needs for using microalgae for sequestering $\mathrm{CO}_{2}$, in particular from fossil fuel-fired power plants and areas that the Energy \& Environmental Research Center (EERC) strengths would be beneficial in solving some of the issues that currently limit the technology.

\subsection{CURRENT RESEARCH STATUS}

Algae farms have been cultivated for many years to produced high-value products such as biofuels, vitamins, cosmetics, and food. Although there has been some effort to intentionally use microalgae to capture $\mathrm{CO}_{2}$ from point sources, most of the research and development has been to produce fuel products. However, beginning in the late 1990s, the potential of a carbonconstrained world has resulted in a renewed interest by select companies, universities, research 
organizations, and the federal government both in the United States and other countries to optimize the ability of microalgae to sequester $\mathrm{CO}_{2}$ from point sources. Some of the challenges and research needs are discussed in this section.

\subsection{Microalgae Cultivation}

The major challenge to industrial microalgae culturing is to devise and develop new procedures for cultivation and the finding of algal strains that have substantially improved solar efficiencies and are better able to utilize $\mathrm{CO}_{2}$. Much of the early work was primarily to identify strains of microalgae that produced high yields of lipids for biofuel production. The most tested strains of microalgae are from species Chlorella, Chlorophyta, and Botryococcus. Substantial work is still ongoing to identify new strains that may offer greater $\mathrm{CO}_{2}$ uptake and higher yields of lipids (5). This includes the testing of both natural and genetically modified strains.

\subsubsection{Open Pond Systems}

Algae are grown either in open pond cultivation systems or closed systems (photobioreactors). Large-scale microalgae cultivation using open pond systems have been in use for some time (6) to produce healthy foodstuffs, food additives, pigments, secondary metabolites, alternative fuel, and in wastewater treatment (7-9). The conventional method for the mass algae cultivation using open ponds is a raceway design, using sun as the light source. Such a system is shown in Figure 1. Open ponds usually consist of either circular ponds with a rotating arm to mix the culture or long channels in a single- or multiple-loop configuration stirred by paddle wheels. The primary advantage of open pond systems is that they are relatively simple to design and only require what nature provides (direct sunlight). However, such an approach suffers from a number of disadvantages, particularly as they relate to treating flue gas from large power plants.

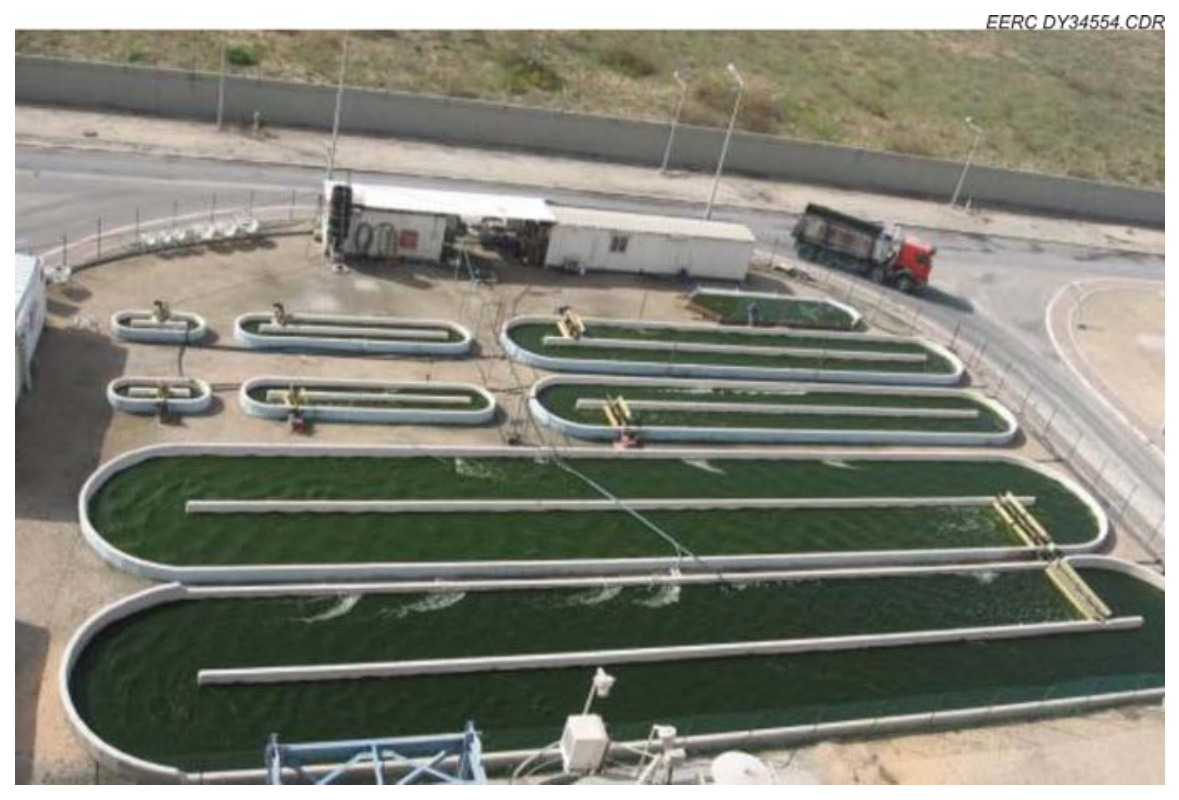

Figure 1. Photograph of Seambiotic small-scale open pond. 


\subsubsection{Low Efficiency in Light Utilization}

Light in the wavelength of 400-700 $\mathrm{nm}$ is the basic energy source for algae growth; hence, light-harvesting efficiency of algae is of critical importance. The penetration distance of light into algal culture is usually less than $10 \mathrm{~cm}$, depending on algal density. As a result, over $60 \%$ of algal culture remains in complete darkness (10), which is the primary reason algal production in open pond systems is far below the theoretical algal productivity (11).

\subsubsection{Requirement of Large Land Areas and Huge Loss of Culture Medium}

As the result of low algae yield and huge volumes of flue gas that need to be treated, enormous land areas are required for open pond systems to capture $\mathrm{CO}_{2}$ effectively from power plants. For example, it is estimated that a 500-MW power plant will need 8000-16,000 acres of algae ponds. Open algal systems usually perform at their best under high sun irradiation conditions. However, this also results in huge loss of culture medium (water) through evaporation. Using methods recommended by the U.S. Environmental Protection Agency (EPA), it is estimated that approximately 1200 tons of water would evaporate per 1000 acres per day $(12,13)$, resulting in the need for large volumes of makeup water.

\subsubsection{Contamination Control}

It is almost impossible to keep the culture environment constant and prevent crosscontamination in an open pond system. Many contaminants from the surrounding environment may enter the algae system and affect algae growth. This includes wild algae strains, bacteria, and other inorganic and organic contaminants.

\subsubsection{High Harvest Cost}

Because of low algal cell density requiring large areas, a huge volume of algal cultures need to be harvested. This greatly magnifies the cost of processing, thus substantially increasing the final cost of the product.

\subsubsection{Closed Systems (photobioreactors)}

As a result of these disadvantages, closed systems (photobioreactors) would most likely be used for larger-scale activities that would be needed to treat flue gas from power plants. Compared to open systems, control of contamination is easier and they provide more accurate control of operational parameters including culture $\mathrm{pH}$, nutrients, temperature, and light irradiation. As a result, closed systems have a much greater potential for improved algae yield. High cell mass productivities attained in a closed system are up to three-fold greater than those obtained in an open system (14). In theory, harvesting of the algae should also be simpler, significantly reducing harvest costs.

Because of their complexity and the intensive capital investment required, closed systems have not been favored by the industry. To become profitable and fully competitive, the challenge is to design a closed system that produces a high concentration of biomass with high metabolite productivity. In this way, the higher capital cost of a closed system can be offset by substantially 
lower operating costs compared to open ponds. The use of larger-scale photobioreactors is still in its infancy, and substantial effort is going into designing novel photobioreactors that are less costly and more efficient (15-17). In order to maximize advantages and minimize disadvantages, several key processing parameters need to be optimized.

\subsubsection{Reactor Design}

A reactor with high area-to-volume ratio is needed to improve light penetration to increase photosynthetic efficiency. Some of the reactors that are designed to increase area-to-volume ratio include are tubular, flat plate, pyramid, and fermenter systems. Figure 2 is a photograph of a small pilot tubular photobioreactor. Tubular and flat plate reactors are the most popular choices since they use free sunlight, while the other two use artificial illumination. However, artificial illumination provides more accurate control. Scale-up of these systems is challenging (18). For example, in order to provide enough culture volume and improve the gas transfer rate, the reactor diameter needs to be large which, in turn, decreases the area-to-volume ratio and, consequently, constrains photosynthetic efficiency. Temperature control in a large-scale application is problematic since algae cultivation generates a considerable amount of heat. There is a decrease in photosynthetic efficiency with increases in temperature. Also, depending on the materials of construction and the configuration of the reactor, the cost of the reactor can be high and large area lands would still be needed.

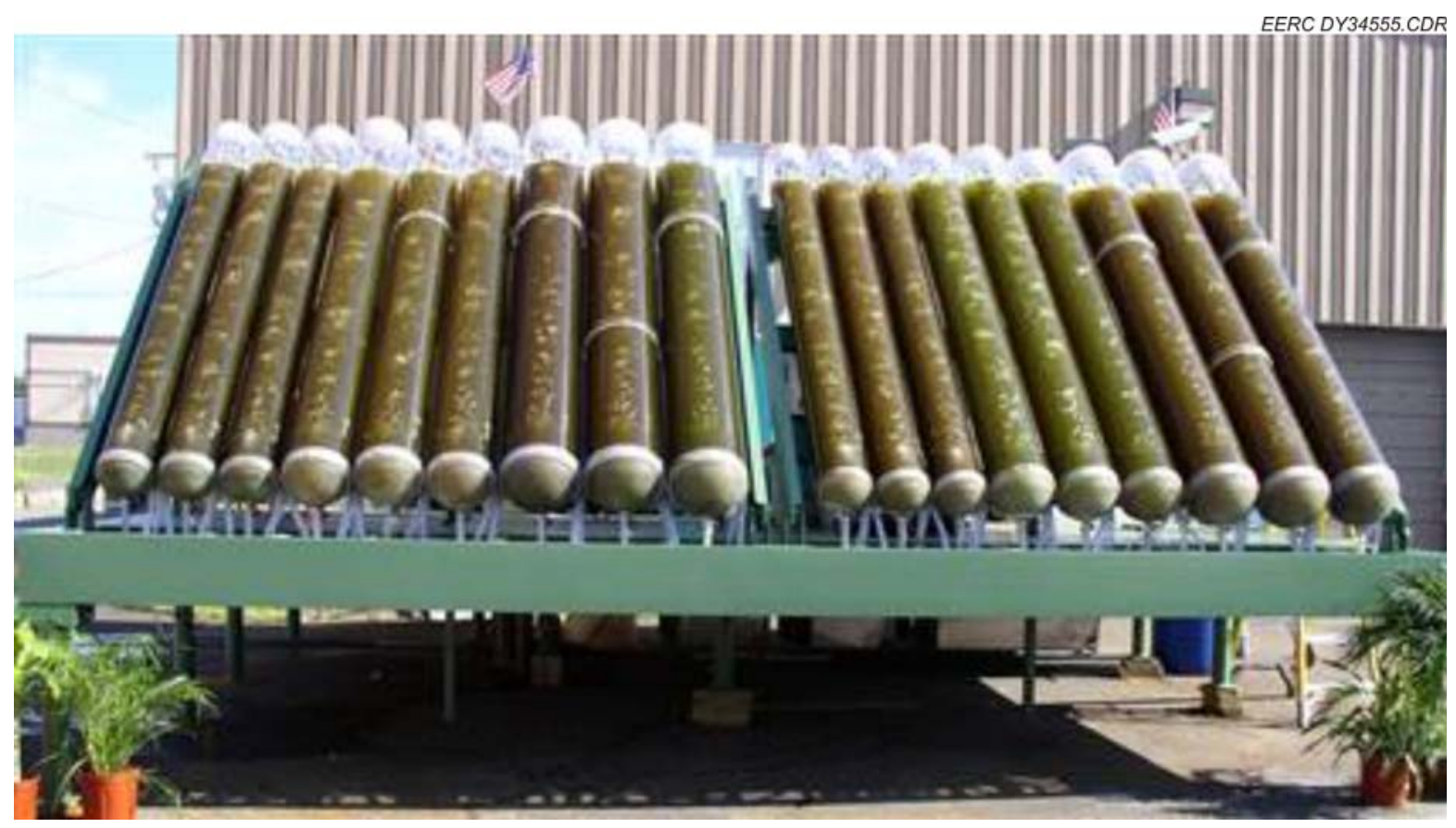

Figure 2. GreenField pilot-scale tubular photobioreactor. 


\subsubsection{2 $\mathrm{CO}_{2}$ Transfer}

When $\mathrm{CO}_{2}$ is injected into a culture, a concentration gradient builds up as it is consumed by cells. Mass transfer of $\mathrm{CO}_{2}$ from the gas phase to the cell phase occurs through sequential stages, with the liquid film providing most of the resistance. Consequently, the liquid film

resistance adjacent to the interface limits the rate of $\mathrm{CO}_{2}$ transfer to the cells (19). The rate of mass transfer of $\mathrm{CO}_{2}\left(\mathrm{~N}_{\mathrm{CO}_{2}}\right)$ is given by:

$$
N_{\mathrm{CO}_{2}}=k_{L} \cdot a \cdot\left(\mathrm{C}_{\mathrm{CO}_{2} L^{*}}-C_{\mathrm{CO}_{2} L}\right)
$$

Where:

$k_{L} \quad=$ liquid-phase mass transfer coefficient.

$a=$ the specific area available for mass transfer.

$\mathrm{CCO}_{2 L^{*}}=$ the concentration of $\mathrm{CO}_{2}$ in the culture medium that would equilibrate its actual partial pressure on the gas side.

$\mathrm{CCO}_{2} \mathrm{~L}=$ the concentration of $\mathrm{CO}_{2}$ in the bulk of culture medium.

The lumped parameter $k_{\mathrm{L}} a$ characterizes the $\mathrm{CO}_{2}$ mass transfer capability of the reactor and is of primary importance in the design, scale-up, and operation of a biomass culture system (20). One example is that comparative studies $(21,22)$ have indicated that microporous hollow fibers instead of plain bubbling enhance $\mathrm{CO}_{2}$ mass transfer. Both passive and active modes have been devised and tested to improve transfer of $\mathrm{CO}_{2}$ through the interface between the gaseous mixture and the liquid medium culture. Passive gas-to-liquid transfer through a membrane in close algal systems can prevent $\mathrm{CO}_{2}$ loss to the atmosphere, provide accurate control of the $\mathrm{CO}_{2}$ transfer rate, and does not require an air/ $\mathrm{CO}_{2}$ mixing chamber. However, passive systems have a high capital investment and suffer from decreasing transfer rate with time as a result of bacterial contamination. Active aeration, on the other hand, is easy to apply in a large-scale system but has to be cleaned periodically because of biofouling and suffers $\mathrm{CO}_{2}$ loss to the atmosphere as a result of the low residence times of the gas in the culture.

\subsubsection{Oxygen Removal}

Oxygen build-up in the medium results in a decrease in the photosynthetic efficiency of the microalgae (16). Also, once dissolved $\mathrm{O}_{2}$ in the liquid culture medium gets above $35 \mathrm{mg} / \mathrm{L}$, it is toxic to most algae. Accumulation of $\mathrm{O}_{2}$ in the liquid culture medium has been one of the most difficult problems to overcome (17) and has been the subject of much research in designing photobioreactors. While different degassing technologies have been tested, the oxygen removal efficiencies from microalgal cultures are still not at a satisfactory level to make the operation profitable. Also a low-cost method to collect oxygen is an essential aspect of many of the scenarios proposed for power plant flue gas treatment. The idea is that the generated oxygen would be pumped back to the combustor, resulting in a more purified $\mathrm{CO}_{2}$ stream to algae. 


\subsubsection{Mixing}

Adequate mixing is required in order to produce a uniform dispersion of microalgae within the culture medium, thus eliminating gradients of light, nutrient concentration (including $\mathrm{CO}_{2}$ ), and temperature. However, current mixing techniques are often insufficient since the induced turbulence is random, i.e., not all algae cells are in and out of the illuminated area of the reactor as planned. Low-extent mixing can promote settling and, hence, emergence of dead zones where anaerobic conditions prevail, thus leading to cell deterioration and a consequent decrease in productivity $(23,24)$. Inadequate mixing also permits clumping of cells into aggregates of varying sizes, which is prone to decreasing mass-transfer rates (25). On the other hand, high mixing rates may lead to shear induced injury of cells $(26,27)$, which hampers their viability. As distinct microalgae have different sensitivities to shear, there is no single optimum mixing system for all microalgal species.

\subsubsection{Light Management}

The algal biofixation rate of $\mathrm{CO}_{2}$ is related directly to light utilization efficiency and to cell density of the microalgae; therefore, optimized light management is crucial in maximizing algae yield in a closed system. The use of sunlight is the cheapest source, but the light cycle cannot be controlled, often precluding high biomass productivity. On the other hand, artificially illuminated reactors are typically expensive. To date, reactors that have shown the highest efficiency of light harvest are also the most expensive and most difficult to scale up. One technology that has shown promise is the use of fiber optic-based solar concentrators. These can effectively introduce light inside large-volume reactors, but it has been difficult to achieve a uniform lighting distribution within the photobioreactor.

Table 3 shows a comparison of the open ponds and the closed bioreactors. As can be seen from Table 3, the greatest advantage of open ponds is lower cost. The greatest advantage of the closed system is contamination control and greater productivity. Clearly, additional research and development are needed.

\subsection{Power Plant Flue Gas and Microalgal Growth}

The direct use of flue gas imposes extreme conditions on algae such as high temperature, high $\mathrm{CO}_{2}$ concentration, and the presence of acid gases $\mathrm{SO}_{\mathrm{x}}, \mathrm{NO}_{\mathrm{x}}$, and $\mathrm{HCl}$. Extensive efforts have been made to evaluate the inhabitation effect of acid gases of $\mathrm{SO}_{2}$ and $\mathrm{NO}_{\mathrm{x}}$ on the growth of algal strains. Some acidophilic algal strains have shown positive growth when aerated with simulated flue gas containing up to $50 \mathrm{ppm} \mathrm{SO} \mathrm{S}_{2}$ and $100 \mathrm{ppm} \mathrm{NO}$ (28-30). A number of benchscale investigations have been conducted to characterize the growth rate of microalgae under simulated coal flue gas conditions (31-36). Table 4 lists examples of bench-scale results that show positive growth of microalgae exposed to a variety of conditions. 
Table 3. Various Parameters Showing the Relativity of Open Ponds vs. Closed Bioreactors ${ }^{1}$

\begin{tabular}{llc}
\hline Parameter & Relative & Notes \\
\hline Capital/Operating Costs & Ponds $<<$ PBRs $^{2}$ & $3-10 \times$ lower cost! \\
Process Control & Ponds $<$ PBRs & Very important in PBRs \\
$\mathrm{O}_{2}$ Inhibition & Ponds $<$ PBRs & $\mathrm{O}_{2}$ greater problem in PBRs \\
$\mathrm{CO}_{2}$ Losses & Ponds $\sim$ PBRs & Depends on pH, alkalinity, etc. \\
Water Losses & Ponds $\sim$ PBRs & Depends upon cooling design \\
Contamination Risk & Ponds $>$ PBRs & Much reduced for PBRs \\
Space Required & Ponds $>$ PBRs & A matter of productivity \\
Productivity & Ponds $<$ PBRs & 3-5 times more productive \\
Biomass Concentration & Ponds $<$ PBRs & $3-5$ times in PBRs \\
\hline${ }^{1}$ Source: National Renewable Energy Laboratory. & \\
${ }^{2}$ Photo bio-reactors. & &
\end{tabular}

Table 4. Effect of Simulated Flue Gas on Microalgae Growth

\begin{tabular}{lcccccccc}
\hline Algae & $\begin{array}{c}\text { Temp., } \\
{ }^{\circ} \mathrm{C}\end{array}$ & $\begin{array}{c}\mathrm{CO}_{2}, \\
\%\end{array}$ & $\begin{array}{c}\mathrm{SO}_{2}, \\
\mathrm{ppm}\end{array}$ & $\begin{array}{c}\mathrm{NO}_{\mathrm{x}}, \\
\mathrm{ppm}\end{array}$ & $\mathrm{pH}$ & $\begin{array}{c}\text { Light Intensity, } \\
\mu \mathrm{E} / \mathrm{m}^{2} / \mathrm{sec}\end{array}$ & $\begin{array}{c}\text { Growth } \\
\mathrm{R} / \mathrm{m}^{3} / \mathrm{day}\end{array}$ & Ref. \\
\hline Chlorella sp. T-1 & 35 & $10-15$ & $5-20$ & $15-60$ & $6-8$ & 110 & $\sim 360$ & 31 \\
Chlorella vulgaris P-12 & 25 & $8-10$ & 2 & 143 & $\mathrm{NA}$ & 1150 & $\sim 2500$ & 33 \\
Chlorella sp. & 26 & $2-15$ & $\mathrm{NA}$ & $\mathrm{NA}$ & $\mathrm{NA}$ & 300 & $127-605$ & 34 \\
Chlorella KR-1 & 25 & $10-15$ & $\sim 50$ & $\sim 100$ & 6.5 & 450 & 800 & 35 \\
Chlorophyta & 25 & 5 & $\sim 300$ & $\sim 300$ & 7.5 & Sunlight & 374 & 36 \\
\hline
\end{tabular}

Limited pilot-scale studies have also been conducted to investigate the feasibility of $\mathrm{CO}_{2}$ mitigation from power plant flue gas using algae. An example has been the development of a pilot-scale membrane photosynthetic reactor using thermophilic organisms. This type of reactor would be much smaller than those currently being proposed and tested (37). Positive growth of microalgae has been reported when a real flue gas from a pilot slipstream at $48^{\circ} \mathrm{C}$ was passed through a low-light-intensity $\left(40-80 \mu \mathrm{E} / \mathrm{m}^{2}\right.$-s) photobioreactor. Pilot-scale testing data (36) also have indicated that $\mathrm{CO}_{2}$ captured by microalgae was directly dependent on the $\mathrm{pH}$ of the culture but was greatly impacted by differences in gas composition. In fact, it was found that maintaining a constant $\mathrm{pH}$ value of 7.5 in algae culture, approximately $75 \% \mathrm{CO}_{2}$ capture efficiency was achieved in a flue gas containing up to $300 \mathrm{ppm} \mathrm{SO}_{2}$ and $\mathrm{NO}_{\mathrm{x}}$, respectively.

Although the tolerances for various components in flue gas will be dependent on the strains of microalgae selected, based on bench- and pilot-scale tests, Table 5 presents an estimate of the most likely limits. Temperature may be the most difficult constraint. A typical flue gas from a wet flue gas desulfurization (FGD) system is about $60^{\circ} \mathrm{C}$, which is too high for most known algal strains and, therefore, some form of cooling will be necessary, resulting in higher costs. The $\mathrm{SO}_{2}$ and $\mathrm{NO}_{\mathrm{x}}$ constraints should not be that difficult to overcome. With the implementation of the Clean Air Act, most utility plants are being required to greatly reduce both gases to levels below those listed in Table 5 . 


$\begin{aligned} & \text { Table 5. Estimated Operational } \\
& \text { Upper Limits of Algal/Power } \\
& \text { Plant System }\end{aligned}$
\begin{tabular}{lc}
\hline Parameter & Value \\
\hline Temperature, ${ }^{\circ} \mathrm{C}$ & 45 \\
$\mathrm{CO}_{2}, \%$ & 50 \\
$\mathrm{SO}_{2}, \mathrm{ppm}$ & 300 \\
$\mathrm{NO}_{\mathrm{x}}, \mathrm{ppm}$ & 300 \\
Dissolved $\mathrm{O}_{2}, \mathrm{mg} / \mathrm{L}$ & 35 \\
$\mathrm{pH}$ & $6-8$ \\
\hline
\end{tabular}

Therefore, the emitted flue gas may only need limited or potentially no additional treatment for these components. In fact, $\mathrm{NO}_{\mathrm{x}}$ is a required nutrient for microalgae, and it may be possible that a high level of $\mathrm{NO}_{\mathrm{x}}$ control such as that provided by an expensive selective catalytic reactor (SCR) may not be necessary or desired. It may be possible that simply installing low- $\mathrm{NO}_{\mathrm{x}}$ burners that are already common on most coal-fired utilities in the United States may be adequate.

\subsection{Harvesting Algae}

Compared to most other energy crops, harvesting algae presents unique problems that are a significant challenge to economical energy production from algae:

- The medium in which algae grows is different - other oilseeds are land crops, while algae grow in water.

- Microalgae's physical characteristics are significantly different from those of the primary oilseeds, the main difference being the size.

- Algae is harvested almost every day, for most, part, or all through the year, whereas harvesting for most oilseeds is quite seasonal in nature.

Owing to these reasons, harvesting algae, especially microalgae, could be a fairly expensive process. Methods that could potentially be used for harvesting include the following:

- Filtration - mechanical harvesting by means of strong membranes, such as microscreens.

- Chemical methods - chemical and/or biological harvesting by means of flocculants.

- Centrifugation 
- Froth flotation - water and algae are aerated into froth, with the algae then removed from the water.

The ease in harvesting the algae depends primarily on the organism's size, which determines how easily the species can be settled and filtered. Unfortunately, the most rapidly growing algal species are frequently the smallest and most difficult to harvest. Thus it is necessary to maintain an effective interaction between the development of harvesting technologies and the selection of algal species.

\subsection{POTENTIAL RESEARCH AREAS SUITED TO EERC STRENGTHS}

It is highly unlikely that the EERC will be directly involved in the biological development of algal strains or in the cultivation process but may well be involved in other aspects of the overall process. For example, the EERC has extensive experience in power plant operation and emission and $\mathrm{CO}_{2}$ mitigation issues that could be beneficial to the algae industry. Some of these are discussed below.

\subsection{Light Management}

Enhancing light harvest efficiency is one method that would greatly enhance algae growth. Therefore, providing an optimized light management system would improve the overall photosynthetic efficiency of algae. The efficiencies of solar concentration systems have significantly improved in recent years; $40 \%-46 \%$ overall efficiencies of the solar collector have been reported (38). However, better methods to uniformly and efficiently distribute light into algal cultures need to be investigated. Several approaches have been considered:

- Geometric configuration of algal cultivation system

- Light source arrangement

- Hybrid usage of natural and artificial light

New light management technologies and/or more innovative use of current technologies such as optical fibers may eventually allow closed photobioreactors to be competitive options for $\mathrm{CO}_{2}$ mitigation for the coal-fired electric utility industry.

\section{2 $\mathrm{CO}_{2}$ Delivery System}

A consistent $\mathrm{CO}_{2}$ supply is a key processing parameter in algae cultivation. Although most of the so-called novel photobioreactors do, in fact, attempt to overcome the constraints related to control of $\mathrm{pH}$, temperature, etc. (19), providing adequate amounts of $\mathrm{CO}_{2}$ to microalgal cells is still poorly developed.

\subsection{Oxygen Removal and/or Utilization}

An efficient method of removing oxygen from the culture medium in massive algaefarming applications is important for two primary reasons. First is to maintain a stable algae 
yield and, second, the generated oxygen is a valuable product both for oxygen-blown combustion and as a feedstock to produce other chemicals. Investigation of technologies and methods for improving the removal and recovery of oxygen provides the potential to not only facilitate algae growth but would also be beneficial from an economic perspective.

\subsection{Water Management}

Algae cultivation consumes a lot of water; therefore, an efficient water recovery management system will significantly reduce the cost of large-scale algae applications. One possibility is to recover the water in the flue gas from the power plant and use it as makeup water for the algae system. This would have the added advantage of cooling the flue gas. For example the Siemens technology for water recovery that is being tested at the EERC may hold some potential (39).

\section{5 pH Management}

Because of the acid gas constituents, continuous flue gas flowing through the algal cultivation system will cause the algae culture to become acidic, which will damage algae growth. However, there is the potential that the solid waste products from wetscrubbers or if a western coal is being fired, the highly basic fly ash can be used to neutralize the acid gases. Study on recycling coal combustion by-products such as fly ash and wet scrubber materials for algae cultivation should be considered.

\subsection{Energy Balance Management}

Since algae growth is very sensitive to temperature, heat management of the bioreactor is extremely important. The temperature of feed flue gas must be accurately controlled before it enters the algal system. In addition, the algae-drying process needs a low-Btu heat source. By providing an integrated heat-transfer system, the recovered waste heat from the power plant may be used for the algae-drying process. This would include utilizing the heat recovered when cooling the flue gas before it can be provided to the algae photobioreactor.

\subsection{Overall Integration of the Algae and Power Plant Systems}

The ultimate goal is to maximize the potential cobenefits that can be realized by operating the algae system and power plant in tandem. This includes the following:

- $\mathrm{CO}_{2}$ to the algae from the flue gas

- $\mathrm{NO}_{\mathrm{x}}$ to the algae from the flue gas

- Water recovery from flue gas to algae

- Oxygen from algae to the power plant

- Biomass waste product after removing the oil to be cofired with coal

- Biofuel that can be fired in the power plant used for transportation or as a feedstock for another product

Figure 3 provides a schematic of the potential of such an integrated system. 


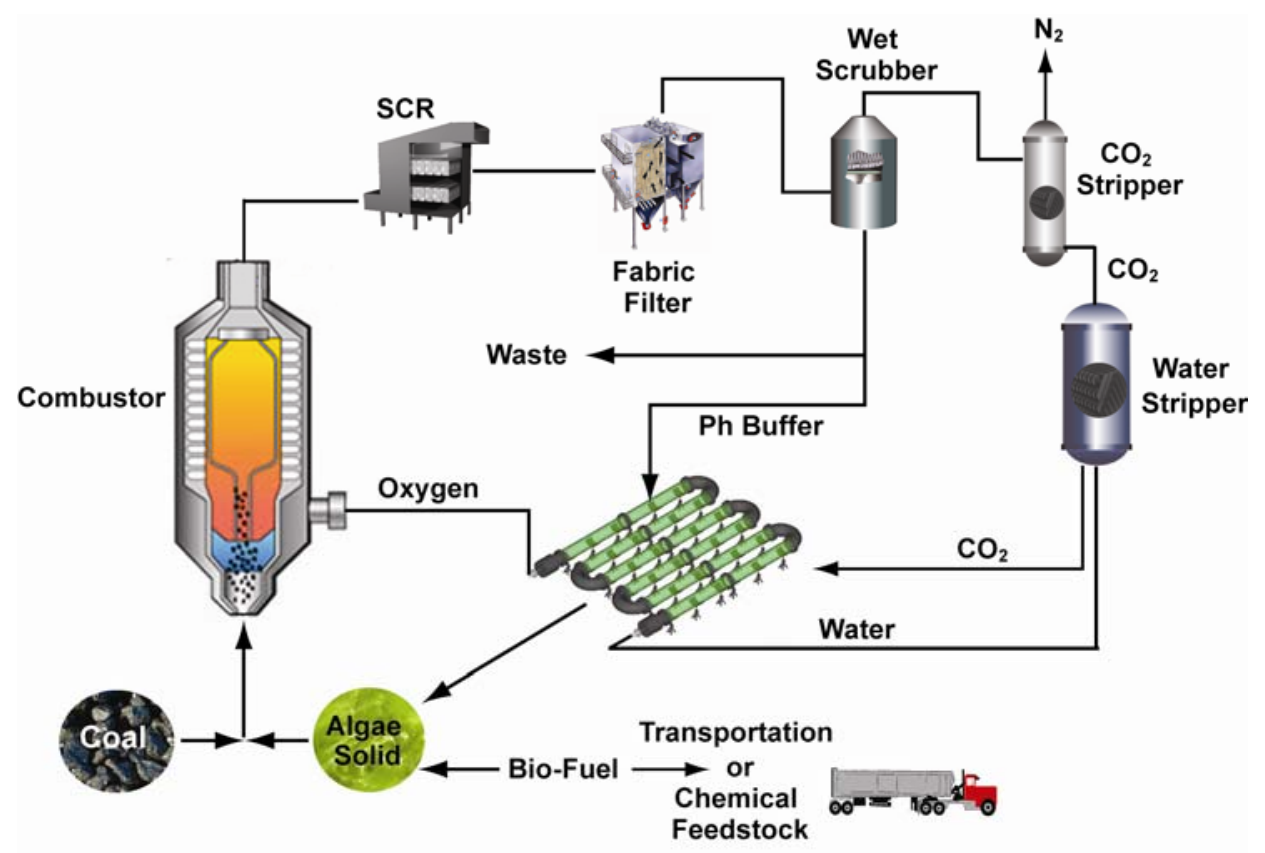

EERC DL34180.AI

Figure 3. Schematic of an intergrated coal-fired power plant utilizing an algae photobioreactor.

\subsection{ECONOMIC COMPARISON}

A detailed economic study was made by Kadam in 1997 (40) comparing the economic impact of microalgae fixation of $\mathrm{CO}_{2}$ to using an monoethanolamine (MEA) $\mathrm{CO}_{2}$ stripper followed by compression of the gas stream followed by the transport of the $\mathrm{CO}_{2}$ stream for utilization or sequestration. The economic study was based on a 500-MW power plant located in the southwestern United States A transportation distance of $100 \mathrm{~km}$ was assumed. For the microalgae option, it was assumed that an open pond system requiring 14,000 ha of land with an algal productivity of $45 \mathrm{~g} / \mathrm{m}^{2} / \mathrm{d}$ would be used. Also the economic comparison evaluated a possible revenue stream from biodiesel production. On an annualized basis, the calculated cost for MEA followed by sequestration was $\$ 40.50 /$ ton of $\mathrm{CO}_{2}$, compared to $\$ 63.80 /$ ton $\mathrm{CO}_{2}$ for the microalgae facility. However, when the revenue stream from the biodiesel is factor, the microalgae pond may be very competitive depending on the value of the biodiesel. More up-todate and detailed economic evaluations based on a variety of factors including a closed system are needed.

\subsection{REFERENCES}

1. Hutchinson, J.J.; Campbell, C.A.; Desjardins, R.L. Some Perspectives on Carbon Sequestration in Agriculture. Agricultur. Forest Meteorol. 2007, 142, 288-302.

2. Usui, N.; Ikenouchi, M. The Biological $\mathrm{CO}_{2}$ Fixation and Utilization Project by RITE (1) Highly Effective Photobioreactor Systems. Energy Conserv. Mgmt. 1996, 38, S487-S492. 
3. Sheehan, J.; Dunahay, T.; Benemann, J.; Roessler, P. A Look Back at the U.S. Department of Energy's Aquatic Species Program - Biodiesel from Algae; NREL/TP-580-24190, July 1998.

4. The Algae Energy Industry Opportunities \& Prospects. Oilgae Digest, updated Feb 15, 2009.

5. Murakami, M.; Ikenouchi, M. The Biological $\mathrm{CO}_{2}$ Fixation and Utilization Project by RITE - Screening and Breeding of Microalgae with High Capability in Fixing $\mathrm{CO}_{2}$. Energy Convers. Mgmt. 1997, 38, S493-S497.

6. Borowitzka, M.A. Commercial Production of Microalgae: Ponds, Tanks, Tubes, and Fermenters. J. Biotechnol. 1999, 70, 313-321.

7. Borowitzka, M.A. Microalgae for Aquaculture: Opportunities and Constraints. J. Appl. Phycol. 1997, 9, 393-401.

8. Yamaguchi, K. Recent Advances in Microalgal Bioscience in Japan, with Special Reference to Utilization of Biomass and Metabolites: A Review. J. Appl. Phycol. 1996, 8, 487-502.

9. Chaumont, D. Biotechnology of Algal Biomass Production: A Review of Systems for Outdoor Mass Culture. J. Appl. Phycol. 1993, 5, 593-604.

10. Richmond, A.; Vonshak, A.; Arad, S.M. Algae Biomass; Elsevier: New York, 1980; pp 6573.

11. Spektorova, L.; Creswell, R.L.; Vaughan, D. Closed Tubular Cultivators: An Innovative System for Commercial Culture of Microalgae. World Aquaculture 1997, June, 39-43.

12. Technical Guidance for Hazards Analysis; U.S. Environmental Protection Agency and Federal Emergency Management Agency, Dec 1987.

13. Risk Management Program Guidance for Offsite Consequence Analysis; U.S. Environmental Protection Agency Publication EPA-550-B-99-009; April 1999.

14. Chaumont, D. Biotechnology of Algal Biomass Production: A Review of Systems for Outdoor Mass Culture. J. Appl. Phycol. 1993, 5, 593-604.

15. Kizililsoley, M; Helvacioglu, S. Microalgae Growth Technology Systems. Presented at the Intergovernmental Institution for the Use of Microalgae Spirulina Against Malnutrition, 2008 .

16. Mirón, A.S.; Gómez, A.C.; Camacho, F.G.; Grima, E.M.; Chisti, Y. Comparative Evaluation of Compact Photobioreactors for Large-Scale Monoculture of Microalgae. J. Biotechnol. 1999, 70, 249-270.

17. Tredici, M.R.; Zittelli, G.C.; Biagiolini, S.; Materassi, R. Novel Photobioreactor for the Mass Cultivation of Spirulina spp. Bull. Inst. Oceanogr. 1993, 89-96. 
18. Martínez-Jerónimo, F.; Espinosa-Chavez, F. A Laboratory-Scale System for Mass Culture of Freshwater Microalgae in Polyethylene Bags. J. Appl. Phycol. 1994, 6, 423-425.

19. Markl, H. $\mathrm{CO}_{2}$ Transport and Photosynthetic Productivity of a Continuous Culture of Algae. Biotechnol. Bioeng. 1977, 19, 1851-1862.

20. Talbot, P.; Gortares, M.P.; Lencki, R.W.; de la Noue, J. Absorption of $\mathrm{CO}_{2}$ in Algal Mass Culture Systems: A Different Characterization Approach. Biotechnol. Bioeng. 1991, 37, 834842.

21. Grima, E.M.; Sanchez-Perez, J.A.; Garcia-Camacho, F.; Robles-Medina, A. Gas-Liquid Transfer of Atmospheric $\mathrm{CO}_{2}$ in Microalgal Cultures. Chem. Technol. Biotechnol. 1993, 56, 329-337.

22. Ferreira, B.S.; Fernandes, H.L.; Reis, A.; Mateus, M. Microporous Hollow Fibres for Carbon Dioxide Absorption: Mass Transfer Model Fitting and the Supplying of Carbon Dioxide to Microalgal Cultures. Chem. Technol. Biotechnol. 1998, 71, 61-70.

23. Becker, E.W. Large-Scale Cultivation. In Microalgae: Biotechnology and Microbiology; Becker, E.W., Ed.; Cambridge University Press: New York, 1994; pp 63-171.

24. Richmond, A. Technological Aspects of Mass Cultivation - A General Outline. In CRC Handbook of Microalgal Mass Culture; Richmond, A., Ed.; CRC Press: Boca Raton, FL, 1986; pp 245-264.

25. Panda, A.K.; Mishra, S.; Bisaria, V.S.; Bhojwani, S.S. Plant Cell Reactors - A Perspective. Enzyme Microb. Technol. 1989, 11, 386-397.

26. Gudin, C.; Chaumont, D. Cell Fragility - The Key Problem of Microalgae Mass Production on Closed Photobioreactors. Bioresour. Technol. 1991, 38, 145-151.

27. Thomas, W.H.; Gibson, C.H. Effects of Small-Scale Turbulence on Microalgae. J. Appl. Phycol. 1990, 2, 71-77.

28. Yoshihara, K.; Nagase, H.; Eguchi, K.; Hirata, K.; Miyamoto, K. Biological Elimination of Nitric Oxide and Carbon Dioxide from Flue Gas by Marine Microalgal NOA-113 Cultivated in a Long Tubular Photobioreactor. J. Fermenta. Bioeng. 1996, 82, 351-354.

29. Hauck, J.T.; Olson, G.J.; Scierka, S.J.; Perry, M.B.; Ataai, M.M. Effects of Simulated Flue Gas on Growth of Microalgae. In Proceedings of 212th ACS National Meeting; Orlando, FL, August 25-30, 1996; Vol. 41, No. 4, pp 1391-1396.

30. Kurano, N.; Ikemoto, H.; Miyashita, H.; Hasegawa, T.; Hata, H.; Miyachi, S. Fixation and Utilization of Carbon Dioxide by Microalgal Photosynthesis. Energy Convers. Mgmt. 1995, 36, 689-692. 
31. Maeda, K.; Owada, M.; Kimura, N.; Omata, K.; Karube, I. $\mathrm{CO}_{2}$ Fixation from the Flue Gas on Coal-Fired Thermal Plant by Microalgae. Energy Convers. Mgmt 1995, 36 (6-9), 717720 .

32. Murakami, M.; Ikenouchi, M. The Biological $\mathrm{CO}_{2}$ Fixation and Utilization Project by RITE - Screening and Breeding of Microalgae with High Capability in Fixing $\mathrm{CO}_{2}$. Energy Convers. Mgmt. 1997, 38, S493-S497.

33. Douskova, I.; Doucha, J.; Livansky, K.; Machat, J.; Novak, P.; Umysova, D.; Zachleder, V.; Vitova, M. Simultaneous Flue Gas Bioremediation and Reduction of Microalgal Biomass Production Costs. Appl. Microbiol. Biotechnol. 2009, 82, 179-185.

34. Chiu, S.-Y.; Kao, C.-Y.; Chen, C.-H.; Kuan, T.-C.; Ong, S.-C.; Lin, C.-S. Reduction of $\mathrm{CO}_{2}$ by a High-Density Culture of Chlorella sp. in a Semicontinuous Photobioreactor. Bioresour. Technol. 2008, 99, 3389-3396.

35. Lee, J.S.; Kim, D.K.; Lee, J.P.; Park, S.C.; Koh, J.H.; Cho, H.S.; Kim, S.W. 2002. Effects of $\mathrm{SO}_{2}$ and $\mathrm{NO}$ on Growth of Chlorella sp KR-1. Bioresour. Technol. 2002, 8, 1-4.

36. Olaizola, M.; Bridges, T.; Flores, S.; Griswold, L.; Morency, J.; Nakamura, T. Microalgal Removal of $\mathrm{CO}_{2}$ from Flue Gases: $\mathrm{CO}_{2}$ Capture from a Coal Combustor. Presented at the 3rd Annual Conference on Carbon Capture \& Sequestration, May 2004.

37. Bayless, D.J.; Kremer, G.G.; Prudich, M.E.; Stuart, B.J.; Vis-Chiasson, M.L.; Cooksey, K.; Muhs, J. Enhanced Practical Photosynthetic $\mathrm{CO}_{2}$ Mitigation. In Proceedings of the 1st National Conference on Carbon Sequestration; U.S. Department of Energy National Energy Technology Laboratory, 2001.

38. Nakamura, T.; Case, J.A.; Jack, D.A.; Cuello, J.L. Optical Waveguide Solar Plant Lighting System for Life Support in Space. In Proceedings of the 29th International Conference on Environment Systems; Warrendale, PA; ICES/SAE, 1999.

39. Folkedahl, B.C.; Weber, G.F.; Collings, M.E. Water Extraction from Coal-Fired Power Plant Flue Gas; Final Report for DE-FC26-03NT41907; Dec 2006.

40. Kadam, K.L. Power Plant Flue Gas as a Source of $\mathrm{CO}_{2}$ for Microalgae Cultivation: Economic Impact of Different Process Options. Energy Convers. Mgmt. 1997, 38, S505S510. 